\title{
PROGRESS IN URBAN GREENERY MITIGATION SCIENCE - ASSESSMENT METHODOLOGIES ADVANCED TECHNOLOGIES AND IMPACT ON CITIES
}

\author{
Mat SANTAMOURIS ${ }^{1 *}$, George BAN-WEISS ${ }^{11}$, Paul OSMOND ${ }^{1}$, Riccardo PAOLINI ${ }^{1}$, \\ Afroditi SYNNEFA ${ }^{1}$, Constantinos CARTALIS ${ }^{2}$, Alberto MUSCIO $^{3}$, Michele ZINZI ${ }^{4}$, \\ Tobi Eniolu MORAKINYO ${ }^{5}$, Edward NG ${ }^{5}, 6$, Zheng TAN ${ }^{5}$, Hideki TAKEBAYASHI ${ }^{7}$, \\ David SAILOR ${ }^{8}$, P. Crank $^{8}$, Haider TAHA ${ }^{9}$, Anna Laura PISELLO ${ }^{10}$, Federico ROSSI ${ }^{10}$, \\ Jiong ZHANG $^{11}$, Denia KOLOKOTSA ${ }^{12}$ \\ ${ }^{1}$ Faculty Built Environment, UNSW, Sydney, Australia \\ ${ }^{2}$ Physics Department, University of Athens, Athens, Greece \\ ${ }^{3}$ University of Modena and Reggio Emilia, Modena, Italy \\ ${ }^{4}$ ENEA, Roma, Italy \\ ${ }^{5}$ Institute of Future Cities, Sha Tin, New Territories, Chinese University of Hong Kong \\ ${ }^{6}$ School of Architecture, Sha Tin, New Territories, Chinese University of Hong Kong \\ ${ }^{7}$ Kobe University, Kobe, Japan \\ ${ }^{8}$ Arizona State University, Tempe, USA \\ ${ }^{9}$ Altostratus Inc., Martinez, California, USA \\ ${ }^{10}$ University of Perugia, 06123 Perugia PG, Italy \\ ${ }^{11}$ University of Southern California, Los Angeles, California, USA \\ ${ }^{12}$ Technical University Crete, Chania 736 00, Greece
}

Received 10 October 2018; accepted 24 October 2018

\begin{abstract}
Urban greenery is a natural solution to cool cities and provide comfort, clean air and significant social, health and economic benefits. This paper aims to present the latest progress on the field of greenery urban mitigation techniques including aspects related to the theoretical and experimental assessment of the greenery cooling potential, the impact on urban vegetation on energy, health and comfort and the acquired knowledge on the best integration of the various types of greenery in the urban frame. Also to present the recent knowledge on the impact of climate change on the cooling performance of urban vegetation and investigate and analyse possible technological solutions to face the impact of high ambient temperatures.
\end{abstract}

Keywords: urban heat island, climate change, cooling cities, urban greenery, mitigation and adaptation, trees and forests, green roofs, vertical greening.

\section{Introduction}

Urban overheating is the most documented phenomenon of climate change. Because of the positive thermal balance, the ambient temperature in cities is several degrees higher that the temperature of the surrounding suburban or rural areas. Higher urban temperatures seriously increase the cooling energy consumption of buildings, the heat related mortality and morbidity, the generation of air pollutants, the indoor and outdoor thermal discomfort and overall footprint of cities (Akbari et al. 2016; Santamouris 2014a, 2014b, 2015). To counterbalance the impact of higher ambient urban temperatures, various mitigation technologies have been developed and implemented in numerous cities. Among other technologies, greenery, reflective materials, the use of evaporative systems and thermal components coupled with cool sinks, like the ground, are the most accepted and implemented systems (Lontorfos et al. 2018).

*Corresponding author. E-mail: msantam@phys.uoa.gr 
The use of greenery in the built environment provides cooling through evapotranspiration and shading. The cooling potential of urban greenery when applied on individual buildings is very well studied and documented. In a similar way, many studies have evaluated the cooling impact of vegetation in cities (e.g. Hamada, Ochta 2010; Bowler et al. 2010), with a significant contribution to the literature. However, the new knowledge on the topic recently made available is quite fragmented. In response to the major scientific challenges like urban expansion, overpopulation, climate change and poverty, recent scientific research has developed and proposed innovative solutions, has enriched information and has provided new knowledge on several issues related to the capacity of greenery to mitigate urban heat. These include the monitoring and evaluation of the greenery's mitigation potential, the optimum integration of greenery in dense cities, with the selection of more efficient vegetation species and the enhancement of the synergetic operation between vegetation and the other mitigation technologies. Another relevant recent expansion of the literature concerns the identification and quantification of the energy and health benefits and the evaluation of the impact of greenery on comfort, air quality, carbon and water cycles. Finally, much research has provided insight in the physiological response of vegetation under extreme heat events, and the development of genetically modified trees to respond to climate change.

Based on a comprehensive analysis of the recent research on the cooling capacity of urban greenery, we have identified four principal research axes along which important progress has been achieved and merits to be reported, namely:

Assessing the mitigation potential of urban greenery, involving research on: a) influence of urban green area on air temperature of surrounding built-up area; $b$ ) the influence of small urban green areas; c) the cooling potential of urban greenery through ventilation; d) the challenge of assessing the mitigation performance of greenery in combination with other technologies; and e) new monitoring methods and techniques focusing on the capacity and the contribution of earth observations and remote sensing techniques to assess the mitigation potential of greenery.

Progress on greenery selection, plant configuration and urban morphology, including research on: a) the possible enhancement of the cooling potential of vegetative species with foliage presenting high solar reflectance; b) the performance of urban greenery in mitigating urban heat island in high-density cities: plant configuration and urban morphology, and c) the development of environmental assessment tools to evaluate the mitigation potential of vegetation.

Assessing the impact of urban greenery on energy and wellbeing, involving research on: a) the energy consumption of buildings and the quantification of the associated energy savings at the city scale; $b$ ) human health and the evaluation of the thermal and non-thermal health benefits; c) the local microclimate, emissions and air quality, and the potential negative impacts of greenery in the built environment; d) outdoor thermal comfort and the quantification of the carbon and water footprint of urban greenery.

Using greenery under extreme climatic conditions, including research on: a) the influence of irrigation on the mitigation potential of greenery and the impact of a possible adoption of drought-tolerant vegetation in cities; b) the transformation of the greenery physiological operation and the corresponding cooling mechanisms; c) the development of genetically engineered trees able to operate under very high ambient temperatures to face climate change.

The present article aims to analyze and report the main achievements and the scientific progress along each of the above-mentioned research branches, and to investigate their potential synergies and propose coordination activities for future research. In the following, we report the progress achieved in the previously identified research axes. In Chapter 1 we analyse the new developments about the assessment of the mitigation potential of urban greenery. Section 1.1 presents and discusses new studies focusing on the influence of urban green zones on the temperature of the surrounding built areas, while Section 1.2 analyzes the climatic impact of small urban green areas. Section 1.3 focusses on the cooling potential of urban greenery through ventilation, and Section 1.4 discusses how to assess the cooling performance of urban greenery when combined with other mitigation technologies. Finally, Section 1.5 presents recent developments related to the use of remote techniques to assess the cooling capacity of vegetation.

Chapter 2 reports the progress achieved on greenery selection, plant configuration and urban morphology. In particular, Section 2.1 presents the possible enhancement of the cooling potential of vegetative species with high solar reflectance, while Section 2.2 discusses the pperformance of urban greenery in mitigating urban heat island in high-density cities.

Chapter 3 reports recent knowledge on the impact of urban greenery. In particular, Section 3.1 focusses on the energy impact of vegetation and Section 3.2 on the non-thermal health benefits of urban greenery. Section 3.3 analyses the impact of vegetation on the local microclimate, emissions and air quality, while Sections 3.4 and 3.5 discuss the impact on outdoor thermal comfort and the quantification of the carbon and water footprint of urban greenery, respectively.

Finally, Chapter 4 focusses on the use of greenery under extreme climatic conditions. Section 4.1 reports new studies on the influence of irrigation on the mitigation potential of greenery and the impact of a possible adoption of drought-tolerant vegetation in cities. Section 4.2 analyzes the transformation of the greenery physiological operation and the corresponding cooling mechanisms and Section 4.3 the development of genetically engineered trees able to operate under very high ambient temperatures to face climate change. 


\section{Assessing the mitigation potential of urban greenery}

\subsection{Influence of urban green area on air temperature of surrounding built-up area}

Cooling by evapotranspiration varies by climate, canopy physical and geometrical properties and season but is typically up to $2-3{ }^{\circ} \mathrm{C}$, sometimes higher (Jonsson 2004; Ellis et al. 2017; Skoulika et al. 2013; Doick et al. 2014; Taha 2015a). In summer, this mechanism produces generally larger cooling $\left(>2.0^{\circ} \mathrm{C}\right)$ than in winter $\left(<0.5^{\circ} \mathrm{C}\right)$ (Hamada, Ohta 2010; Taha 2015a). Diurnally, the localized effects differ in magnitude and sign depending on the physical characteristics of the urban green areas relative to those of the surroundings. Urban vegetation has been observed to cool the air more at night than during the day in summer, e.g. up to $3.3^{\circ} \mathrm{C}$ versus up to $2.3^{\circ} \mathrm{C}$ (Taha et al. 2018). In other cases, canopies cool the air equally during the day and at night (Sun et al. 2009) or with changing signs between winter and summer, e.g., larger cooling at night in winter but larger cooling during the day in summer (Hamada, Ohta 2010; Taha 2015a).

Cooling from vegetation is larger if canopies and ground cover are implemented in targeted configurations, e.g., urban parks, rather than spread out over large areas (Taha 2013; Taha et al. 2015). Such configurations also enable the transport of cool air some meters outside of the green and into surrounding built-up areas (Hamada, Ohta 2010; Takebayashi 2017; Bernard et al. 2018). Several recent studies have measured the extension of parks' cool temperatures to the surrounding urban zones (Moriyama et al. 1997; Honjo, Takakura 1990-1991; Bowler et al. 2010; Ca et al. 1998; Yu, Hien 2006; Takebayashi 2017; Declet-Barrero et al. 2013; Vanos et al. 2012; Watkins 1999; Watkins et al. 2002; Zoulia et al. 2009). It is concluded that the cooling influence is extended up to several hundred meters beyond the urban park borders and is determined by the structure and the size of the parks, the watering frequency, the type of plants and the sky obstruction, as well as on the characteristics of the surrounding urban zones, like density, capacity of radiative cooling, generation of anthropogenic heat and finally, from the weather and wind conditions and climatic zone of the area.

Several studies carried out in dense urban areas with high anthropogenic heat concluded that the impact of the parks may be low or even insignificant (Zoulia et al. 2009; Saito et al. 1990-1991). On the contrary other studies carried out under favourable wind characteristics and low generation of anthropogenic heat, found that the effect of the parks may be extended up to a distance equal to the length of the urban park or even $1100 \mathrm{~m}$ beyond the park boundary (Upmanis et al. 1998; Spronken-Smith 1994).

The impact of wind on the mitigation potential of urban parks was studied by Moriyama et al. (1997), who have conducted numerical simulations to examine increases and decreases in air temperature in urban areas adjacent to green areas. They used the following conditions: an inflow upper wind velocity of 2 to $6 \mathrm{~m} / \mathrm{s}$ at $50 \mathrm{~m}$ above the ground, a ground surface temperature difference of 1 to $5{ }^{\circ} \mathrm{C}$ between green and urban areas, and a roughness parameter of 0.1 to $1.0 \mathrm{~m}$ for green areas and 0.5 to $1.0 \mathrm{~m}$ for urban areas. They concluded that the influence of the green space extends to about $150 \mathrm{~m}$ from the urban-green boundary.

The potential temperature reduction around urban parks was studied by Bowler et al. (2010) and Ca et al. (1998). They have carried out field measurements to determine the cooling influence of a park on the surrounding area in the Tama New Town, a city in the west of Tokyo. They found that a $0.6 \mathrm{~km}^{2}$ park can reduce the air temperature by up to $1.5^{\circ} \mathrm{C}$ at noon in a leeward commercial area at distance of $1 \mathrm{~km}$.

Takebayashi (2017) has performed extensive measurements at four urban areas in Kobe City. Since sea breezes dominate on summer days in many cities in Japan, air temperature reduction due to advection effects is expected in regions leeward of urban green areas. Takebayashi (2017) also carried out simulation using a numerical model incorporating advection and diffusion, to clarify the characteristics of air temperature rise in an urban area on the leeward side of a green area, as a contribution to the practical planning of urban greening. Calculation results and measurement results for air temperature rise with distance from the green area are compared when an isotropic diffusion model and an incorporated buoyancy model are applied for the vertical diffusion term, as shown in Figure 1.

From the comparison with the measurement results in Kobe (Takebayashi 2017) as well as in Tokyo (Kato et al. 2006) and Osaka (Moriyama et al. 2001), it is considered that air temperature does not rise as it enters the part of the urban area beyond more than $50 \mathrm{~m}$ from the edge of the green area. The air temperature rise in the urban area near the green area, due to the development of the urban boundary layer, is expressed using the sensible heat flux from the ground surface, the distance from the green area and the wind velocity.

Other cooling considerations include the effects of green roofs and the effects of canopy growth. If implemented at city-scale, green roofs can produce cooling ranging from 0.3 to $3.0^{\circ} \mathrm{C}$ on average (Santamouris 2014;

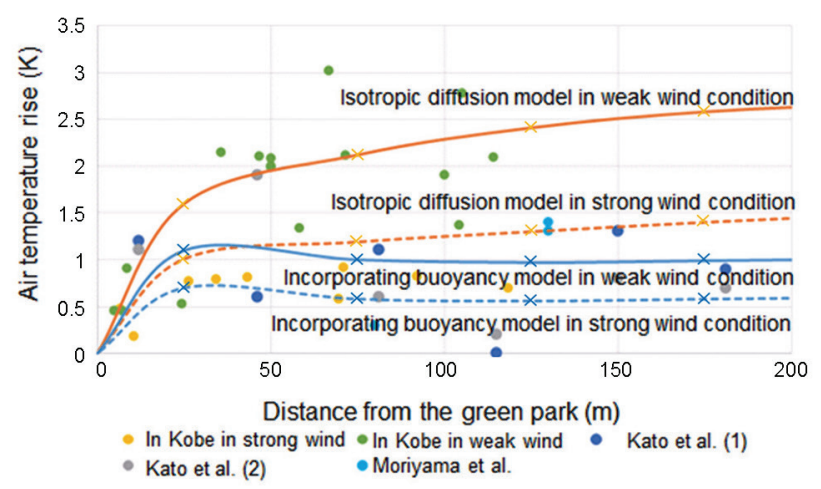

Figure 1. Distance from the green area and the air temperature rise in several urban areas in the daytime 
Sharma et al. 2016; Georgescu 2015). On the other hand, the cooling effects of canopy growth alone (e.g. of several hundred thousand urban trees) with no addition of new canopy, can reach up to $1-1.6^{\circ} \mathrm{C}$ over a growth period of 10-15 years (Taha et al. 2015; Cao et al. 2015).

\subsection{Influence of small urban green areas}

In densely built urban environments, small green areas are often considered as cool oases, able to reduce the thermal stress respect to surrounding zones and provide more comfortable conditions. If a wide bibliography about generic urban parks exists, the same does not apply for small green areas. Several studies demonstrated how the park size is a crucial parameter for the mitigation potential and that, in some cases, small parks may behave as heat islands, contrary to the desired effect (Chen et al. 2012; Chang et al. 2007; Xiao et al. 2018). Other studies showed that evolution of microclimatic conditions in such areas is much more unstable than in larger green zones and that they may act as heat islands under specific conditions, but the overall cooling potential is not necessarily much lower than that of larger parks (Cao et al. 2010); moreover, small parks might also cool the neighboring streets in some conditions (Chang, Li 2014).

Extensive reviews on the effect of small urban green area focused on identifying the relation between cooling potential and most relevant parameters were recently carried out (Venhari et al. 2017; Saaroni et al. 2018). Well-vegetated courtyard gardens were monitored in Tel Aviv, Israel in 1994 (Shashua-Bar, Hoffman 2004). Comparing the temperature in the courtyard with respect to a reference station 100 meters away, the average summer temperature difference at 3:00 p.m. was $2.5^{\circ} \mathrm{C}$ and $3.3^{\circ} \mathrm{C}$. The same authors (Shashua-Bar, Hoffman 2000) monitored 11 small parks, ranging from 0.05 to 1.1 ha in summer 1996. Average hourly temperature differences between the parks and the surrounding areas ranged between $0.2{ }^{\circ} \mathrm{C}(6.00 \mathrm{a}$ a.m. $)$ to $2.8^{\circ} \mathrm{C}$ (3.00 p.m.). No direct dependence on park size was found. Small urban parks and gardens were monitored by ground measurements in the city of Florence, Italy (Bacci et al. 2003). The analysis was also carried out in terms of comfort and discomfort hours and it was found the conditions in two small areas ( 0.07 and $0.02 \mathrm{ha}$ ) was in the same range as those of larger parks ( 6.90 and $6.27 \mathrm{ha}$ ), with comfort hours of $70-75 \%$. The two small areas registered maximum diurnal air temperature reduction of $1.5^{\circ} \mathrm{C}$ and $3{ }^{\circ} \mathrm{C}$, the latter conditions also achieved thanks to the shading effect of high trees and high walls surrounding the area. The monitored temperature reduction was below $1{ }^{\circ} \mathrm{C}$ at night, less effective than in larger parks. A detailed analysis was carried out for a 0.60 ha garden with high trees in a densely built neighborhood in Lisbon, Portugal (Oliveira et al. 2011); peak temperature reductions of $6.9^{\circ} \mathrm{C}$ were measured and the median difference between the garden and the surrounding urban area was $1.6^{\circ} \mathrm{C}$. The study concluded that impacts of the wind velocity and direction as well as the urban geometry are very significant. Another wide-range monitoring experiment was carried out for the city of Taipei, China (Chang et al. 2007). In total, 61 of 490 city parks were monitored and it was found that in almost all cases, the temperature reduction in small areas was lower than that of larger parks.

A study on a small public area to be used for urban regeneration was carried out for the city of Beirut, Lebanon (Kaloustian et al. 2018). It was found that a maximum temperature reduction close to $0.5^{\circ} \mathrm{C}$ can be achieved in areas of $100 \mathrm{~m}^{2}$ or smaller. The impact of the sky view factor and wind paths on the cooling potentials of small urban parks was studied in Hong Kong (Zheng et al. 2016). It was found that the benefits of small treed parks are more substantial for high sky view factors (0.4-0.8). A parametric study about the impact of a small green park replacing a building block in a densely built urban grid in Athens Greece, was carried out by Dimoudi and Nikolopoulou (2003), the main outcome was a $2-6{ }^{\circ} \mathrm{C}$ air temperature reduction around the park; however, the authors state that effective values might be lower, since a heat source (building) was replaced by a heat sink (park) in the implemented thermo-fluid dynamic model.

\subsection{The cooling potential of urban greenery through ventilation}

The fact that cooler air can be advected away from vegetation over significant distances is important in benefiting a larger area and reducing temperaturedependent biogenic and anthropogenic emissions not only in the canopy vicinity but also in the non-vegetated surroundings (Taha 2015b). Such length scales, or "fetch", for cool-air transport are a function of wind speed (Taha et al. 2018) and can be used as a basis for establishing the various heat-island mitigation modeling and implementation levels (Taha 2017).

The function of green infrastructure in modifying air movement can be conceptualised in terms of regulating ecosystem services (Alcamo 2003), particularly the services of temperature modification and regulation of wind speed (DeakSjöman 2016). These ecosystem services help to shape "salutogenic", or health-supporting, urban environments (Declet-Barreto et al. 2013). However, the interaction between urban greenery and wind may also produce disservices, such as reducing the dispersion of pollutants, trapping heat and obstructing natural ventilation, as well as uncomfortable (hot or cold) winds (Vos et al. 2013; Pitman et al. 2015), as Oke (1982) explains: "a solution that is geared to one problem may create another".

As previously mentioned, at city (meso) scale $\left(10^{4}\right.$ to $2 \times 10^{5}$ metres (Oke 2002)) the increased surface roughness consequent on urbanisation limits the capacity of winds to modify surface heat gain (Huang et al. 1990), although depending on a settlement's size, sufficiently strong winds "can reduce or even completely eliminate the heat island" (Landsberg 1970). On the other hand, tree planting may amplify surface roughness, further decreasing average wind speeds (Akbari et al. 1989, 2001; Huang et al. 
1990). Urban wind patterns are complex, and depend on building form and street orientation and geometry as well as the presence or absence of greenery (Erell et al. 2012). Heisler (1990) highlights the difficulty of differentiating the effects of urban form from those of the urban forest (urban vegetation in aggregate) because of the typically irregular interspersed pattern of trees and buildings; his own field-based research confirms the significant potential of the urban forest to reduce mean wind speeds in suburbs composed of single-family detached housing. The extent to which this wind flow may be modified by vegetation depends on vegetation type, the surrounding urban form and the direction of the wind (Gehrels et al. 2016). For example, tree canopy cover may retain warm air whereas an open grassed area which offers low resistance to air flow may facilitate convective cooling (Bowler et al. 2010). Planning and establishing an urban forest for heat island mitigation must therefore be approached systematically to achieve the desired outcomes (Beatty 1989).

While the physical effects of green infrastructure on air movement are limited compared to the effects of built form geometry at city scale, the interaction between air movement and evapotranspirative cooling can facilitate the spread of lower air temperatures downwind of vegetated "cool islands" such as urban parks (Spronken-Smith, Oke 1998) as noted in Sections 1.1 and 1.2 above. Since the wind direction during heatwaves generally differs from the prevailing direction over most of the year, vegetation on the windward side of built-up areas has the most useful cooling effect during these conditions (Gehrels et al. 2016).

At the local scale $\left(10^{2}\right.$ to $5 \times 10^{4}$ metres (Oke 2002)), canyon aspect ratio and street pattern and orientation are the main factors influencing air movement - a gridded layout is ideal for facilitating wind flow throughout the area (Deak Sjöman 2016). Accordingly, to achieve maximum ventilation and cooling, green infrastructure should be positioned in line with the street alignment (Gehrels et al. 2016), and more generally, tree planning patterns should be designed to enhance wind corridors (Nagashima 1996).

Local scale is particularly relevant to outdoor thermal comfort. It is pertinent too to note that the conditions which ameliorate human outdoor thermal comfort also improve growing conditions for plants (Clark, Kjelgren 1990), potentially leading to a "virtuous circle". Thermally acceptable outdoor conditions diverge widely from conditions typically expected in indoor settings (de Dear, Kim 2016). de Dear and Kim (2016) point out that while this discrepancy has usually been rationalised in terms of different comfort expectations, a more thorough explanation is provided by the hypothesis of "alliesthesia", which for example explains "why a meal tastes particularly delicious when we are hungry" (de Dear, Kim 2016). From this perspective, occupants may accept significantly warmer outdoor environments provided there is some transient cooling from air movement relative to the occupant.

At the microscale $\left(10^{-2}\right.$ to $10^{3}$ metres (Oke 2002)) pertinent to individual buildings, both the configuration (arrangement) of green infrastructure and the structural properties of individual vegetation species (Deak Sjöman 2016) become significant. Whether the objective is to block unwelcome hot or cold winds (Heisler, Dewalle 1988), funnel cooling breezes (Akbari et al. 1992) or deflect wind from one direction to another, the distribution of vegetation (dispersed, clumped, linear, single or multiple rows), its height (shrubs, hedges, small / tall trees), the type and density of foliage and seasonal variation (Bartesaghi Koc et al. 2017) will determine the capacity of green infrastructure to achieve the anticipated outcomes.

\subsection{The challenge of assessing the mitigation performance of greenery in combination with other technologies}

As in any complex problem, urban overheating must be counteracted with multiple strategies and techniques to target all the terms of the urban energy balance leading to heat gains with the domain. The literature is as clear about this need as on the fact that the combination of different mitigation technologies provides a lower contribution than the theoretical sum of the effects of the individual approaches (Santamouris et al. 2017). This occurs as different mitigation technologies are in part complementary and in part overlapping, as they target different terms of the surface energy balance (considering the formulation by Oke (1982)). Here, we discuss the difference between the theoretical sum of the parts and the actual combined performance, the mechanisms that hinder the development of a constructive synergy, if these can be potentially overcome and the challenges in isolating and measuring the effects. In particular, we focus on urban trees.

Santamouris et al. (2017) have considered 220 mitigation projects. The separate use of grass and trees can reduce the peak ambient temperature by $1.2 \mathrm{~K}$ and $1.5 \mathrm{~K}$, respectively; while an average increase of the albedo of a given area by 0.2 may lead to a drop of $1.5 \mathrm{~K}$. When greenery and reflective materials are used in the same area the peak reduction is of $2.3 \mathrm{~K}$, thus $0.5-0.7 \mathrm{~K}$ less than their sum. Also, different vegetation strategies when combined do not provide a cumulative effect. For instance, the interquartile range of the peak ambient reduction offered by trees is between 0.6 and $3 \mathrm{~K}$, and for grass between 0.2 and $1.2 \mathrm{~K}$, while their combined use leads to a peak reduction between 0.8 and $4 \mathrm{~K}$ in $50 \%$ of the studies, with a median lower than their separate use (Santamouris et al. 2017). However, to understand the reasons for these differences, it is necessary to distinguish the contributions.

At the present time, the isolation of the effects of different mitigation technologies on the urban climate is particularly challenging and is pursued in two main ways: climate modelling (Mirzaei, Haghighat 2010) and diachronic statistical analysis with different land use and land cover (Stewart et al. 2014), often supported by artificial neural networks or similar approaches. While in principle measurement campaigns could support the quantification 
of the different contributions, full eddy covariance observations of the surface energy balance of the built environment are seldom performed. Moreover, only a few campaigns included simultaneous measurements at two sites (Kotthaus, Grimmond 2014), given the cost and difficulty in finding two nearby locations, one including a combination of mitigation technologies and a control one, otherwise identical. A rare and notable example is the campaign conducted by Grimmond et al. (1996), where they compared side by side two areas in California: one with $30 \%$ and the other with $10 \%$ tree and shrub cover, during 18 clear sky summer days with low wind speed $\left(<0.5 \mathrm{~m} \mathrm{~s}^{-1}\right)$. Moreover, the two neighbourhoods displayed a different watering profile resulting from the total area to be irrigated, though the watering per unit area was the same.

While the latent heat flux was greater at the site with high vegetation than at the site with limited tree cover, as can be easily predicted, so were the net radiation and sensible heat flux, contrary to the common expectation, with ambient temperatures slightly greater at the site with higher tree cover. The observation of maximum daily temperature at sites with the greatest tree cover has been documented by others too (Howe et al. 2017), though with a network of stations. Some of the variability and impact on local temperatures can be ascribed to different species, which can display very diverse differences between tree canopy and ambient temperatures, which for some species is minimal and it is exceeding $4 \mathrm{~K}$ in other cases (Meier, Scherer 2012). Although not originally planned as a study to investigate the performance of urban trees in combination with other mitigation technologies, de facto the study by Grimmond et al. (1996) shows that even a perfectly planned and executed campaign cannot completely isolate the complexity of overlapping mitigation strategies.

Different types of trees and configurations display an extensive range of attenuation of the incoming solar radiation (Monsi, Saeki 2005). In urban settings, clusters of trees can provide attenuation of the incident solar radiation at ground level of the order of $80 \%$, with a considerable reduction of the sky view factor, even below 10\% (de Abreu-Harbich et al. 2015). The decrease in sky view factor can explain the increase in net radiative balance with tree cover indicated by Grimmond et al. (1996), which is indicative of a reduced escape of short- and longwave radiation. Therefore, the mitigation potential of cool materials, especially if implementing radiative coolers (Raman et al. 2014), can be reduced by the presence of trees, which increase the radiative entrapment in the urban canopy layer, while technologies such as retro-reflective surfaces might avoid the problem (Rossi et al. 2014). Moreover, trees can display a wide range of albedos. The impact of increased tree plantation on the overall albedo of a community has been assessed by Rose and Levinson (2013) with orthophotos and LiDAR in conjunction with a shading algorithm to study the yearly changes. With low albedo trees (0.14) they computed a decrease of the community albedo by 0.07 , and a negligible reduction by
0.01 even with high albedo trees $(0.20)$, being the albedo of parking areas and driveways respectively equal to 0.15 and 0.22 . These calculations are consistent with the observation of increased net radiation with increased tree cover by Grimmond et al. (1996). Therefore, we can infer that the mitigation potential of the combined use of trees and cool pavements, with albedo 0.3-0.4 even when aged (Kyriakodis, Santamouris 2017), would display a reduced mitigation potential due to the decreased albedo of the area, compared with an only cool pavements scenario.

The increased aerodynamic roughness introduced by additional urban trees may reduce the penetration of cool winds. In fact, the representation of the drag coefficient of trees in computational fluid dynamic models has been deeply investigated in the last years, moving from discrete (Mochida, Lun 2008) to bulk approaches (Gülten et al. 2016), fewer model improvements have been proposed for urban canopy parametrizations, with notable exceptions (Krayenhoff et al. 2015). Unfortunately, this aspect is still not fully incorporated in the urban tile of land surface models (Oleson et al. 2010), with the common approach being a bulk increase of aerodynamic roughness or a more detailed partitioning of the fluxes (Chen et al. 2011). A finer representation of the aerodynamic roughness of trees in climate models has been proposed and applied only recently (Kent et al. 2017a, 2017b). Also, in the vertical direction trees reduce the air mixing at the top and within the canyon, which has been studied primarily to understand their impact on urban air quality due to reduced pollutants removal, with the maximum relative reduction of wind speed in low velocity regimes (Buccolieri et al. 2009). Wind tunnel measurements in different configurations demonstrate different impacts on the vortex dimensions and air mixing at the top of the canyon, which is in any case reduced by the trees (Gromke 2011).

The maximum transpiration occurs at the top of the trees, where solar absorption is maximum (Manickathan et al. 2018). Therefore the spectral radiative balance within the urban canyon has a direct influence on the cooling performance of trees. Also, the evapotranspirative cooling increases downstream of the trees with increasing wind speeds up to a plateau (Dimoudi, Nikolopoulou 2003; Manickathan et al. 2018).

Yu et al. (2018) considered the impact of the boundary conditions on the evapotranspiration in different climate contexts, and they found it to be highly reduced with high ambient humidity and increased with increasing wind speed. This can be a predictor of a reduced combined action of trees together with water sprinkling, which can locally increase the ambient humidity by $20 \%\left(\right.$ at $30^{\circ} \mathrm{C}$ ) and, naturally, up to saturation conditions in humid climates (Wong, Chong 2010). A reduction in water fluxes is observed for deciduous trees, due to both the increased humidity and reduced leaf temperature (Kupper et al. 2011). Moreover, both water misting and vegetation mitigate the urban climate, dissipating heat with water phase change, namely they overlap. 
All these aspects have important consequences on the urban energy balance, and they need better representation in climate models. In some cases, the solution is relatively incremental as it concerns the retrieval of appropriate input data, while it does not entail a radical change in the structure of climate models. In some other cases, combined mitigation strategies induce important secondorder effects which are currently not represented in climate models. In addition to the necessary improvement in the representation of the stomatal conductance (Kala et al. 2016), for instance, urban canopy parametrizations cannot fully describe the latent heat exchanges, as demonstrated by an extensive model intercomparison (Grimmond et al. 2010,2011 ). As a consequence, the quantification of the combined mitigation performance of trees with other technologies still cannot be fully understood.

\subsection{Assessing the mitigation potential of greenery using earth observation}

Remotely sensed data from earth observation satellites contribute considerably to urban green monitoring especially given the new and expanding series of satellites which allow the extraction of information on land cover in urban areas at high and very high resolutions (e.g. for multispectral: World View at $1.24 \mathrm{~m}$, GeoEye- 1 at $1.84 \mathrm{~m}$, Gaofen-2 at $3.2 \mathrm{~m}$, SkySat-1,-2 at $1.0 \mathrm{~m}$, SPOT-6,-7 at $6 \mathrm{~m}$, Sentinel-2A at $10 \mathrm{~m}$, ASTER at $15 \mathrm{~m}$ for VNIR and Landsat- 8 at $30 \mathrm{~m}$ ). In addition, land cover information for urban areas may be also obtained for previous periods from the databases of satellites Quick Bird and IKONOS at 2.62 and $3.28 \mathrm{~m}$ spatial resolution (in the multispectral), respectively (Satelite Imaging Corporation 2018). Important information can be also extracted with the use of medium resolution satellites. In particular MODIS on board the Aqua and Terra NASA satellites and AVHRR on board the NOAA series provide satellite imagery at spatial resolutions of $250 \mathrm{~m}$ to $1.1 \mathrm{~km}$. Such imagery is useful for an overall view of urban dynamics as these relate to urban green; however, the coarse resolution results in pixels containing different types of land cover, especially in non-homogeneous urban areas, a fact which restricts their use for urban management at a rather strategic level of planning (Qian et al. 2015a; Li et al. 2012).

In particular, remotely sensed data is used to measure vegetation so as to describe the urban and biophysical attributes of the vegetation itself, to understand the dynamic of greenspaces in urbanized areas (Qian et al. 2015b), to map urban vegetation cover (Van de Voorde et al. 2008; Dennis et al. 2018; Lang et al. 2018), to assess the state of urban ecosystems (Ayanu et al. 2012; Yang et al. 2015a, 2015b; Maes et al. 2014), to analyze urban processes and factors related to vegetation, such as land cover change (Brazel et al. 2007), the thermal environment in urban areas and quality of life (Yuan, Bauer 2007; Yue et al. 2017; Yan et al. 2014; Cartalis et al. 2016; Kim et al. 2016).

A typical application of remote sensing is the estimation of the Normal Difference Vegetation Index (NDVI) on a pixel by pixel basis with the use of data in the visible and near infrared parts of the spectrum (Grover, Singh 2015). Values of NDVI for a given pixel always result in a number that ranges from -1 to 1 . A pixel without any greenery gives a value close to zero and may well refer to an urbanized area. Negative values refer to pixels with the respective surface covered by water whereas values close to +1 (in the range $0.8-0.9$ ) refer to the highest possible density of green leaves. Healthy vegetation absorbs most of the incident radiation in the visible and reflects a large portion of near-infrared radiation. Unhealthy or sparse vegetation reflects more radiation in the visible and less near-infrared radiation.

From an image processing point of view, a number of methods for measuring vegetation are used: a) the pixel-based supervised classification where each pixel is assigned to one single class; b) the subpixel-based spectral mixture analysis which first takes care of the "unmixing" of the pixel so as to estimate the digital value and consequently the spectral reflectance or emissivity; c) statistical models, such as ordinary least squares and polynomial regression to develop relationships between pixels and the respective ground elements; and d) fuzzy classification, which takes advantage of object based image processing (Wu 2004; Myint 2006; Mathieu et al. 2007; Ban et al. 2010; Myint et al. 2011; Pinho et al. 2012).

Integrating satellite imagery with land cover data, especially data reflecting urban greenery, contributes to the analysis of the thermal environment in urban areas including surface urban heat islands. Li and de Foy (2012) evidenced that the spatial pattern of green space in urbanized Beijing affects land surface temperature and Peng et al. (2012) verified the key role of vegetation feedbacks in reducing the intensity of surface urban heat islands of large urban areas during the day, in particular during the growing season. Naeem et al. (2018) used Gaofen (GF-1) and Landsat- 8 satellite imagery to examine the relationship between green space characteristics and land surface temperature. A number of landscape metrics were used to estimate - with the use of remotely sensed data - the spatial patterns of green spaces, namely the \% of landscape, the patch density, the edge density and the landscape shape index. Mavrakou et al. (2018) correlated (thermal) hot and cold spots in the city of Athens with the presence and extent of urban greenery. Furthermore, they estimated intraurban greenery variations which may influence a number of environmental conditions, from urban heat to air quality and energy consumption for cooling.

A critical aspect for the study of the relationship between urban greenery and the thermal environment in cities are the spatial and temporal resolutions of satellite data in thermal infrared. Spatial resolutions vary from 90 to $100 \mathrm{~m}$ (ASTER and Landsat-8 respectively) to $1 \mathrm{~km}$ (Sentinel-3, MODIS and AVHRR), thus considerably coarser than the respective ones in the visible part of the spectrum (as a matter of fact Landsat resamples the images at spatial resolution of $30 \mathrm{~m}$ ). In terms of the temporal resolution, ASTER and Landsat have revisit times of 16 days, 
whereas the respective revisit times for Sentinel-3, MODIS and AVHRR are in the order of 1-2 days. To overcome the problem of the inverse relationship between spatial and temporal resolution of satellite data in the thermal infrared, a number of studies have been concentrating on downscaling to higher spatial resolutions. In this way, $1 \mathrm{~km}$ satellite data in the thermal infrared are depicted in such resolutions as $100 \mathrm{~m}$ or less, whereas at the same time they retain their high temporal resolution, a fact which allows their use for assessing the role and impact of urban greenery at the city scale and in fine detail (Stathopoulou, Cartalis 2009; Kustas et al. 2003; Merlin et al. 2010; Essa et al. 2013, 2017).

A critical aspect, namely the cooling intensity of noncanopied vegetated areas (e.g. parks) can also be estimated with the combined use of remote sensing data in the visible and thermal infrared parts of the spectrum, in view of defining land cover and land surface temperature respectively. Cao et al. (2010), Ren et al. (2013), Cartalis (2017) and $\mathrm{Du}$ et al. (2017) used satellite data to uncover the relationship between urban park characteristics (presence of urban greenery, size and shape) and park cooling intensity. Ren et al. (2013) used Landsat-5 and SPOT satellite data and Cartalis (2017) Landsat-8 and Sentinel-2 satellite data to show that the cooling intensity is irrelevant to the size of the park, once this exceeds roughly $30 \mathrm{ha}$. This finding supports, if the amelioration of urban heat is concerned, an urban design approach emphasizing the development of several small parks - appropriately dispersed in the urban web, instead of large parks.

Haas and Ban (2018) documented the suitability of Sentinel-2A MSI data for urban land cover mapping and urban ecosystem service analyses. In particular, the Sentinel-2A MSI red band was found effective in distinguishing urban green spaces. Nichol and Lee (2005) showed that vegetation in urban areas can be accurately quantified using automated multispectral remote sensing techniques and that similar accuracy may be obtained with the use of very high resolution images (namely IKONOS) and false color aerial photographs. Furthermore Nichol and Wong (2007) remotely sensed urban vegetation life form by spectral mixture analysis of high-resolution IKONOS satellite images.

A considerable boost to vegetation studies is reflected in the use of active remote sensing. The combined use of Sentinel-1A/1B Synthetic Aperture Radar (SAR) \& Sentinel-2A MSI data has proven reliable (overall accuracy of $82.75 \%$ ) for the definition of urban green structure and changes (Haas, Ban 2017); the fusion of Quickbird MS and RADARSAT SAR data (Ban et al. 2010) improved classification accuracies regarding urban land cover mapping. Integrating LIDAR data and multispectral imagery (Bork, Su 2007) allows the enhanced classification of vegetation. Overall with the use of LiDAR data it is possible to estimate several vegetation parameters (tree height, cover, vertical stratification).

Particular reference is made to Urban Atlas (2012), an initiative within the framework of the Copernicus pro- gram of the European Union. Urban Atlas (2012) provides land use and land cover data for Functional Urban Areas (FUA), a fact which strongly supports urban greenery studies, including change detection and planning. An important asset of these data is that they are provided at the paneuropean level and are comparable. Taken that the presence of canopied vegetation (i.e. trees) influences the state of the thermal environment in urban areas, especially at the street level, it is important to refer to the Street Tree Layer (STL) product. STL is separate layer of Urban Atlas (2012), produced with the use of SPOT 5 high resolution data between the months of March and November. STL provides contiguous rows or patches of trees over artificial surfaces inside FUAs covering $500 \mathrm{~m}^{2}$ or more and with a minimum width of 10 meters (Copernicus 2018).

\section{Progress on greenery selection, plant configuration and urban morphology}

\subsection{Solar reflective greenery: plant selection and performance assessment}

The foliage canopy of a green roof can absorb less solar radiation than a dark roof surface such as concrete or bitumen thanks to its higher solar reflectance, or albedo, $r_{s o l}$, that is the ratio of reflected and incident solar radiation. This ranges from 0 to 1 and can be very low for dark built surfaces or bare soil. Indeed a thermal balance of the foliage canopy such as that in the green roof model FASST (Frankenstein, Koenig 2004), implemented in the widely use EnergyPlus code (Sailor 2008), is enough to verify that latent heat effects are generally dominant in greenery: well-watered plants can dissipate significant amounts of solar heat by vaporization of water through the leaf stomata and thus keep low the temperature of leaves, immediately surrounding air and underlying soil substrate. In summer, plants with high stomatal conductance, i.e. the rate at which plants transpire moisture, can reduce heat transfer to the building below much more than succulents such as Sedum, a genotype commonly used for extensive or semi-extensive green roofs in view of its tolerance to dry conditions (Monterusso et al. 2005; Nagase, Dunnett 2010).

However, accompanying a low stomatal resistance with a high albedo of the foliage canopy can provide the best performance in terms of protection from solar radiation. Yellow-leaved Heuchera with $r_{\text {sol }}=0.27$ was found to provide significantly better cooling performance than darker purple-leaved Heuchera with $r_{\text {sol }}=0.20$, similar to that of plants with same albedo but higher stomatal conductance such as Salvia or Stachys byzantina (Vaz Monteiro et al. 2017). On a canopy of Stachys byzantina, a plant that can often show an ashen color thanks to the presence of a white silky-lanate hair, a relatively high value of $r_{\text {sol }}=0.27$ was measured during a measurement campaign of the Energy Efficiency Laboratory, University of Modena and Reggio Emilia, whereas a value of $r_{\text {sol }}=0.19$ was contemporarily measured on a Sedum cano- 


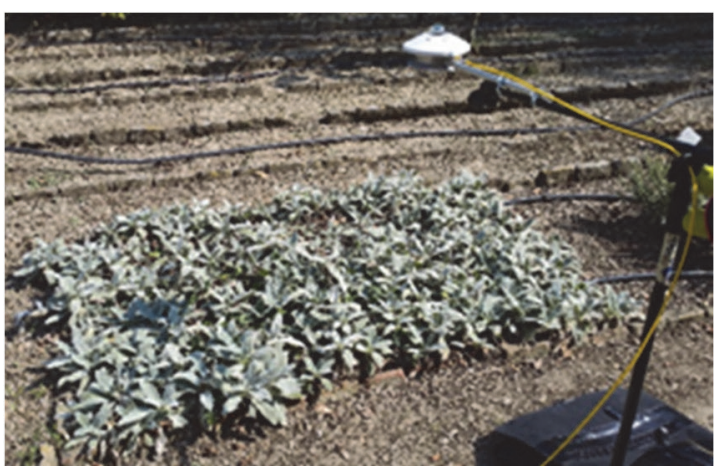

Figure 2. Measurement of canopy albedo on Stachys byzantina according to ASTM E1918-16 (2016)

(Modena, September 2016)

py. With the same two genotypes, foliage temperatures were measured (Blanusa et al. 2013) of $27.8^{\circ} \mathrm{C}$ and $28.3^{\circ} \mathrm{C}$ for well-watered and under-watered Stachys, compared to $32{ }^{\circ} \mathrm{C}$ and almost $35^{\circ} \mathrm{C}$ for well-watered and under-watered Sedum, in the same hot day with ambient air temperature and bare dry soil temperatures in excess of $30^{\circ} \mathrm{C}$ and $40{ }^{\circ} \mathrm{C}$, respectively - all this thanks to the superior combination of stomatal conductance and albedo of Stachys. In well-watered conditions, the soil temperature measured $5 \mathrm{~mm}$ below the surface was $34.2{ }^{\circ} \mathrm{C}$ and $37.1^{\circ} \mathrm{C}$ for Sedum and bare soil, respectively, but as low as $22.2^{\circ} \mathrm{C}$ for Stachys. Generally speaking, plants with more reflective and thus cooler foliage canopy can reduce not only the temperature gradient and the heat flow through the canopy but also the temperature of the surrounding environment, i.e. the contribution to the urban heat island. Moreover, a proper optimization of the albedo may help during heat waves, when plants increase their stomatal resistance, or in cases in which the cost associated with water use can be relevant such as in Schweitzer and Erell (2014).

Knowledge of albedo and other properties is crucial to accurately model the thermal behavior of a green roof and predict or verify its performance (Peri et al. 2016), and measurement may be the easiest way to gain such knowledge. In this regard, the albedo of the whole foliage canopy can be measured as the ratio of upward reflected radiation and downward solar radiation, measured by means of a solar radiometer or pyranometer. A standard test method is available in ASTM E1918-16 (2016), in which reflected and downward radiation are measured simultaneously by two coupled and optimized pyranometers, oppositely oriented (Figure 2). The albedo of a single leaf can be measured in the laboratory by averaging the reflectivity spectrum over the wavelength range of solar radiation $(0.3-2.5 \mu \mathrm{m})$, measured continuously by a UV-Vis-NIR spectrometer (ASTM E903-12 2012) or at several wavebands by a solar reflectometer (ASTM C1549-16 2016), in both cases weighted by a reference spectrum of solar radiation. The albedo of the whole foliage canopy can then be calculated from that of a single leaf and other parameters (Frankenstein, Koenig 2004; Palomo del Barrio 1998) such as leaf area index (LAI), i.e. the the one-sided leaf area per unit ground surface, however, this seems relatively complex and impractical. Nevertheless, spectral measurements can provide interesting information: for example, a significant spread of the reflectivity spectrum was found (Vaz Monteiro et al. 2017) in the NIR wavelength range $(0.7-2.5 \mu \mathrm{m})$, not visible to the human eye but comprising more than $50 \%$ of solar radiation, for leaves of several genotypes having similar spectrum in the visible range $(0.4-0.7 \mu \mathrm{m})$ and, therefore, similar color tone. The importance of the albedo is underlined in the "cool-green roof" concept proposed in Pisello et al. (2016), in which plants that have high albedo but a compact greenery layer are selected as covering vegetation for flat roofs in historical or other contexts where the use of white solar-reflective cool roof coatings is not acceptable. Use of Helichrysum italicum "Curry plant", an aromatic herb with measured leaf albedo as high as 0.44 , was calculated to decrease by 98\% the number of overheating hours in summer, with a slight beneficial effect also in winter. The choice of plants with cyclic greenery development or pruning at the beginning of the winter season, are also recommended in order to turn the surface from reflecting to absorbing in winter.

Green roof plants exchange heat with the sky above and the ground substrate below by emission of longwave infrared radiation, i.e. thermal radiation at ambient temperature. This is governed by the thermal emissivity of the foliage canopy, $e_{f}$, which ranges from 0 to 1 or $100 \%$. It is very close to that of single leaves for LAI $>1$ (Vaz Monteiro et al. 2017). In this regard, thermal emissivity is around 0.90-0.95 for non-metallic surfaces such as biological ones and LAI typically ranges between 0.5 and 5.0 (Sailor 2008). A longwave infrared camera can be used to retrieve the leaf or canopy emissivity in the instrument wavelength range of $8-14 \mu \mathrm{m}$, where a large part of ambient-temperature thermal radiation falls (but not the total). More precisely, but also impractically, the broadband emissivity (5-50 $\mu \mathrm{m}$ range) of flat leaves of a few centimeters size can be accurately measured in the laboratory by emissometers based on standard test methods (ASTM C1371-15 2015; EN 15976:2011 2011). Nonetheless, for common LAI values, $e_{f}$ is always set close to 0.96 in widely accepted green roof models such as FASST (Frankenstein, Koenig 2004), with very small chance of discrepancy, and experimental analyses on several plant species yielded similar values of the leaf emissivity (Vaz Monteiro et al. 2017; Pisello et al. 2016), therefore the measurement and optimization of such property seems of little relevance. It is also worth noting that, on summer nights with clear sky and low-wind conditions, green roof canopies may limit night cooling by longwave radiation heat transfer with the cooler sky, yet this is not an issue if a green roof is mounted on a building with daytime use.

\subsection{Performance of urban greenery in mitigating urban heat island in high-density cities: plant configuration and urban morphology}

It is well known that urban green infrastructure (UGI) is sustainable strategy for urban heat mitigation among other 
ecosystem services. However, because some trees (and other green infrastructure by extension) do not perform well in urban heat mitigation there is an ongoing campaign for the "right tree (UGI) at the right place" in many cities' greening guidelines (Arbor Day Foundation 2016; Doick, Hutchings 2013; GLTMS 2015). Thus, landscape professionals and urban designers now seek easy to use guides and tools to implement green infrastructure within the urban landscape. Findings from recent studies (Alexandri, Jones 2008; Morakinyo, Lam 2016; Ng et al. 2012; Norton et al. 2015) found a strong relationship between urban morphological parameters, thermal performance of UGI, and plant structural characteristics indicating the potential of these parameters, e.g. sky-view factor or aspect ratio as a tool for implementing the right green infrastructure in the right place; and also to choose the right plant species especially for the purpose of urban heat mitigation. This factor is crucial for the growth, optimum performance and maintenance of green infrastructures.

Several studies (Berardi 2016; Wong et al. 2003b, 2007) have shown the potential of green roofs to lower air and radiant temperature up to $1.2 \mathrm{~m}$ above the vegetation zone thus improving the thermal environment on the rooftop. Lowered surface temperature indicates reduced heat exchange to indoor spaces, thus lowered cooling energy consumption (La Roche, Berardi 2014; Morakinyo et al. 2017a). However, parametric tests on the temperature regulation potential of green roofs implemented in a neighbourhood with changing urban morphology (i.e. aspect ratio) have shown a negligible cooling effect at pedestrian level for medium to high density neighbourhoods (Berardi 2016; Morakinyo et al. 2017a; $\mathrm{Ng}$ et al. 2012). This is because the cooler air generated diffused before advection to the pedestrian level due to the high vertical gradient. The reverse was observed for low aspect ratio cases irrespective of the climate classification of the study area, type of green roof (semi or fully extensive or intensive) and other plant characteristics (Morakinyo et al. 2017a; Ng et al. 2012). This indicates that green roof implementation irrespective of types and scales targeted at urban heat mitigation at pedestrian level in high-density neighbourhoods or cities will yield no desired results. Regarding the choice of efficient plant species and configuration for green roof projects, lists of recommended plants exist for some cities (e.g. National Parks Board 2017); however, plants with key attributes such as high foliage density, large spatial scale and high vegetation height should be prioritized for maximum benefit (Alcazar et al. 2015; Bevilacqua et al. 2015; Morakinyo et al. 2017a; Ng et al. 2012; Santamouris 2014a).

Vertical greening, also referred to as green wall or facade greening, is likewise helping cities adapt to climate change by reducing air and facade surface temperatures and peak energy demand (Cheng et al. 2010; De Jesus et al. 2017; Kalani et al. 2016). However, location, placement, and plant configuration determine their effectiveness in terms of surface and air temperature reduction and energy saving. Meanwhile, a recent study (Morakinyo et al. 2017c) has shown how urban morphological characteristics relate to the heat mitigation potential of green wall interventions. In the study, facade greenery of varying façade coverage ratio was implemented in an idealized neighbourhood in Hong Kong with varying urban densities. Results reveal the importance of a higher green facade ratio ahead of orientation for improved urban cooling, as corroborated by other studies where isolated and low coverage facade greening made no significant difference to ambient temperature (Hoelscher et al. 2016; Jänicke et al. 2015; Tan et al. 2014). However, noticeable temperature regulation and thermal comfort improvement are only found with $80-85 \%$ and $30-50 \%$ green facade ratio (of the total facade surface area) in medium and high-density neighbourhoods respectively, whereas $100 \%$ coverage provides no significant cooling in low density neighbourhoods. As very high green facade coverage is unrealistic, implementation for outdoor heat mitigation is somewhat limited to highdensity urban settings with at least $30 \%$ average coverage. Even though nearness to pedestrians often ensures more benefits, innovative placement within a podium height of $20 \mathrm{~m}$ could augment for high coverage requisite (Morakinyo et al. 2017c; Wong et al. 2010). Nonetheless, it is important to mention that significant facade surface temperature reduction is realizable irrespective of urban density. In terms of plant selection and configuration, high foliage density and substrate moisture content (depending on prevailing climate) were found to be the most crucial factors in obtaining the optimum thermal effect from plants, while other factors such as radiative properties and plant traits have negligible impact on the urban heat mitigation (Dahanayake et al. 2017; Hoelscher et al. 2016).

Of all the urban green infrastructures, ground level trees are the most effective for urban heat mitigation. However, due to the variable magnitude of temperature regulation and thermal comfort realizable with different trees species, recent studies are moving past generalization of trees to a species-specific analysis of their thermal benefits and energy saving at building, neighbourhood and city scales (Kong et al. 2017; Morakinyo et al. 2017b; Tan et al. 2017). To understand the relationship between tree performance and urban density, these studies have compared the cooling benefits of certain tree species in street canyons of variable densities and sky view factor. Their results revealed the performance of trees generally dwindled as urban density increases. This is due to the outweighing impact of building shadow effects over the tree shade. This finding suggests that high density areas are not top priority areas for tree planting targeted at heat mitigation even though greening irrespective of urban density is encouraged. Rather, the priority rating increases with the openness of the sky view or decrease in urban density. Thus, the urban density mapping technique has been recommended and evaluated for the selection of tree species for urban planting (Morakinyo et al. 2017b, 2018). Regarding the interplay among tree structural characteristics, urban density and cooling impact, results have likewise shown that foliage density is the major driver of this thermal regulation by trees, as 
denser trees attenuate more direct solar radiation, lessen more surface and air temperature and transpire more water. Also, small-leafed species are found to be more effective for air cooling through their capacity to regulate crown temperatures than larger-leafed species (Leuzinger et al. 2010). However, the role of trunk height and total tree height cannot be overemphasized, even as the crown height and width shows a neutral impact on the cooling benefits. Thus, planning recommendations should include the proposition of tall, higher trunk, short crown width, and less dense trees species for high density areas (Sky View Factor, SVF $\leq 0.2$ ) where the shadowing effect is more dominant, while the reverse is proposed for low density and open areas (SVF $>0.2$ ). This proposition is equally efficient for pollutant diffusion in high density settings (Morakinyo, Lam 2015).

\section{Assessing the impact of urban greenery on energy and well-being}

\subsection{The impact of urban greenery mitigation techniques on the energy consumption of cities}

Many studies have shown that on average the cooling potential of urban greenery ranges between 0 and $3.5^{\circ} \mathrm{C}$ (Santamouris et al. 2017). This reduction of the ambient air temperature from the large-scale implementation of greenery in the urban environment results in lower cooling energy demand for buildings.

In order to quantify the energy impact of increasing trees and vegetation in the urban environment, the effects on local climate must first be calculated. This is done by the use of mesoscale meteorological models (WRF, CSUMM, MM5 etc.). Based on the calculated results for specific days and the use of appropriate statistical techniques, modified hourly weather data files are developed to account for the mitigated climatic conditions that would prevail in the area after the increase of urban greenery. The energy use and savings for representative building types are then calculated using building energy simulation (BES) programs (Energy Plus, TRNSYS, DOE-2, etc.) and the base case (unmitigated) and modified (mitigated) weather files. City scale energy impacts can then be estimated from the BES results using statistical data. Taha et al. (1996) estimated the impact on ambient air temperature from a large-scale tree-planting program in ten US cities. The results of the mesoscale simulations showed that for all simulated areas, on average, the maximum air temperature reduction due to the additional trees ranged from $1-3{ }^{\circ} \mathrm{C}$ with an average value of $1.7^{\circ} \mathrm{C}$. The corresponding HVAC savings for old and new residential and commercial buildings ranged from $\$ 0$ per year per $100 \mathrm{~m}^{2}$ of roof area of residential buildings in Philadelphia to $\$ 12$ per year per $100 \mathrm{~m}^{2}$ of roof area of old commercial buildings in Los Angeles. As expected, the reported savings are higher for old residential and commercial buildings (as opposed to new constructions) and for hotter climates. Based on the results by Taha et al. (1996, 2000), Rosenfeld et al.
(1998) estimated the potential benefits of 11 million (M) additional trees for the Los Angeles Basin. They found that the $3{ }^{\circ} \mathrm{C}$ ambient cooling due to the increase in vegetation results in $35 \mathrm{M}$ \$/year in HVAC energy savings and $0.3 \mathrm{GW}$ reduction in peak power for the whole area. Konopacki and Akbari $(2000,2002)$ have estimated the potential metropolitan-wide benefits of HIR strategies for all air-conditioned residential, office, and retail buildings in five US cities. In terms of indirect energy benefits, urban reforestation with high-reflective pavements and building surfaces are considered and reported together as a combined scenario. The annual metropolitan wide energy savings (electricity savings minus heating penalty) resulting from the ambient cooling due to heat island reduction strategies range between $0.8 \mathrm{M} \$$ for Salt Lake City to $15.6 \mathrm{M} \$$ for Houston. Additionally, peak power avoidance is estimated at 20,12.8, 106, 218, and $33 \mathrm{MW}$ for Salt Lake City, Baton Rouge, Sacramento, Houston, and Chicago, respectively. It is also reported that savings from the indirect impact of heat island reduction strategies is $15 \%, 23 \%, 22 \%, 18 \%$ and $19 \%$ of the overall savings for Baton Rouge, Sacramento, Salt Lake City, Chicago and Houston respectively. Akbari and Konopacki (2005) have developed summary tables (sorted by heating and cooling degree days) to estimate the potential of heat island reduction strategies (i.e. solar-reflective roofs, shade trees, reflective pavements, and urban vegetation) to reduce cooling-energy use in three types of buildings (old - pre 1980 and new - 1980+, residential, office and retail store buildings) for 240 US cities. The tables provide estimates of savings for both direct effect (reducing heat gain through the building shell) and indirect effect (reducing the ambient air temperature), and they consider the increase in albedo and urban greenery combined for the indirect savings. In residences heated with gas and in climates with cooling-degree-days greater than 1000, the annual electricity savings in pre-1980 stock ranged from 115 to $224 \mathrm{kWh} / 1000 \mathrm{ft}^{2}$; for $1980+$ stock savings ranged 51-103 kWh/1000 $\mathrm{ft}^{2}$. For all building types, the indirect savings accounted for less than $25 \%$ of the total savings. As expected, the indirect savings reported in the study would be lower if only urban greenery was taken into consideration. The results of this study have been used for the development of the EPA Mitigation Impact Screening Tool (MIST), a software tool that estimates the impacts of urban heat island mitigation strategies, including increased vegetation, on urban air temperatures, ozone, and energy consumption for a large number of US cities (Sailor, Dietsch 2007). Using a similar methodology, Akbari and Konopacki (2004) have calculated the effect of heat-island reduction strategies on annual energy savings and peakpower avoidance in the building sector of the Greater Toronto Area. The potential annual indirect electricity savings were estimated at about $35 \mathrm{GWh}$ (23\% of the total annual electricity savings) and the peak power avoided due to ambient cooling was estimated to $65 \mathrm{MW}$, representing $26 \%$ of the total peak power avoided. It should be noted 
that ambient cooling results from the combined increase in vegetation and albedo.

Paolini et al. (2018) have developed a variant of the previous methodology. They have used advanced 3D microclimate modeling (ENVI-met) in an effort to quantify the local impacts and energy benefits of different urban heat mitigation scenarios: the increase of greenery, albedo, use of water, misting, and their combination for the Western Sydney area. Eight representative precincts have been selected and modeled. The maximum ambient temperature reduction average for all the modelled precincts is $1.6^{\circ} \mathrm{C}$, when increased greenery is considered. Based on the microclimate modeling results and the use of appropriate statistical techniques, modified hourly weather data files have been developed to account for the mitigated climatic conditions. The energy use and savings for representative residential and commercial buildings were then calculated using BES and appropriate statistical data. The annual cooling load savings for residential and commercial buildings for the whole area of Western Sydney resulting from the application of greenery is estimated to be $1073 \mathrm{GWh}$. The impact of greenery increases by $12 \%$ when combined with water technologies. Following a similar methodology for the City of Darwin, Australia, Santamouris et al. (2018) found that an increase in urban greenery by $30 \%$ results in a maximum ambient air temperature reduction of $1.2^{\circ} \mathrm{C}$. Considering the whole residential and commercial building stock of the City of Darwin, the total cooling load savings, on an annual basis, resulting from the application of greenery is estimated to be $88.4 \mathrm{GWh}$. If greenery is combined with albedo increase and street shading the annual cooling load savings reach $265.2 \mathrm{GWh}$.

In a different approach, Silva and Fillpot (2018) have used a numerical zero-dimensional energy balance model that replicates the urban characteristic temperature and performed a correlation analysis involving meteorological data and total daily energy (TDE) consumption in the Phoenix, Arizona, USA, metropolitan region to estimate a reduction in power usage if UHI mitigation strategies (increasing the overall (1) emissivity, (2) vegetated area, (3) thermal conductivity, and (4) albedo of the urban environment in a series of increases by $5,10,15$, and $20 \%$ ) were implemented. The predicted average annual reduction in Phoenix total daily energy usage ranges from $1553.2 \mathrm{GWh}$ for a $5 \%$ increase in vegetation to $1631.7 \mathrm{GWh}$ for a $20 \%$ increase.

At the district scale, Morakinyo et al. (2018) have used a validated ENVI-met model to investigate the impacts of increasing greenery coverage ratio (GCR) to $30 \%$ in a selected neighbourhood in Hong Kong. They found that compared to the reference case (no trees), the maximum temperature is reduced by $0.5-1.0^{\circ} \mathrm{C}$ and cooling energy is decreased by $\sim 1900-3000 \mathrm{kWh}$. They also highlight the importance of species-specific analysis as the variations in the estimated benefits correspond to different tree species considered in the study. Castaldo et al. (2018) performed coupled microclimate analyses and dynamic thermal-energy simulation of buildings to assess the effect of microclimate mitigation strategies including increased greenery, on building energy needs at settlement level for an Italian near-Zero Energy residential settlement. The increased greenery scenario results in an average ambient air temperature reduction of $0.22{ }^{\circ} \mathrm{C}$ invoking a decrease in cooling energy needs of $4.42 \mathrm{kWh} / \mathrm{m}^{2} / \mathrm{y}$. Kong et al. (2016), combining in-situ measurements and 3D ENVI-met microclimate simulations studied the effect of green spaces on the outdoor thermal environment and quantified potential cooling energy savings at Gulou Campus of Nanjing University, China. It was found that removal of green spaces increased mean air temperature by $0.5^{\circ} \mathrm{C}$ and the cooling benefits of green spaces in relation to the mean height of buildings on Gulou Campus yielded $5.2 \mathrm{~W} / \mathrm{m}^{2}$ cooling energy, saving totally $1.3 \times 104 \mathrm{kWh}$ during a single daytime hot summer period. Kikegawa et al. (2006) have used a multi-scale model system describing the interaction between building energy use and urban meteorological conditions to estimate the possible impacts of urban heat-island countermeasures (including increase of vegetation) on building energy use during summer in Tokyo. It was found that vegetative fraction increase on the side walls of buildings in residential canopies decreased near-ground summer air temperature by $0.5^{\circ} \mathrm{C}$ and results in cooling energy-savings of about $20 \%$.

\subsection{Non-thermal health benefits of urban greenery}

The health benefit of urban greenery has been a key component of landscape architecture theory since the mid19th century (Eisenman 2013). Early landscape architects sought to increase urban greenery for better ventilation, improved sanitation and healthier indoor conditions. However, as noted by Howard (1898), urban greenery also contributes to improved physical and mental wellbeing, particularly in dense urban settings, that despite their crowded conditions, are rife with social isolation. He conjectured that brighter dwellings and more open spaces with greenery should have a calming influence and even improve societal cohesion. The possibility that urban greenery and green infrastructure have positive effects (direct and indirect) on human health has been confirmed by three decades of psychology and ecology research exploring the relationship between nature contact and human wellbeing (Tzoulas et al. 2007).

Late in the 20th century, researchers from landscape architecture, urban climatology and public health disciplines returned to these ideas with new methods and approaches to analyze the impact urban greenery has on human health. New research continues to point to faster recovery time in hospitals (Frumkin 2003). For example, in a comparative study of 46 patients recovering from similar hospital procedures, Ulrich (1984) found average recovery times of 7.96 days for patients whose recovery rooms faced a small grove of trees beside the hospital and 8.70 days for those whose recovery rooms faced brick walls. 
In addition to the physical recovery of patients, research points to the generally healthier lifestyles of those with more green access (Takano et al. 2002; Tanaka et al. 1996; Tzoulas et al. 2007). In a review of green infrastructure (GI) as it pertains to the urban ecosystem and human health, Tzoulas et al. (2007) document the connections between GI and improved well-being for humans and ecosystems. Takano et al. (2002) found that many senior citizens (2211 of 3144) in Japan lived longer when living near walkable green space $(\mathrm{p}<0.05)$. Tanaka et al. (1996) found an inflection point (60\% land use classified as urban) in general health levels (mortality rate, coping attitudes and self-perceived health status) in Tokyo based on urban density. These studies continue to point to qualitative health benefits of urban greenery and GI.

In a broad analysis of GI in urban planning documents in Sweden, Sandström (2002) saw GI as a multi-purpose component of the urban fabric, and just as important to urban function and vitality as road infrastructure. This perspective elevates GI as an integral component of the urban form. Nevertheless, additional research is needed to quantitatively evaluate the role of these environmental factors across the spectrum of human health outcomes.

Mental well-being, especially within urban populations, is a concern among public health researchers (March et al. 2008; Vassos et al. 2016) and urban greenery has been found to improve a variety of psychological conditions in the urban population (Barton, Pretty 2010; Kuo, Sullivan 2001; Ulrich et al. 1991). R. Kaplan and S. Kaplan (1989) used empirical research (similar to Ulrich (1984)) as a foundation for their claim of the psychological importance of nature. Many prior studies point to the reduction in anxiety and stress due to time spent in green spaces. For example, Ulrich et al. (1991) found that after experiencing stress, subjects who viewed nature exhibited a quicker recovery (measured by $\mathrm{p}<0.05$ for pulse transit time, electrocardiogram, skin conductance, and muscle tension) than those exposed to common urban environmental scenes (vehicle or pedestrian traffic). Kuo and Sullivan (2001) found that both aggression and violence were connected to lack of green space and green infrastructure via mental fatigue. This was confirmed by student $t$ tests that determined greenness was related to positive mood and lower stress. Using these metrics, Kuo and Sullivan (2001) isolated greenness as a factor in reducing aggression in public housing districts of Chicago. Barton and Pretty (2010) found through meta-analysis of 10 studies that just 5 to 10 minutes of exercise (walking, cycling, horse-riding, farming, gardening, or sailing) in a green space led to improved mood and self-esteem across all demographics. Independent of age, gender, and existence of prior mental health concerns, exercise significantly improved mood and self-esteem. This effect (even over a very short time scale), was found to be greatest in environments where water and urban greenery were present. It is important to note that none of the 10 studies used a control exercise group; therefore, there may be some confounding factors associated with exercise itself. Urban greenery may also have links to cognitive function.

Despite the likely health benefits of urban greenery, there is a possible adverse unintended consequence. Specifically, the provision of green infrastructure may result in ecological gentrification that comes with such improvements to local urban environments. Ecological gentrification is the phenomenon of gentrification that occurs as a result of increases in green infrastructure and space (Dooling 2009; Wolch et al. 2014). Specifically, as green infrastructure is introduced to a neighborhood, the resulting improvement in eco-services and corresponding increase in neighborhood popularity can result in increases in housing prices, driving out lower income populations who may benefit the most from increased green infrastructure.

Although causal pathways and relationships are still unclear and the impacts are not fully quantifiable, the past three decades have provided a growing body of work that points to the non-thermal benefits of urban greenery and green infrastructure for almost all aspects of human health. The benefits encompass both the physiological and psychological realms of human health: from improved physical health and recovery to higher selfesteem, decreased anxiety, and reduced intensity of mental disorders. These non-thermal benefits of urban greenery and GI are not always easy to measure; but the impact on human well-being cannot be denied and must be considered whenever discussing the implementation of greenery in the urban fabric.

\subsection{Greenery, emissions, and air-quality}

The net effects of urban greening on local microclimate, emissions, and air quality result from multiple competing physical and chemical processes that are highly sitespecific and that can produce both positive (beneficial) and negative impacts. Thus, while generalizations are impossible, it is informative to consider the orders of magnitude involved in some of these processes, such as the various cooling mechanisms and air-quality impact pathways of urban greenery.

In terms of air quality, two relevant considerations are: (1) use of urban greening to improve air quality, and (2) use the changes in air quality as indicators to or constraints on the amount of cooling targeted. The goal of the latter is to prevent or minimize negative impacts (Taha 2013). The net air-quality effects for ozone are beneficial if low-emitting species are used in urban greening, i.e. those emitting less than $2 \mu \mathrm{g} \mathrm{g}^{-1} \mathrm{~h}^{-1}$ of isoprene (per dry leaf mass) and less than $1 \mu \mathrm{g} \mathrm{g}^{-1} \mathrm{~h}^{-1}$ of monoterpenes (Taha 1996, 2008a, 2015b). Typical net reductions in daytime peak ozone are up 2-3 ppbv and the 8-hour average peak ozone concentrations are reduced by $1-2 \%$ (Taha et al. 2015; Nowak et al. 2000). In addition to the cooling effects, shading from urban greening, e.g. on parking lots, also has beneficial air-quality impacts. For example, Scott et al. (1999) found that if canopy cover over parking lots 
in Sacramento County, CA, is increased from $8 \%$ to $50 \%$, it would reduce county-wide reactive organic gases (ROG) evaporative emissions by $0.85 \mathrm{t} \mathrm{day}^{-1}(\sim 2 \%)$ and NOx start emissions by $1 \mathrm{t} \mathrm{day}^{-1}(\sim 1 \%)$.

The reductions in ground-level ozone resulting from these various pathways, in turn, can help reduce radiative forcing locally, which has been found to be $0.017 \mathrm{~W} \mathrm{~m}^{-2}$ for each 1 ppbv change in ozone (Taha, Sailor 2010). This feedback effect can cool the air further.

Another urban greening strategy, replacing businessas-usual tree species in urban areas with a low-emitting mix (with no increase in canopy cover) can reduce peak ozone concentrations in the order of $0.5-3 \mathrm{ppbv}$ and the 8 -hour concentrations by up to $2 \%$ (Taha et al. 2015).

In terms of particulate matter (PM), trees and ground cover can remove up to $\sim 10 \mathrm{~g} \mathrm{~m}^{-2} \mathrm{yr}^{-1}$, with evergreen species being about $15-20 \%$ more efficient than deciduous species (Nowak et al. 2006; Marando et al. 2016). The efficacy of trees in removing $\mathrm{PM}_{10}$ falls within the range of $2-7 \%$ of the locally-emitted $\mathrm{PM}_{10}$ (Selmi et al. 2016; Baumgardner et al. 2012; Speak et al. 2012). Green roofs can remove 2-8 $\mathrm{g} \mathrm{m}^{-2} \mathrm{yr}^{-1}$ of $\mathrm{PM}_{10}$, up to $2 \mathrm{~g} \mathrm{~m}^{-2} \mathrm{yr}^{-1}$ of $\mathrm{NO}_{2}$, and up to $7 \mathrm{~g} \mathrm{~m}^{-2} \mathrm{yr}^{-1}$ of $\mathrm{O}_{3}$ (Jayasooriya et al. 2017; Currie, Bass 2008; Yang et al. 2008; Rowe 2011). Calculations suggest that the localized reductions in particulate matter via scavenging by urban vegetation may be larger than the potential increases in concentrations resulting from reductions in mixing because of the cooling effect. The efficacy of urban greening in removing gaseous and particulate pollutants can be enhanced further by geometry, such as in urban canyons (Pugh et al. 2012). In relatively more open areas, e.g. around larger roadways, the localized effects of urban trees on gaseous pollutants are generally small or negligible but their ability to reduce particulate matter is still relatively significant (Yli-Pelkonen et al. 2017).

To estimate net effects, the benefits from urban greening must be weighed against the potential negative impacts of (1) higher biogenic volatile organic compound (BVOC) emissions and (2) reductions in mixing or venting. These aspects are highly site-specific and must be determined locally prior to implementing any large-scale greening measures, some general thoughts are discussed here.

The overwhelming majority of BVOC emissions consists of isoprene $\left(\mathrm{C}_{5} \mathrm{H}_{8}\right)$ and monoterpenes $\left(\mathrm{C}_{10} \mathrm{H}_{16}\right)$, depending on temperature and, in the case of isoprene, on sunlight as well (Harrison et al. 2013; Guenther et al. 1993; Guenther, Wiedinmyer 2004; Taha et al. 2015; Taha 1996). The worst tree emitters could inject as much as $40 \mu \mathrm{g} \mathrm{g}^{-1} \mathrm{hr}^{-1}$ of isoprene and as much as $4 \mu \mathrm{g} \mathrm{g}^{-1} \mathrm{hr}^{-1}$ of monoterpenes under standard conditions $\left(28^{\circ} \mathrm{C}\right.$ and $1000 \mu \mathrm{E} \mathrm{m}^{-2} \mathrm{~s}^{-1}$ ) (Ghirardo et al. 2016; Scott, Benjamin 2003; Benjamin, Winer 1998). Compare this with the rates of low emitters discussed above. Introducing moderate amounts of low-emitting species in an area like the Los Angeles region can reduce population exceedance exposure to ozone above the 1-hour NAAQS (120 ppbv) from $18 \%$ (base) to $16 \%$ and with a larger implementation of low emitters, exposure is reduced further to $14 \%$ (Taha 2013, 1996; Taha et al. 2015). However, when introducing moderate amounts of medium emitters (emitting on average $4 \mu \mathrm{g} \mathrm{g}^{-1} \mathrm{~h}^{-1}$ of isoprene and $2 \mu \mathrm{g} \mathrm{g} \mathrm{g}^{-1} \mathrm{~h}^{-1}$ of monoterpenes), exceedance exposure can increase to $27 \%$. This highlights the importance of carefully selecting tree species when implementing urban greening measure (i.e. in this case, the changes in air quality should be used as constraint on the amount of cooling to be achieved).

In terms of mixing and venting, as the urban surface is cooled (past a certain threshold) via widespread urban greening, the depth of the boundary layer is reduced (Taha 2007, 2008a, 2008b, 2013, 2015b) and the production and dissipation of turbulent kinetic energy are locally altered by the presence of vegetation in the urban boundary layer (Gromke, Blocken 2014; Taha 2008b). For example, the decrease in boundary-layer depth because of city-wide implementation of tree canopies and green roofs can range from 100 to $500 \mathrm{~m}$ (Taha 2015a; Sharma et al. 2016) out of a boundary layer depth that is typically up to $3-4 \mathrm{~km}$ in summer afternoons. However, there appear to be cityspecific thresholds for cooling at which the impacts of temperature reduction far outweigh the impacts of reduced vertical and/or horizontal mixing (Taha 2007, 2008a, 2013). Such area-specific thresholds should be identified on a case-by-case basis, and used as a target for the amount of cooling to be achieved from urban greening measures.

In summary, one major purpose of urban greening is to achieve cooling, especially during hotter weather and excessive heat events. However, the higher temperatures and sunlight during such conditions can also increase BVOC emissions, negatively impacting air quality and negating some or all of the greening benefits that were sought in the first place. Thus, to maximize the positive effects of urban afforestation while minimizing inadvertent air-quality impacts, three aspects must be considered: (1) planting of low-emitting species (Taha et al. 2015; McPherson et al. 2000, 2018; TreePeople 2017), (2) implementing urban greening in tandem with other anthropogenic-emission control measures (Churkina et al. 2017) not just as standalone measures, and (3) observing the area-specific thresholds for cooling (Taha 2005, 2007, 2008a, 2013). Holistic site-specific multi-dimensional modeling and observations of the impacts of urban greening, as well as integrated approaches, are needed to account for all possible interactions and outcomes and maximize the benefits sought after. Some such thinking in this direction already is underway (e.g. Taha 2017; Taha et al. 2018; Zhang et al. 2017; Reeve et al. 2015; Jim 2013; Jennings et al. 2016 among others). Thus far, most studies demonstrate that there is great potential for urban greening to improve microclimate and air quality if all of the various site-specific physical and chemical processes are factored in during the design of mitigation measures. 


\subsection{The role of greenery in outdoor thermal comfort with varying heat stress}

The evapotranspiration role of greenery is compromised during extreme hot events and in dry conditions or, even worse, it can be perceived as a non-pleasant contribution to increase relative-humidity related heat stress in the tropical context. Special microclimate conditions in any outdoor environment are known to be responsible for dominant effects modifying the human body energy balance (Gulyás et al. 2006). In this view, a recent review paper by Potchter et al. (2018) was elaborated with the purpose to clarify the massive literature about this open issue and the authors highlighted about 165 human thermal indices frequently used to clarify citizens' perceptions in the outdoors, while only 4 of these (PET, PMV, UTCI, $\mathrm{SET}^{*}$ ) were more frequently used for outdoor thermal perception studies. In this panorama, the investigation of greenery potential benefits and their variability in dense urban areas due to peculiar conditions (urban heat island and heat waves, etc.) becomes a crucial issue to be addressed, and it needs a careful analysis also by considering the comfort model selection and its assumptions, since it may be responsible for different interpretation of the same environmental conditions. This is even truer if we also consider human personally-driven perception drivers while comparing between various impervious surfaces (cool or dark ones). In fact, people survey-based studies demonstrated how pedestrians typically express much better thermal and visual perception in greener environments, even if measured physical parameters affecting their body energy balance are the same (or even worse) as other conditions (Rosso et al. 2016). Despite that, as stated in this review, greenery's role in mitigating the urban heat island phenomenon at mesoscale and improving citizens' wellbeing at microscale has been widely acknowledged and demonstrated by a variety of modelling and experimental field studies all around the world, where their evapotranspiration and shading contributions are investigated (Perini, Magliocco 2014; Besir, Cuce 2018). Kosaka et al. (2018) investigated, for instance, possible overheating risks occurring during Tokyo city marathon which will take place in 2020 by means of the COMFA model, able to connect environmental variables such as temperature, humidity, wind and radiation with personal factors consisting of metabolic rate and clothing insulation level to estimate thermal comfort and potential heat stress. With this aim, they equipped test cars and bicycles with meteorological sensors and traced such parameters along the running path. Although these measurements may be of some help for such specific conditions (city marathon run circuits), they are not representative of the most common conditions of people walking over dedicated sidewalks, much closer to buildings and affected, at the same time, by street traffic and impervious surfaces' radiation. Therefore, dedicated wearable systems were developed with the purpose to monitor the pedestrian level microclimate parameters directly interacting with the human body and suitable for more reliable energy budget calculation (Nakayoshi et al. 2014; Pigliautile, Pisello 2018). In fact, deep personal heat stress analysis at individual scale has been demonstrated to be driven by measurable and nonmeasurable parameters and indexes coming from multidisciplinary fields of investigation such as behavioural sciences, people's susceptibility, medical conditions and environmental comfort outcomes. All these components may be assessed by means of dedicated monitors, surveys, personal interviews, and ethnographic, social and health approaches helping the identification of urban overheating exposure risks. In any case, the classic approach of fixed measurement points and only environmental based correlation lacks fine-scale precision, much needed to mitigate health risks related to urban heat exposure (Kuras et al. 2017).

Urban greenery, as previously mentioned, being able to produce a double benefit due to evapotranspiration and local shading, but, at the same time, being also an "alive" strategy, has to be carefully evaluated since its effect may be related to particular meteorological conditions (1) and the greenery maintenance regime and configuration itself (2). The former condition is mostly related to super dry or/and super wet conditions, being responsible for evapotranspiration performance. The latter condition affects greenery morphology and therefore, its potential shading contribution. Both these variables may hugely compromise urban greenery mitigation effects at both local and mesoscale, in terms of pedestrians' thermal comfort in particular. Given the typical high expectation rate associated with greenery benefits perceived by citizens, the variability of these two conditions may be crucial for determining its reliability during particularly hot times of the day or, even worse, super dry or super wet heat waves. These peculiar circumstances, the frequency of which is rapidly increasing over recent decades and also interacting with UHI phenomenon (Ghobadi et al. 2018; Ward et al. 2016) may therefore exacerbate human risks imputable to overheating. In fact, while perception-based studies state that greenery and access to it from a visual and physical perspective are the key drivers toward better urban health and wellbeing (Jackson 2003), its passive cooling contribution may be largely compromised, if we see the same issue from a more physicalbased approach (Ward et al. 2016). Gill et al. (2007) indeed demonstrated how green infrastructures may produce, as expected, thermal stress reduction in general urban conditions but, in case of severe drought, such benefit is significantly reduced due to the lack of water supply to the vegetation, responsible for its transpiration capability. Additionally, the effect of greenery as mitigation strategy is even more complex to identify, given its dependency on morphology and space distribution in urban areas.

\subsection{Green roof life cycle with varying heat stress}

In the actual context of climate change and mitigation and adaptation needs, it is important to study viable solutions which match changing boundary conditions, assessing 
their long-term effectiveness and sustainability. Environmental and economic analysis by Life Cycle Assessment (LCA) and Life Cycle Costing (LCC) were adopted to assess the effectiveness of green roofs as mitigation technology. From the environmental and economic point of view, green roofs as an urban mitigation measure are generally sustainable. As discussed in the previous sections, the benefits are obtained in terms of energy savings, stormwater runoff management and air quality (reduction of pollutants and urban overheating) (Belussi, Barozzi 2015), but need a high initial investment. In general, in terms of LCA the supporting structure of green roofs has the highest impact; by this, several researchers proposed the development of structures made of industrial waste materials and industrial sub-products (Manso et al. 2018).

However, for greenery, a standard procedure for LCA assessment has not been adopted yet. For example different terms of life phases are adopted; hence a homogeneous comparison is quite difficult (Belussi, Barozzi 2015). Furthermore, as a matter of fact, none of the papers in the literature considers the effect that non-predictable heat waves, temporary events, UHI and the reduction of water availability have on the maintenance, the replacement, the energy consumption and the lifetime of greenery solutions. These phenomena, already existing and probably likely to worsen in the future, affect several aspects and can cause huge variations in terms of initial costs, maintenance costs, lifetime, sustainability and effectiveness of greenery solutions. The first aspect is related to the greenery design and the selection of natural species. This choice is already very challenging and mostly depends on the type of green roof- intensive, semi-intensive or extensive -, species availability and the local microclimate conditions. The types of greenery differ for the species and number of plants, the thickness of the substrate and the maintenance and watering needs (Manso et al. 2018; FLL 2008). The species availability, sizes, health, maintenance and adaptability to the local climate must also be considered. For example, in the mild climate of the Czech Republic (Central Europe) (Vacek et al. 2017) ground covers, small herbaceous plants, grasses or small shrubs were selected as suitable species for semi-green roofs because they need moderate maintenance and occasional irrigation during long periods without precipitation. In a dry climate like that of South Australia (Razzaghmanesha et al. 2014), instead, the selection of native species was influenced by the highly variable rainfall patterns and the uniqueness of vegetation that caused a very high initial cost of installation. Thus, the selection of native species is already critical where the microclimatic conditions are extreme. It is very likely that if the climatic variations, the heat stress and the non-predictability of mid-to-long-term urban climate were considered, the greenery design would become more complex even in apparently milder climates, where drought and heat tolerant species could be also required (Savi et al. 2016).

The expected service life of greenery solutions is another aspect affected by extreme heat events. The service life is in general considered as 20 years (e.g. for green roofs), based on the materials' technical specifications and recommendations provided by the producers. After 20 years it is assumed that full renovation and the replacement of most layers are required. However, any renovation in general is hard to predict since the need of renovation depends on many variables, such as local climate and the quality of the materials. Such estimates were omitted in the mentioned studies because "they would unnecessarily increase the uncertainty of the assessment's results" (Vacek et al. 2017). Further uncertainties in the expected service life would be introduced by heat stress. In addition, taking into account that high substrate temperature represents a stress factor affecting plant survival more than drought per se; it becomes even more difficult to estimate the expected service life in heat stress conditions (Savi et al. 2016).

At the same time, the need to protect greenery from early deterioration due to heat stress and climatic variations seems to conflict with one of the main targets in green roof research of reducing substrate depth, to limit installation weight and costs (Cao et al. 2014). According to Savi et al. (2016) this might lead to even more extreme temperatures in the substrate and plants death during heat waves events or caused by UHI.

\section{Using greenery under extreme climatic conditions}

\subsection{The influence of urban irrigation and adopting drought-tolerant vegetation on urban climate}

Urban irrigation is essential for many species of vegetation to grow and survive (Clark, Kjelgren 1990). Irrigation also adds anthropogenic moisture to the atmosphere and soil, influencing the hydrological cycle and surface energy balance, and causing changes in urban air temperatures. Irrigation has been simulated to increase latent heat fluxes and significantly reduce daytime near-surface air temperature in Southern California (Vahmani, Hogue 2015; Coleman et al. 2010), while Georgescu et al. (2011) found trivial influence of irrigation on temperatures in Phoenix, Arizona. Broadbent et al. (2018) investigated the climate effects of irrigation with different amounts of water consumption, and suggested that timing, location, and volume of irrigation should be optimized for urban cooling.

Cities without sufficient water supply are promoting the adoption of drought-tolerant vegetation as a way to reduce irrigation water use while maintaining city "greenness". For example, Californian cities have been experiencing severe drought (Mao et al. 2015) and therefore have provided rebates for residents to transform lawns to drought-tolerant plants that require less water. Vahmani and Ban-Weiss (2016) for the first time simulated the climate impacts of adopting drought-tolerant vegetation using a regional climate model. Replacing lawns with drought-tolerant shrubs was found to increase daytime near-surface air temperatures by up to $1.9^{\circ} \mathrm{C}$ and decrease 
night time near-surface air temperatures by $3.2^{\circ} \mathrm{C}$ during summer in Southern California. The night time cooling was mainly attributed to reductions in irrigation water, which led to decreased soil moisture; as the soils became drier, the soil heat conductivity decreased, reducing upward ground heat flux from the soil to the land surface. The daytime warming was attributed to (a) decreases in irrigation that led to reductions in evaporative cooling and latent heat fluxes, and (b) increases in leaf stomatal resistance that reduced evapotranspiration. In another scenario where all urban vegetation (i.e. both lawns and trees) was transformed to drought-tolerant shrubs, nearsurface air temperatures were simulated to decrease during both day $\left(-0.2{ }^{\circ} \mathrm{C}\right)$ and night $\left(-3.1^{\circ} \mathrm{C}\right)$. Changing trees to shrubs led to daytime cooling because decreases in surface roughness length led to increases in the onshore sea breeze. The cooling from reductions in roughness length outweighed the warming influence of reductions in evaporative cooling from converting lawns and trees to shrubs that require no irrigation. Yang and Wang (2017) simulated the climate impacts of replacing all vegetation in Phoenix with shrubs and found that irrigation water use could be reduced by $0.77 \pm 0.05 \times 10^{8} \mathrm{~m}^{3}$, leading to increases in daily average near-surface air temperature by $1.2{ }^{\circ} \mathrm{C}$ in summer. Vahmani and Ban-Weiss (2016), Yang and Wang (2017) suggest that strategies for reducing irrigation that alter urban vegetation cover can result in significant atmospheric feedbacks that should be considered in city planning.

\subsection{On the mitigation potential of greenery during extreme ambient temperature conditions}

The frequency and the duration of heat waves and extreme summer weather conditions have been increasing constantly during the last twenty years (Yao et al. 2013), and are expected to further intensify in the near future (Cowan et al. 2014). Heat waves have a synergetic effect with the urban heat island resulting in a further increase of the ambient temperature in cities (Founta, Santamouris 2017), while extreme temperature synoptic conditions are usually associated with drought and a decline of precipitation (Stéfanon et al. 2014). Several studies have shown that during heat waves the cooling potential of trees may be reduced significantly (Lu et al. 2012; Skoulika et al. 2013) and their mitigation capacity and potential may be seriously limited.

Excessive ambient heat occurring during heat waves affects transpiration and the other physiological processes of plants resulting in a considerable reduction of the latent heat released to the atmosphere. Heat stress and the respiration rate of plants depend on the magnitude of the ambient temperature, duration of the exposure, humidity of the soil and the specific resistance of plants to high temperatures and drought (Teskey et al. 2015). When excessive ambient temperatures are combined with drought, it may cause closure of the stomates, senescence of leaves, increase of their surface temperature above the ambient temperature, disturbances to the plants' water and nutrient transport systems and may trigger mortality of the trees (Teskey et al. 2015; Allen et al. 2010; Haldimann et al. 2008; Zweifel et al. 2006). Higher leaf temperatures increase the sensible heat released to the atmosphere and result in higher ambient temperatures. Stomates are tiny pores on plant leaves with a variable aperture used by the plants to regulate gas exchange and transpiration. Stomatal conductance measures the extent of stomatal opening, which controls the exchange of $\mathrm{CO}_{2}$ and water vapor between leaf and atmosphere.

Plants can fix part of the thermal damage caused during heat waves through several mechanisms such as the production of heat shock proteins (Colombo, Timmer 1992), increase of the reflectivity of leaves to absorb less solar radiation (Ehleringer, Mooney 1978; Curtis et al. 2012), while they can also adjust their physiological processes, physiological acclimatization, to respond to long term changes of the ambient temperature (Reich et al. 2016).

Watering of plants during heat waves is of high importance. Extreme temperature conditions increase the evaporation from the soil and reduce its moisture content. In parallel, this translates into hot draughts that can cause increased transpiration from the plants. Thus, under high atmospheric and soil dryness, trees require high levels of hydration to avoid a failure of their transport systems (Anderegg et al. 2012). Watering of the plants during extreme heat and drought is essential to keep the physiological processes of trees at acceptable levels. Several experiments (Bauweraerts et al. 2013) have shown that during heat waves seedlings in low soil water conditions have significantly reduced their transpiration levels compared to the period prior to the heat wave, while in well-watered seedlings transpiration was not affected. Experiments carried out in Australia during heat waves have shown that well irrigated vines maintained their sap flow at high levels and even increased sap flow during the hottest days. On the contrary, the sap flow of the non-irrigated plants was reduced to about 50\% compared to the irrigated plants. Higher sap flow is associated with a much higher transpiration rate and cooling potential of the plants (Forster, Eglefield 2018).

It is believed that during heat waves, most plants close stomates to limit the loss of water resulting in reduced transpiration and ambient cooling. However, the response of different species to extreme heat varies significantly, and even under very high ambient temperature conditions, the stomates of several species remain open while transpirational cooling is still effective to minimize the heat stress of the leaves and to cool the stems by heat convection caused by the moving water in the stems (Ameye et al. 2012; Kolb, Robberecht 1996). Very little is known about the tree species that employ transpirational cooling to hydrate and protect their leaves. Classical theory describing the physiology of plants relate stomatal conductance to the photosynthetic rate and the vapor pressure deficit (Ball 
et al. 1987; Leuning 1995; Medlyn et al. 2011). Under very high temperatures, above $40^{\circ} \mathrm{C}$, stomatal conductance and photosynthetic rate may decrease substantially and thus it is expected that the transpiration rate should also decrease or minimize. However, as previously mentioned, several experiments performed under heat wave conditions using small well watered pot plants have shown that stomatal conductance, photosynthetic rate and transpiration may be decoupled, and the transpiration rate may be significant provided that the hydraulic system of the plants is functioning and there is enough water in the soil to be transferred to the leaves (Ameye et al. 2012; von Caemmerer, Evans 2015; Rogers et al. 2017; Urban et al. 2017). Other experiments performed under simulated heat wave conditions using mature Eucalyptus plants, have shown also that trees were able to maintain a high transpiration and cooling potential even under very high ambient temperatures (Drake et al. 2018). High transpiration rates during heat waves result in important cooling of the ambient air by the plants and a significant mitigation potential of greenery.

Based on existing observations, a new model to predict stomatal conductance has been proposed by Lin et al. (2015). The model assumes that the stomates are regulated to maximize photosynthesis minus the carbon cost of transpiration. The proposed stomatal conductance model has been incorporated into an earth system model (Kala et al. 2016), to calculate the temperature amplitude of heat waves in Western Europe and Asia. It was found that when the updated stomatal conductance of plants is used, and it is not as previously considered that plants with the same photosynthetic characteristics employ similar water use strategies, then the maximum air temperature may increase substantially, up to $5^{\circ} \mathrm{C}$ on top of the temperature increase caused by the rise of the atmospheric carbon dioxide. The study has not identified any change in the frequency of the heat waves. The predictions of the study considerably exceed previous predictions by other similar studies aiming to evaluate the cooling impact of greenery during heat waves (Lorenz et al. 2013; Stéfanon et al. 2012). According to these studies, a decrease of the soil moisture by $25 \%$ during the 2003 heat wave in Europe could result in a maximum increase in ambient temperature of up to $2{ }^{\circ} \mathrm{C}$. The results of these specific studies demonstrate how important it is to improve our knowledge of the physiological processes of plants during extreme ambient temperature conditions, while revealing the extreme importance of greenery and its impact on social economic, environmental and energy issues under the current and future climatic conditions.

Several experiments have been performed to characterize the sensitivity of several families of trees to extreme heat and drought and provide guidance on the type of trees to be used under the future climatic conditions. It is reported (Bigras 2000), that plants with superior height efficiency are more sensitive to extreme heat and stress than families of plants with a lower rate of height growth. Also, faster growing trees originating from fertile and humid ar- eas are less efficient in water management and use, compared to plants growing in areas with reduced resources (Monclus et al. 2009; Pita et al. 2005). In parallel, plants with a deep rooting system can collect water from deep in the soil profile and present a high transpiration rate even when the moisture of the soil is reduced. However, shallow rooting plants may not be capable to collect water from deep underground and keep a high transpiration rate and mitigation potential during heat waves (Drake et al. 2018). Selection of trees for mitigation purposes should consider all the above criteria of tolerance of extreme temperature and drought.

\subsection{Genetically engineered trees to face climate change of $21^{\text {st }}$ century}

Genotypic variation in response to extreme future climatic conditions should be further investigated to increase growth in tree species and increase trees resilience under the future abiotic and biotic stresses due to climate change. Abiotic stress for trees involves drought, salinity, heat and cold conditions while biotic stress involves insects and disease that may also occur due to climate differentiation.

Temperature is one of the dominant parameters for trees' development and endurance. Even if we study the same tree genotypes, temperature creates differences (Teskey et al. 2015). There are tree genotypes from warmer areas that grow faster than their genotypes from cooler areas. For example, Savva et al. (2007) studied the impact of climate change as well as seed transfer of 21 provenances of jack pine showing that the radial growth of the jack pine populations is mainly related to temperature at the seed origin. Bigras (2000) studied the damage of 12 openpollinated families of white spruce (Picea glauca) that differ in growth performance by exposing them to a 30 -min heat treatment of $42{ }^{\circ} \mathrm{C}, 44{ }^{\circ} \mathrm{C}, 46^{\circ} \mathrm{C}, 48{ }^{\circ} \mathrm{C}$ or $50{ }^{\circ} \mathrm{C}$ with or without heat preconditioning at $38^{\circ} \mathrm{C}$ for $5 \mathrm{~h}$. Damage was evaluated based on chlorophyll fluorescence and on visible damage during and after the heat treatments. The study showed that tree families with superior height-growth performance had low photochemical efficiencies in the light after heat treatment. What was noticeable is that heat preconditioning reduced the heat stress related damage. There are more studies showing that white spruce (Picea glauca) and black spruce (Picea mariana) seedlings exhibit reduced heat injury after heat preconditioning (Koppenaal et al. 1991).

Therefore, in the context of extreme heat and drought conditions, trees' increased thermotolerance is a desirable attribute and can be used as a means of assessing trees' plasticity to conditions that might arise during global warming (Colombo et al. 1995; Guha et al. 2018; Koppenaal et al. 1991).

In this framework, research is performed to breed future desirable traits with increased tolerance in abiotic stresses and especially thermotolerance (Bigras 2000; Koppenaal et al. 1991; Wahid et al. 2007). Thermotolerance of 
trees requires a thorough understanding of physiological responses of plants to high temperature, mechanisms of heat tolerance and identification of possible strategies The process can be done either with traditional breeding methods or with genetic engineering.

Producing with traditional methods a cultivar with increased heat stress tolerance depends on several plant physiological parameters and mechanisms, such as amendments to essential processes, e.g. photosynthesis and concomitant increases of transcripts coding for proteins involved in protection (Bita, Gerats 2013). In many cases, a heat-tolerant variety is characterized by higher photosynthetic rates, increased membrane thermostability and heat avoidance such as leaf rolling, early maturation, change of leaf orientation, etc. Moreover the breeding of desirable thermotolerance in trees using traditional methods is very slow and with a lot of complications (Wahid et al. 2007):

1. It is quite difficult to identify genetic resources with heat tolerance attributes. In many species, limited genetic variations exist within the cultivated species necessitating identification and use of wild accessions.

2. Heat tolerance has to be distinct from growth potential. In this sense, trees may perform better in heat tolerance regardless of the growing conditions.

3. Breeding for stress tolerance; often it is necessary that the derived species are able to perform well under both stress and non-stress conditions. Development of such genotypes may hide inherent difficulties.

4. It is necessary to identify which stages of the trees' life cycle are the most vulnerable to heat stress avoiding severe damage.

Nevertheless, there are works showing that heat tolerant cultivars have been developed using traditional breeding protocols. Examples can be drawn from food plantation and cultivation (Cairns et al. 2013).

Genetic engineering for trees can be an alternative in providing fast improvement in thermotolerance and drought tolerance. Nowadays genetic engineering has advanced to the point at which genes for desirable traits can now be introduced and expressed efficiently (Harfouche et al. 2011). Examples of desirable traits involve stress tolerance (biotic and abiotic), improved wood properties, root formation, etc.

Concerning abiotic stress, molecular control of plants' response is complex. It usually involves coordinated expression of several genes either that are involved in signalling and regulatory pathways or that encode proteins conferring stress tolerance or enzymes present in pathways leading to the synthesis of functional and structural metabolites.

The use of known abiotic-stress-associated genes from other species to enhance tolerance in trees has been limited (Vinocur, Altman 2005). However, recent studies in genomics, transcriptomics and proteomics in several tree species and the draft Eucalyptus grandis genomic sequence release, have provided new tools for improving abiotic stress tolerance in trees (Harfouche et al. 2011).
A substantial and durable increase in the thermotolerance of hybrid poplar (Populus tremula $\times$ Populus alba) is reported by Merino et al. (2014). This is achieved by overexpression of a major small heat shock protein (sHSP). The baseline levels of the transgene product were up to $1.8 \%$ of total leaf protein. Protein analysis shows that this accumulation is not matched either by endogenous sHSPs in both heat-stressed poplar plants and field-grown adult trees.

In addition, quantitative trait locus (QTL) mapping has recently become the method of choice to identify specific chromosome segments that contain candidate genes for heat tolerance (Bita, Gerats 2013). The key benefit of QTLbased approaches is that they allow loci that are linked to heat tolerance to be identified. The identification of markers linked to QTLs enables breeding of stress-tolerant crops by combining or pyramiding QTLs for tolerance to various stresses. Several QTL studies relating to various abiotic stress tolerances have already been reported especially in food industry. QTL mapping studies for heat tolerance have been conducted on various rice populations at flowering stages (Ye et al. 2012). Multiple loci for heat tolerance have been identified in wheat (Paliwal et al. 2012). Concerning trees E. urophylla has been used in breeding programmes for its resistance to drought and diseases and these results suggest that it might also provide useful germplasm for heat resistance. Moreover in Populus simonii, a heat-resistant species with wide distribution in China, 35 microsatellite markers have been identified that could be useful in marker-assisted breeding of stressresistant germplasm.

These results reinforce the feasibility of improving valuable genotypes for forestry where long breeding cycles and other practical factors constrain traditional breeding protocols. More studies though are needed to allow the observation of effects over longer periods and conditions that closely mimic the life span of greenery and plantations. Additionally, cycles of stress and stress recovery are also prevalent processes that influence the trees' life span. Thus, the degree of recovery from stress, which also has its molecular basis, is as relevant as the response to stress.

Another critical point is the rules and methodologies that should be followed to allow the genetically engineered trees to be commercially available. Policy and social stakeholders will most likely demand a reassurance and methodologies for mitigating the risk of transgene spread and persistence in the environment (Ye et al. 2011). Transgene confinement can be achieved by developing genetically engineered trees that do not produce functional flowers using various strategies. Therefore, genetically engineering trees that are reproductively sterile may help alleviate public and regulatory concerns.

\section{Assessment aspects related to mitigating effect of vegetation in Green building rating tools (GBRTs)}

Green building rating tools (GBRTs) are established to provide simultaneous and comprehensive means of 
assessing a broad range of environmental considerations in building sectors (Haapio, Viitaniemi 2008). To name a few mainstream GBRTs, there are LEED (USA), BREEAM (UK), Green Star (Australia and New Zealand), and those in the Asian context such as CASBEE (Japan), BEAM Plus (Hong Kong), and Green Mark (Singapore). In recent versions, GBRTs have shifted the focus from buildings alone to neighborhood scale (Ameen et al. 2015; Berardi 2013; Hamedani, Huber 2012). GBRTs assess the mitigating effect of urban greenery on cities at the practical level, and the performance of vegetation is evaluated through its relationship with buildings, the development site and the neighborhood. In GBRTs, the recognized and highlighted benefits of green infrastructure include improving thermal performance of building facades and microclimate around buildings, mitigating heat islands and adapting to climate change, and enhancing the comfort and well-being of building users and the general public (Huo et al. 2018; Hui 2010).

Greenery is assessed in various aspects and by different methods in GBRTs. The quantity of the vegetation on site is the main aspect being evaluated in term of the mitigating effect on heat islands. To obtain credits in the rating systems, minimum percentages in vegetated areas within the site boundary or on buildings (green walls and roofs, podiums, sky gardens, etc.) need to be achieved. Meanwhile, studies (Berndtsson 2010; Chen 2013; Shahidan et al. 2012) have pointed out that the quantity of vegetation is not the only factor related to mitigation performance. Tree configuration and planting pattern have also shown profound influence on microclimate and thermal conditions (Feldhake 2001; Morakinyo, Lam 2016; Kong et al. 2017). Total leaf area (LAI) of the greenery on site, tree crown diameter, width of shaded pedestrian route, as well as building setback for street trees and maximum planting intervals are also key indices being evaluated or specified in BEAM Plus and Green Mark. Moreover, studies have also emphasized the importance of the selection of species and proper maintenance on the mitigation performance (Solecki et al. 2005; Mbow et al. 2014; Wong et al. 2003a, $2003 \mathrm{~b})$. The value of native and other suitable species in enhancing climate resilience and ecological function has been highlighted in GBRTs (BEAM Plus, CASBEE, LEED, BREEAM, etc.). LEED suggests appropriate planting and maintenance methods to sustain the mitigation efficiency of vegetation on site.

Several GBRTs, such as LEED and BEAM plus, adopt a prescriptive-based method and give out direct instruction on greenery provision and maintenance. Such prescriptive-based approaches may limit options and margins in practice (Wedding, Crawford-Brown 2007). On the other hand, principles and strategies, instead of concrete actions, are provided in performance-based GBRTs like BREEAM and Green Mark. Documentary evidence (microclimatic simulation/study report of greenery on site, site photographs of tree planting) is required in BREEAM and Green Mark for evaluating performance and confirming compli- ance. Furthermore, performance-based assessment systems urge the designers to pay attention to the synergic effects as well as potential conflicts between different environmental aspects, for example the function and benefit of greenery across multi-scales (Shashua-Bar et al. 2009).

One of the anticipated roles of GBRTs is to stimulate action and good practices at different stages of planning and design (Todd et al. 2001). With clearly defined scope, GBRTs encourage design teams to communicate with clients or stakeholders on project aims and environmental considerations at an early stage (LEED, Green Mark), and produce assessment reports on site aspects, environmental issues and impact of development. Guidance notes for the design and as-built stages are provided in GBRTs, for example the green infrastructure plan and landscape design, proposed tree species and calculated LAI value should be prepared during the design stage for assessment. At the as-built stage, site photographs of design specification, as-built drawings with delivery orders of the plants, recalculated LAI of greenery over total site area, etc., are required as documentary evidence for verification (BREEAM, Green Mark). To manage realistic situations in development, exclusions or compensation measures for sites with constraints are also specified in GBRTs (BEAM Plus, BREEAM). References such as existing guidelines and regulations, scientific reports and documents are attached to offer additional support for designers (BEAM Plus). Furthermore, in terms of scales, GBRTs address policy across a range of planning levels from strategic planning, master planning, to town planning (Green Star).

GBRTs have applicably incorporated scientific understanding into design guidance and enormously contributed to furthering the promotion of sustainable practice in the real world (Cole 2005). Several possibilities can be postulated for way forwards in the future.

Firstly, the regionalization of GBRTs and climate-specific responses. Many rating systems such as LEED and CASBEE were developed for national or even international application and regional variations in environmental concerns has been overlooked (Cole 1998). Local climate is an essential factor in the evaluation of mitigation performance of urban greenery (Wong et al. 2007; $\mathrm{Ng}$ et al. 2012). GBRTs catered for a specific region or climate type, such as BEAM Plus (Hong Kong) and Green Mark (Singapore), emphasize the application of climatic responsive strategies, including vertical greenery on east and west facades in the (sub)tropics, shading of trees in hot-humid climates, species-based assessment for climatic adaptation.

Secondly, the contextualization of GBRTs and practical consideration in urban environments. Prior research has shown that the cooling effect of urban greenery is largely affected by building geometry (Morakinyo et al. 2017a, 2017b, 2017c). To optimize thermal benefits, planting strategies should consider the co-existing effect of buildings and urban morphology (Tan et al. 2017). From a practical perspective, planning and design would need to overcome constraints on greenspace provision in cities (Jim 
2002). GBRTs should encourage innovative design that maximizes greening potential in urban areas, for example green facade and sky garden in a compact urban setting.

Thirdly, user-based consideration in GBRTs. Human factors, including the physiological, psychological, and social aspects should be taken into account in the sustainable design process (Zuo, Zhao 2014; Santos Nouri et al. 2018). For further refinement, it is suggested the planning and design of urban greenery be assessed not just in terms of cooling outcome and environmental effect, but also the contribution to pedestrian comfort, place making and social provision.

Finally, but maybe most importantly, the harmonization and coordination between GBRTs and local planning guidelines and building regulation systems. To realize sustainable action in daily practice, GBRTs and the science and principles behind them should not be fancy add-ons or extra credit points, but the essential part of industry standards (Ding 2008; Ng 2009).

\section{Conclusions and further research}

Urban greenery is a natural solution to cool cities and provide comfort, clean air and significant social, health and economic benefits. Modern research on the cooling capacity of urban greenery has mainly followed following more an empirical approach. Researchers employing conventional experimental processes have identified the local cooling caused by the various urban greenery configurations ranging from simple trees to urban parks. The serious variability with the climatic conditions, urban configuration and structural greenery characteristics, between the numerous experiments reported in the literature, offers rich but quite fragmented knowledge and information. The recent development of computational fluid dynamic tools able to estimate the meso and microclimatic conditions in cities made possible the evaluation of the mitigation potential of urban greenery, and offered an important tool to planners, designers, and urban climatologists. It is well recognised that the green infrastructure offers optimum thermal benefits only when deployed in the right place, determined by the urban density or morphological average of the installation sites, after the selection of the right plant species. However, the serious restrictions regarding the algorithms used to evaluate the time-varying evapotranspiration of trees and vegetation, the grid dependant performance and the fuzziness on the climatic boundary conditions, limit the accuracy of the existing tools and may be the source of important errors. Development of more accurate climatic models is of primary importance for the future.

Large or even small-scale urban mitigation projects involve the combined use of several mitigation technologies. Although climate models can estimate the combined cooling effect, their performance in assessing overlapping mitigation strategies is unknown and untested, lacking benchmarks for this purpose. Moreover, there is not enough knowledge on the response of vegetation and other mitigation to all possible boundary conditions, including stress periods of different length. Additionally, climatic complexity induces important second-order effects which are currently not represented in climate models. As a result, the prediction of the combined mitigation efficiency may suffer from important inaccuracies while it is almost impossible for the model users and the urban designers to parameterize the performance, optimise the corresponding sizing of the greenery mitigation subsystems and propose more efficient combinations of the technologies. The latter is a serious defect, as recent experimental research has shown that different combinations may either reduce the efficacy of each system and the corresponding combined performance, or they may instead enhance their individual performance and multiply the combined cooling efficiency. This is the case between interactive ventilative and evapotranspirative cooling urban systems that may work synergistically and adapt their combined thermal result to the specific climatic needs. Although knowledge on the topic has considerably increased, mainly on the interaction of small-scale greenery and ventilative systems, scientific insight and experimental evidence has to be further developed and implemented at the city scale.

Advanced remote sensing monitoring techniques are now able to describe the urban and biophysical attributes of the vegetation itself. They help to explore and understand the dynamic of greenspaces in cities and map in detail the urban green ecosystems, assessing their state. Moreover they support the investigation of urban processes and parameters related to vegetation, such as land cover change, the thermal environment in urban areas and quality of life. Such powerful monotoning tools permit a global knowledge of the status of greenery in cities and allow public administrations to avoid damage and maintain greenery at high operational status. Nonetheless, remote sensing techniques are not yet ready to provide information on the evapotranspiration of urban trees and the corresponding cooling provided by vegetation. This is a major research challenge and task for the future.

Very important knowledge has been developed to assess the energy, health and environmental impact of greenery at the city scale. While most studies refer to the impact of vegetation on individual buildings, important modelling studies have evaluated the influence of vegetation on the global energy consumption of a precinct or a city. Depending on the features of the urban cluster and vegetative species and climatic conditions, greenery seems to deliver energy savings exceeding 35\%. However, most of the studies are not validated because of the very limited number of real case studies and the important effort necessary to perform the assessments. Future research should concentrate on the collection and provision of experimental and precise information at the precinct and city scale to better document the energy savings impact of urban vegetation.

It is widely accepted that urban greenery provides very significant health benefits. Non-thermal health ben- 
efits are well documented, and more evidence and knowledge is constantly gained. However, increased urban temperatures induced by the local and global climate change increase tremendously the heat-related mortality and morbidity and this seems to be the peak scientific challenge of the near future. Several recent simulation studies have provided evidence that additional urban greenery may reduce substantially the heat-related mortality and morbidity. Although studies are based on the best estimates of the cooling potential of greenery and recent epidemiological studies, further research validating the findings is necessary.

Climate change causes a serious increase of the ambient temperature combined with extended drought periods. High ambient temperatures and lack of water affects the physiological system of the trees and may reduce substantially their cooling capacity. Recent research has concentrated on the mechanisms of the physiological change and the selection of species able to resist to the climate change. The role of irrigation is widely explored, and it is generally accepted that it is the key factor affecting the transpiration of plants. The development of genetically modified vegetation to operate under much higher ambient temperatures seems to be a very promising perspective. It is sure that research on the issue of vegetation adaptation will be intensified and important new developments and achievements can be expected.

\section{Contribution of the Authors}

M. Santamouris prepared Section 4.2, Introduction and Conclusions, while he had the coordination of the article, E. Ng, Tobi Eniolu Morakinyo and Zheng Tan contributed to Section 2.2 and Section 5. George Ban-Weiss and Jiachen Zhang authored Section 3.1. D. Sailor and C. Crank contributed to Section 3.2, P. Osmond authored Section 1.3, H. Takebayashi - Section 1.1, M. Zinzi - Section 1.2, C. Cartalis - Section 1.5, R. Paolini - Section 1.4, A. Muscio - Section 2.1, M. Zinzi - Section 1.2, A. Synnefa - Section 3.1, H. Taha - Section 3.3, A. L. Pisselo Section 3.4, F. Rossi - Section 3.5 and D. Kolokotsa - Section 4.3 .

\section{Funding Sources}

This work was partly supported by the "Vice-Chancellor's Discretionary Fund" of the Chinese University of Hong Kong under Grant 4930752. Also, Georges Ban Weiss was supported in part by the National Science Foundation under grants CBET-1512429 and 1752522

\section{References}

Akbari, H.; Cartalis, C.; Kolokotsa, D.; Muscio, A.; Pisello, A. L.; Rossi, F.; Santamouris, M.; Synnefa, A.; Wong, N. H.; Zinzi, M. 2016. Local climate change and urban heat island mitigation techniques - The state of the art, Journal of Civil Engineering and Management 22(1): 1-16. https://doi.org/10.3846/13923730.2015.1111934
Akbari, H.; Davis, S.; Dorsano, S.; Huang, J.; Winnett, S. 1992. Cooling our communities. A guidebook on tree planting and light-colored surfacing. US Environmental Protection Agency, USA.

Akbari, H.; Huang, J.; Martien, P.; Rainer, L.; Rosenfeld, A.; Taha, H. 1989. Saving energy and reducing atmospheric pollution by controlling summer heat islands, in K. Garbesi, H. Akbari, P. Martien (Eds.). Controlling summer heat islands. Berkeley, California: Lawrence Berkeley Laboratory.

Akbari, H.; Konopacki, S. 2004. Energy effects of heat-island reduction strategies in Toronto, Canada, Energy 29(2): 191-210. https://doi.org/10.1016/j.energy.2003.09.004

Akbari, H.; Konopacki, S. 2005. Calculating energy-saving potentials of heat-island reduction strategies, Energy Policy 33(6): 721-756. https://doi.org/10.1016/j.enpol.2003.10.001

Akbari, H.; Pomerantz, M.; Taha, H. 2001. Cool surfaces and shade trees to reduce energy use and improve air quality in urban areas, Solar Energy 70(3): 295-310. https://doi.org/10.1016/S0038-092X(00)00089-X

Alcamo, J. 2003. Ecosystems and human well-being: a framework for assessment. Washington: Island Press.

Alcazar, S. S.; Olivieri, F.; Neila, J. 2015. Green roofs: Experimental and analytical study of its potential for urban microclimate regulation in Mediterranean-continental climates, Urban Climate 17: 304-317. http://doi.org/10.1016/j.uclim.2016.02.004

Alexandri, E.; Jones, P. 2008. Temperature decreases in an urban canyon due to green walls and green roofs in diverse climates, Building and Environment 43(4): 480-493.

http://doi.org/10.1016/j.buildenv.2006.10.055

Allen, C. D.; Macalady, A. K.; Chenchouni, H.; Bachelet, D.; McDowell, N.; Vennetier, M.; Kitzbergerg, T.; Rigling, A.; Breshears, D. D.; (Ted) Hogg, E. H.; Gonzalez, P.; Fensham, R.; Zhang, Z.; Castro, J.; Demidova, N.; Li, J.-H.; Allard, G.; Running, S. W.; Semerci, A.; Cobb, N. 2010. A global overview of drought and heat induced tree mortality reveals emerging climate change risks for forests, Forest Ecology and Management 259: 660-684. https://doi.org/10.1016/j.foreco.2009.09.001

Ameen, R. F. M.; Mourshed, M.; Li, H. 2015. A critical review of environmental assessment tools for sustainable urban design, Environmental Impact Assessment Review 55: 110-125. https://doi.org/10.1016/j.eiar.2015.07.006

Ameye, M.; Wertin, T. M.; Bauweraerts, I.; McGuire, M. A.; Teskey, R. O.; Steppe, K. 2012. The effect of induced heat waves on Pinus taeda and Quercus rubra seedlings in ambient and elevated CO2 atmospheres, The New Phytologist 196: 448-461. https://doi.org/10.1111/j.1469-8137.2012.04267.x

Anderegg, W. R. L.; Berry, J. A.; Field, C. B. 2012. Linking definitions, mechanisms, and modeling of drought-induced tree death, Trends in Plant Science 17: 693-700. https://doi.org/10.1016/j.tplants.2012.09.006

Arbor Day Foundation. 2016. The right tree for the right place. Tree City USA.

ASTM C1371-15 Standard test method for determination of emittance of materials near room temperature using portable emissometers. ASTM International, 2015. https://doi.org/10.1520/C1371-15

ASTM C1549-16 Standard test method for determination of solar reflectance near ambient temperature using a portable solar reflectometer. ASTM International, 2016.

https://doi.org/10.1520/C1549-16

ASTM E1918-16 Standard test method for measuring solar reflectance of horizontal and low-sloped surfaces in the field. ASTM International, 2016. https://doi.org/10.1520/E1918-16 
ASTM E903-12 Standard test method for solar absorptance, reflectance, and transmittance of materials using integrating spheres. ASTM International, 2012. https://doi.org/10.1520/E0903-12

Ayanu, Y. Z.; Conrad, C.; Nauss, M.; Wegmann, M.; Koellner, T. 2012. Quantifying and mapping ecosystem services supplies and demands: a review of remote sensing applications, Environmental Science Technology 46: 8529-8541.

https://doi.org/10.1021/es300157u

Bacci, L.; Morabito, M.; Raschi, A.; Ugolini, F. 2003. Thermohygrometric conditions of some urban parks of Florence (Italy) and their effect on human wellbeing, in Proceedings of the "Fifth International Conference on Urban Climate", 1-5 September 2003, Lodz, Poland.

Ball, J.; Woodrow, I.; Berry, J. A. 1987. A model predicting stomatal conductance and its contribution to the control of photosynthesis under different environmental conditions, in Progress in Photosynthesis Research, Proceedings of the VII ${ }^{\text {th }}$ International Congress on Photosynthesis Providence, 10-15 August 1987, Rhode Island, USA, 221-224.

https://doi.org/10.1007/978-94-017-0519-6_48

Ban, Y.; Hu, H.; Rangel, I. 2010. Fusion of QuickBird MS and RADARSAT SAR data for urban land-cover mapping: objectbased and knowledge based approach, International Journal of Remote Sensing 31: 1391-1410.

https://doi.org/10.1080/01431160903475415

Bartesaghi Koc, C.; Osmond, P.; Peters, A. 2017. Towards a comprehensive green infrastructure typology: a systematic review of approaches, methods and typologies, Urban Ecosystems 20(1): 15-35. https://doi.org/10.1007/s11252-016-0578-5

Barton, J.; Pretty, J. 2010. What is the best dose of nature and green exercise for improving mental health - A multi-study analysis, Environmental Science \& Technology 44: 3947-3955. https://doi.org/10.1021/es903183r

Baumgardner, D.; Varela, S.; Escobedo, F. J.; Chacalo, A.; Ochoa, C. 2012. The role of a peri-urban forest on air quality improvement in the Mexico City megalópolis, Environmental Pollution 163: 174-183.

https://doi.org/10.1016/j.envpol.2011.12.016

Bauweraerts, I.; Wertin, T. M.; Ameye, M.; McGuire, M. A.; Teskey, R. O.; Steppe, K. 2013. The effect of heat waves, elevated [CO2] and low soil water availability on northern red oak (Quercus rubra L.) seedlings, Global Change Biology 19: 517-528. https://doi.org/10.1111/gcb.12044

Beatty, R. A. 1989. Planting guidelines for heat island mitigation and energy conservation, in Controlling Summer Heat Islands, Proceedings of the Workshop on Saving Energy and Reducing Atmospheric Pollution by Controlling Summer Heat Islands, 23-24 February, Berkeley, California, USA.

Belussi, L.; Barozzi, B. 2015. Mitigation measures to contain the environmental impact of urban areas: a bibliographic review moving from the life cycle approach, Environmental Monitoring and Assessment 187(12): 745.

https://doi.org/10.1007/s10661-015-4960-1

Benjamin, M. T.; Winer, A. M. 1998. Estimating the ozoneforming potential of urban trees and shrubs, Atmospheric Environment 32: 53-68. https://doi.org/10.1016/S1352-2310(97)00176-3

Berardi, U. 2013. Sustainability assessment of urban communities through rating systems, Environment, Development and Sustainability 15(6): 1573-1591.

https://doi.org/10.1007/s10668-013-9462-0

Berardi, U. 2016. The outdoor microclimate benefits and energy saving resulting from green roofs retrofits, Energy and Buildings 121: 217-229. http://doi.org/10.1016/j.enbuild.2016.03.021
Bernard, J.; Rodler, A.; Morille, B.; Zhang, X. 2018. How to design a park and its surrounding urban morphology to optimize the spreading of cool air, Climate 60: 10.

https://doi.org/10.3390/cli6010010

Berndtsson, J. C. 2010. Green roof performance towards management of runoff water quantity and quality: A review, Ecological Engineering 36(4): 351-360.

https://doi.org/10.1016/j.ecoleng.2009.12.014

Besir, A. B.; Cuce, E. 2018. Green roofs and facades: A comprehensive review, Renewable and Sustainable Energy Reviews 82(Part 1): 915-939.

https://doi.org/10.1016/j.rser.2017.09.106

Bevilacqua, P.; Coma, J.; Pérez, G.; Chocarro, C.; Juárez, A.; Solé, C.; Solé, C.; De Simone, M.; Cabeza, L. F. 2015. Plant cover and floristic composition effect on thermal behaviour of extensive green roofs, Building and Environment 92: 305-316. http://doi.org/10.1016/j.buildenv.2015.04.026

Bigras, F. J. 2000. Selection of white spruce families in the context of climate change: Heat tolerance, Tree Physiology 20(18): 1227-1234. https://doi.org/10.1093/treephys/20.18.1227

Bita, C. E.; Gerats, T. 2013. Plant tolerance to high temperature in a changing environment: scientific fundamentals and production of heat stress-tolerant crops, Frontiers in Plant Science 4: 273. https://doi.org/10.3389/fpls.2013.00273

Blanusa, T.; Vaz Monteiro, M.; Fantozzi, F.; Vysini, E.; Li, Y.; Cameron, R. W. F. 2013. Alternatives to Sedum on green roofs: Can broad leaf perennial plants offer better 'cooling service'?, Building and Environment 59: 99-106. https://doi.org/10.1016/j.buildenv.2012.08.011

Bork, E.; Su, J. 2007. Integrating LIDAR data and multispectral imagery for enhanced classification of rangeland vegetation: A meta-analysis, Remote Sensing of Environment 111: 11-24. https://doi.org/10.1016/j.rse.2007.03.011

Bowler, D. E.; Buyung-Ali, L.; Knight, T. M.; Pullin, A. S. 2010. Urban greening to cool towns and cities: A systematic review of the empirical evidence, Landscape and Urban Planning 97(3): 147-155. https://doi.org/10.1016/j.landurbplan.2010.05.006

Brazel, A. P.; Gober, S. J.; Lee, S.; Grossman-Clarke, J.; Hedquist, Z. B.; Comparri, E. 2007. Determinants of changes in the regional urban heat island in metropolitan Phoenix between 1990 and 2004, Climate Research 33: 171-182. https://doi.org/10.3354/cr033171

Broadbent, A. M.; Coutts, A. M.; Tapper, N. J.; Demuzere, M. 2018. The cooling effect of irrigation on urban microclimate during heatwave conditions, Urban Climate 23: 309-329. https://doi.org/10.1016/j.uclim.2017.05.002

Buccolieri, R.; Gromke, C.; Di Sabatino, S.; Ruck, B. 2009. Aerodynamic effects of trees on pollutant concentration in street canyons, Science of the Total Environment 407: 5247-5256. https://doi.org/10.1016/j.scitotenv.2009.06.016

Ca, V. T.; Asaeda, T.; Abu, E. M. 1998. Reductions in air conditioning energy caused by a nearby park, Energy and Buildings 29: 83-92. https://doi.org/10.1016/S0378-7788(98)00032-2

Cairns, J. E.; Crossa, J.; Zaidi, P. H.; Grudloyma, P.; Sanchez, C.; Luis Araus, J.; Thaitad, S.; Makumbi, D.; Magorokosho, C.; Bänziger, M.; Menkir, A.; Hearne, S.; Atlin, G. N. 2013. Identification of drought, heat, and combined drought and heat tolerant donors in maize, Crop Science 53(4): 1335-1346. https://doi.org/10.2135/cropsci2012.09.0545

Cao, C. T. N.; Farrell, C.; Kristiansen, P. E.; Rayner, J. P. 2014. Biochar makes green roof substrates lighter and improves water supply to plants, Ecological Engineering 71: 368-374. https://doi.org/10.1016/j.ecoleng.2014.06.017 
Cao, Q.; Yu, D.; Georgescu, M.; Han, Z.; Wu, J. 2015. Impacts of land use and land cover change on regional climate: A case study in the agro-pastoral transitional zone of China, Environmental Research Letters 10(12). https://doi.org/10.1088/1748-9326/10/12/124025

Cao, X.; Onishi, A.; Chena, J.; Imura, H. 2010. Quantifying the cool island intensity of urban parks using ASTER and IKONOS data, Landscape Urban Planning 96: 224-231. https://doi.org/10.1016/j.landurbplan.2010.03.008

Cartalis, C. 2017. Prerequisites for nature based solutions in cities, in European Forum on Nature Based Solutions, October 2017, Tallinn, Estonia.

Cartalis, C.; Santamouris, M.; Polydoros, A.; Nyktarakis, G.; Mavrakou, T. 2016. Assessing the interlinks between urbanization, the built environment and the thermal environment in view of smart and sustainable urban development: a demonstration application for Athens, International Journal of Earth and Environmental Sciences 1. Article ID 1:IJEES-107. https://doi.org/10.15344/2456-351X/2016/107

Castaldo, V. L.; Pisello, A. L.; Piselli, C.; Fabiani, C.; Cotana, F.; Santamouris, M. 2018. How outdoor microclimate mitigation affects building thermal-energy performance: A new designstage method for energy saving in residential near-zero energy settlements in Italy, Renewable Energy 127: 920-935. https://doi.org/10.1016/j.renene.2018.04.090

Chang, C. R.; Li, M. H.; Chang, S. D. 2007. A preliminary study on the local cool-island intensity of Taipei city parks, Landscape and Urban Planning 80(4): 386-395.

Chang, C.-R.; Li, M.-H. 2014. Effects of urban parks on the local urban thermal environment, Urban Forestry and Urban Greening 13(4): 672-681.

https://doi.org/10.1016/j.ufug.2014.08.001

Chen, C. F. 2013. Performance evaluation and development strategies for green roofs in Taiwan: A review, Ecological Engineering 52: 51-58.

https://doi.org/10.1016/j.ecoleng.2012.12.083

Chen, F.; Kusaka, H.; Bornstein, R.; Ching, J.; Grimmond, C. S. B.; Grossman-Clarke, S.; Loridan, T.; Manning, K. W.; Martilli, A.; Miao, S.; Sailor, D.; Salamanca, F. P.; Taha, H.; Tewari, M.; Wang, X.; Wyszogrodzki, A. A.; Zhang, C. 2011. The integrated WRF/urban modelling system: development, evaluation, and applications to urban environmental problems, International Journal of Climatology 31: 273-288. https://doi.org/10.1002/joc.2158

Chen, X.; Su, Y.; Li, D.; Huang, G.; Chen, W.; Chen, S. 2012. Study on the cooling effects of urban parks on surrounding environments using Landsat TM data: a case study in Guangzhou, southern China, International Journal of Remote Sensing 33(18): 5889-5914.

https://doi.org/10.1080/01431161.2012.676743

Cheng, C. Y.; Cheung, K. K. S.; Chu, L. M. 2010. Thermal performance of a vegetated cladding system on facade walls, Building and Environment 45(8): 1779-1787. http://doi.org/10.1016/j.buildenv.2010.02.005

Churkina, G.; Kuik, F.; Bonn, B.; Lauer, A.; Grote, R.; Tomiak, K.; Butler, T. M. 2017. Effect of VOC emissions from vegetation on air quality in Berlin during a heat wave, Environmental Science \& Technology 51: 6120-6130. https://doi.org/10.1021/acs.est.6b06514

Clark, J.; Kjelgren, R. 1990. Water as a limiting factor in the development of urban trees, Journal of Arboriculture 16(8): 203-208.
Cole, R. J. 1998. Emerging trends in building environmental assessment methods, Building Research \& Information 26(1): 3-16. https://doi.org/10.1080/096132198370065

Cole, R. J. 2005. Building environmental assessment methods: redefining intentions and roles, Building Research \& Information 33(5): 455-467. https://doi.org/10.1080/09613210500219063

Coleman, R. F.; Drake, J. F.; McAtee, M. D.; Belsma, L. O. 2010. Anthropogenic moisture effects on WRF summertime surface temperature and mixing ratio forecast skills in Southern California, Weather and Forecasting 25(5): 1522-1535. https://doi.org/10.1175/2010WAF2222384.1

Colombo, S. J.; Timmer, V. R. 1992. Limits of tolerance to high temperatures causing direct and indirect damage to black spruce, Tree Physiology 11: 95-104.

https://doi.org/10.1093/treephys/11.1.95

Colombo, S.; Timmer, V.; Colclough, M.; Blumwald, E. 1995. Diurnal variation in heat tolerance and heat shock protein expression in black spruce (Piceamariana), Canadian Journal of Forest Research 25(3): 369-375.

https://doi.org/10.1139/x95-041

Copernicus. 2018. Urban atlas [online]. Available from Internet: https://land.copernicus.eu/local/urban-atlas/street-tree-layerstl/view

Cowan, T.; Purich, A.; Perkins, S.; Pezza, A.; Boschat, G.; Sadler, K. 2014. More frequent, longer, and hotter heat waves for Australia in the twenty-first century, Journal of Climate 27: 5851-5871. https://doi.org/10.1175/JCLI-D-14-00092.1

Currie, B. A.; Bass, B. 2008. Estimates of air pollution mitigation with green plants and green roofs using the UFORE model, Urban Ecosystems 11: 409-422. https://doi.org/10.1007/s11252-008-0054-y

Curtis, E. M.; Leigh, A.; Rayburg, S. 2012. Relationships among leaf traits of Australian arid zone plants: alternative modes of thermal protection, Australian Journal of Botany 60: 471-483. https://doi.org/10.1071/BT11284

Dahanayake, K. C.; Chow, C. L.; Long Hou, G. 2017. Selection of suitable plant species for energy efficient Vertical Greenery Systems (VGS), Energy Procedia 142: 2473-2478. http://doi.org/10.1016/j.egypro.2017.12.185

de Abreu-Harbich, L. V.; Labaki, L. C.; Matzarakis, A. 2015. Effect of tree planting design and tree species on human thermal comfort in the tropics, Landscape and Urban Planning 138: 99-109. https://doi.org/10.1016/J.LANDURBPLAN.2015.02.008

de Dear, R.; Kim, J. 2016. Thermal comfort inside and outside buildings, in Y. Tamura, R. Yoshie (Eds.). Advanced environmental wind engineering. Springer, 89-99.

De Jesus, M. P.; Lourenço, J. M.; Arce, R. M.; Macias, M. 2017. Green façades and in situ measurements of outdoor building thermal behaviour, Building and Environment 119: 11-19. http://doi.org/10.1016/j.buildenv.2017.03.041

Deak Sjöman, J. 2016. The hidden landscape: On fine-scale green structure and its role in regulating ecosystem services in the urban environment, Acta Universitatis Agriculturae Sueciae 3.

Declet-Barreto, J.; Brazel, A. J.; Martin, C. A.; Chow, W. T. L.; Harlan, S. L. 2013. Creating the park cool island in an innercity neighborhood: heat mitigation strategy for Phoenix, AZ, Urban Ecosystems 16(3): 617-635. https://doi.org/10.1007/s11252-012-0278-8

Dennis, M.; Barlow, D.; Cavan, G.; Cook, P.; Gilchrist, A.; Handley, J.; James, P.; Thompson, J.; Tzoulas, K.; Wheater, P.; Lindley, S. 2018. Mapping urban green infrastructure: 
A novel landscape-based approach to incorporating land use and land cover in the mapping of human-dominated systems, Land 7: 17-25. https://doi.org/10.3390/land7010017

Dimoudi, A.; Nikolopoulou, M. 2003. Vegetation in the urban environment: microclimatic analysis and benefits, Energy and Buildings 35: 69-76.

https://doi.org/10.1016/S0378-7788(02)00081-6

Ding, G. K. 2008. Sustainable construction - The role of environmental assessment tools, Journal of Environmental Management 86(3): 451-464.

https://doi.org/10.1016/j.jenvman.2006.12.025

Doick, K. J.; Peace, A.; Hutchings, T. R. 2014. The role of one large greenspace in mitigating London's nocturnal urban heat island, Science of the Total Environment 493: 662-671. https://doi.org/10.1016/j.scitotenv.2014.06.048

Doick, K.; Hutchings, T. 2013. Air temperature regulation by urban trees and green infrastructure. Forestry Commission, UK.

Dooling, S. 2009. Ecological gentrification: A Research agenda exploring justice in the city, International Journal of Urban and Regional Research 33: 621-639.

https://doi.org/10.1111/j.1468-2427.2009.00860.x

Drake, J. E.; Tjoelker, M. G.; Vårhammar, A.; Medlyn, B. E.; Reich, P. B.; Leigh, A.; Pfautsch, S.; Blackman, C. J.; López, R.; Aspinwall, M. J.; Crous, K. Y.; Duursma, R. A.; Kumarathunge, D.; De Kauwe, M. G.; Jiang, M.; Nicotra, A. B.; Tissue, D. T.; Choat, B.; Atkin, O. K.; Barton, C. V. M. 2018. Trees tolerate an extreme heatwave via sustained transpirational cooling and increased leaf thermal tolerance, Global Change Biology 24(6): 2390-2402. https://doi.org/10.1111/gcb.14037

Du, H.; Cai, W.; Xu, Y.; Wang, Z.; Wang, Y.; Cai, Y. 2017. Quantifying the cool island effects of urban green spaces using remote sensing data, Urban Forestry \& Urban Greening 27: 24-31.https://doi.org/10.1016/j.ufug.2017.06.008

Ehleringer, J. R.; Mooney, H. A. 1978. Leaf hairs: Effects on physiological activity and adaptive value to a desert shrub, Oecologia 37: 183-200. https://doi.org/10.1007/BF00344990

Eisenman, T. S. 2013. Frederick Law Olmsted, green infrastructure, and the evolving city, Journal of Planning History 12: 287-311. https://doi.org/10.1177/1538513212474227

Ellis, K. N.; Hathaway, L.; Mason, R.; Howe, D. A.; Epps, T. H.; Brown, V. M. 2017. Summer temperature variability across four urban neighborhoods in Knoxville, Tennessee, USA, Theoretical and Applied Climatology 127(3-4): 701-710. https://doi.org/10.1007/s00704-015-1659-8

EN 15976:2011 Flexible sheets for waterproofing - Determination of emissivity. European Committee for Standardization (CEN), 2011.

Erell, E.; Pearlmutter, D.; Williamson, T. 2012. Urban microclimate: designing the spaces between buildings. Routledge. https://doi.org/10.4324/9781849775397

Essa, W.; Verbeiren, B.; van der Kwast, J.; Batelaan, O. 2013. Downscaling of thermal images over urban areas using the land surface temperature - Impervious percentage relationship, International Journal of Applied Earth Observation 23: 95-108. https://doi.org/10.1016/j.jag.2012.12.007

Essa, W.; Verbeiren, B.; van der Kwast, J.; Batelaan, O. 2017. Improved DisTrad for downscaling thermal MODIS imagery over urban areas, Remote Sensing 8: 1243-1250. https://doi.org/10.3390/rs9121243

Feldhake, C. M. 2001. Microclimate of a natural pasture under planted Robinia pseudoacacia in central Appalachia, West Virginia, Agroforestry Systems 53(3): 297-303.

https://doi.org/10.1023/A:1013331628494
FLL. 2008. Guidelines for the planning, construction and maintenance of green roofing. Bonn: Forschungsgesellschaft Landschaftsentwicklung Landschaftsbau e.V. (FLL).

Forster, M.; Englefield, A. 2018. Can soils assist grapevines in coping with heatwaves?, Soil Science Australia 186.

Founta, D.; Santamouris, M. 2017. Synergies between Urban Heat Island and Heat Waves in Athens (Greece), during an extremely hot summer, Scientific Reports - Nature 7. Article number 10973.

Frankenstein, S.; Koenig, G. 2004. FASST vegetation models. Technical Report TR-04-25U.S. Army Engineer Research and Development Center, Cold Regions Research and Engineering Laboratory (ERDC/CRREL).

Frumkin, H. 2003. Healthy places: Exploring the evidence, American Journal of Public Health 93: 1451-1456.

https://doi.org/10.2105/AJPH.93.9.1451

Gehrels, H.; van der Meulen, S.; Schasfoort, F.; Bosch, P.; Brolsma, R.; van Dinther, D.; Geerling, G.; Goossens, M.; Jacobs, C.; Kok, S. 2016. Designing green and blue infrastructure to support healthy urban living. TO2 Federatie.

Georgescu, M. 2015. Challenges associated with adaptation to future expansion, Journal of Climate 31: 2544-2563. https://doi.org/10.1175/JCLI-D-14-00290.1

Georgescu, M.; Moustaoui, M.; Mahalov, A.; Dudhia, J. 2011. An alternative explanation of the semiarid urban area "oasis effect", Journal of Geophysical Research Atmospheres 116(24): 1-13. https://doi.org/10.1029/2011JD016720

Ghirardo, A.; Xie, J.; Zheng, X.; Wang, Y.; Grote, R.; Block, K.; Wildt, J.; Mentel, T.; Kiendler-Scharr, A.; Hallquist, M.; Butterbach-Bahl, K.; Schnitzler, J.-P. 2016. Urban stressinduced biogenic VOC emissions and SOA-forming potentials in Beijing, Atmospheric Chemistry and Physics 16: 2901-2920. https://doi.org/10.5194/acp-16-2901-2016

Ghobadi, A.; Khosravi, M.; Tavousi, T. 2018. Surveying of heat waves impact on the urban heat islands: Case study, the Karaj City in Iran, Urban Climate 24: 600-615. https://doi.org/10.1016/j.uclim.2017.12.004

Gill, S. E.; Handley, J. F.; Ennos, A. R.; Pauleit, S. 2007. Adapting cities for climate change: The role of the green infrastructure, Built Environment 33(1): 115-133.

https://doi.org/10.2148/benv.33.1.115

GLTMS. 2015. Appendix 8 - Right tree right place quick reference guide. Development Bureau, HKSAR.

Grimmond, C. S. B.; Blackett, M.; Best, M. J.; Baik, J.-J.; Belcher, S. E.; Beringer, J.; Bohnenstengel, S. I.; Calmet, I.; Chen, F.; Coutts, A.; Dandou, A.; Fortuniak, K.; Gouvea, M. L.; Hamdi, R.; Hendry, M.; Kanda, M.; Kawai, T.; Kawamoto, Y.; Kondo, H.; Krayenhoff, E. S.; Lee, S.-H.; Loridan, T., Martilli, A.; Masson, V.; Miao, S.; Oleson, K.; Ooka, R.; Pigeon, G.; Porson, A.; Ryu, Y.-H.; Salamanca, F.; Steeneveld, G. J.; Tombrou, M.; Voogt, J. A.; Young, D. T.; Zhang, N. 2011. Initial results from Phase 2 of the international urban energy balance model comparison, International Journal of Climatology 31(2): 244-272. https://doi.org/10.1002/joc.2227

Grimmond, C. S. B.; Blackett, M.; Best, M. J.; Barlow, J.; Baik, J.-J.; Belcher, S. E.; Bohnenstengel, S. I.; Calmet, I.; Chen, F.; Dandou, A.; Fortuniak, K.; Gouvea, M. L.; Hamdi, R.; Hendry, M.; Kawai, T.; Kawamoto, Y.; Kondo, H.; Krayenhoff, E. S.; Lee, S.-H.; Loridan, T.; Martilli, A.; Masson, V.; Miao, S.; Oleson, K.; Pigeon, G.; Porson, A.; Ryu, Y.-H.; Salamanca, F.; Shashua-Bar, L.; Steeneveld, G.-J.; Tombrou, M.; Voogt, J.; Young, D.; Zhang, N. 2010. The international urban energy balance models comparison project: First results from 
phase 1, Journal of Applied Meteorology and Climatology 49: 1268-1292. https://doi.org/10.1175/2010JAMC2354.1

Grimmond, C. S. B.; Souch, C.; Hubble, M. D. 1996. Influence of tree cover on summertime surface energy balance fluxes, San Gabriel Valley, Los Angeles, Climate Research 6(1): 45-57. https://doi.org/10.3354/cr006045

Gromke, C. 2011. A vegetation modeling concept for Building and Environmental Aerodynamics wind tunnel tests and its application in pollutant dispersion studies, Environmental Pollution 159: 2094-2099.

https://doi.org/10.1016/j.envpol.2010.11.012

Gromke, C.; Blocken, B. 2014. Influence of avenue-trees on air quality at the urban neighborhood scale. Part I: Quality assurance studies and turbulent Schmidt number analysis for RANS CFD simulations, Environmental Pollution 196: 214223. https://doi.org/10.1016/j.envpol.2014.10.016

Grover, A.; Singh, R. B. 2015. Analysis of Urban Heat Island (UHI) in relation to Normalized Difference Vegetation Index (NDVI): A comparative study of Delhi and Mumbai, Environments 2: 125-138. https://doi.org/10.3390/environments2020125

Guenther, A. B.; Zimmerman, P. R.; Harley, P. C.; Monson, R. K.; Fall, R. 1993. Isoprene and monoterpene emission rate variability - model evaluations and sensitivity analyses, Journal of Geophysical Research 98: 12609-12617.

https://doi.org/10.1029/93JD00527

Guenther, A.; Wiedinmyer, C. 2004. User's guide to the Model of Emissions of Gases and Aerosols from Nature (MEGAN) [online], [cited 01 July 2018]. Available from Internet: http://acd.ucar.edu/

Guha, A.; Han, J.; Cummings, C.; McLennan, D. A.; Warren, J. M. 2018. Differential ecophysiological responses and resilience to heat wave events in four co-occurring temperate tree species, Environmental Research Letters 13(6). https://doi.org/10.1088/1748-9326/aabcd8

Gülten, A.; Aksoy, U. T.; Öztop, H. F. 2016. Influence of trees on heat island potential in an urban canyon, Sustainable Cities and Society 26: 407-418. https://doi.org/10.1016/J.SCS.2016.04.006

Gulyás, A.; Unger, J.; Matzarakis, A. 2006. Assessment of the microclimatic and human comfort conditions in a complex urban environment: Modelling and measurements, Building and Environment 41: 1713-1722.

https://doi.org/10.1016/j.buildenv.2005.07.001

Haapio, A.; Viitaniemi, P. 2008. A critical review of building environmental assessment tools, Environmental Impact Assessment Review 28(7): 469-482.

https://doi.org/10.1016/j.eiar.2008.01.002

Haas, J.; Ban, Y. 2017. Sentinel-1A SAR and sentinel-2A MSI data fusion for urban ecosystem mapping, Remote Sensing Applications: Society and Environment 8: 41-53.

https://doi.org/10.1016/j.rsase.2017.07.006

Haas, J.; Ban, Y. 2018. Urban land cover and ecosystem service changes based on Sentinel-2A MSI and Landsat TM Data, IEEE Journal of Selected Topics in Applied Earth Observations and Remote Sensing 11: 485-497. https://doi.org/10.1109/JSTARS.2017.2786468

Haldimann, P.; Galle, A.; Feller, U. 2008. Impact of an exceptionally hot dry summer on photosynthetic traits in oak (Quercus pubescens) leaves, Tree Physiology 28: 785-795. https://doi.org/10.1093/treephys/28.5.785

Hamada, S.; Ohta, T. 2010. Seasonal variations in the cooling effect of urban green areas on surrounding urban areas, Urban Forestry \& Urban Greening 9: 15-24. https://doi.org/10.1016/j.ufug.2009.10.002
Hamedani, A. Z.; Huber, F. 2012. A comparative study of DGNB, LEED and BREEAM certificate systems in urban sustainability, WIT Transactions on Ecology and The Environment 155: 1121-132. https://doi.org/10.2495/SC120111

Harfouche, A.; Meilan, R.; Altman, A. 2011. Tree genetic engineering and applications to sustainable forestry and biomass production, Trends in Biotechnology 29(1): 9-17.

https://doi.org/10.1016/j.tibtech.2010.09.003

Harrison, S. P.; Morfopoulos, C.; Dani, K. G. S.; Prentice, I. C.; Arneth, A.; Atwell, B. J.; Barkley, M. P.; Leishman, M. R.; Loreto, F.; Medlyn, B. E.; Niinemets, Ü.; Possell, M.; Peñuelas, J.; Wright, I. J. 2013. Volatile isoprenoid emissions from plastid to planet, New Phytologist 197: 49-57. https://doi.org/10.1111/nph.12021

Heisler, G. M. 1990. Mean wind speed below building height in residential neighborhoods with different tree densities, ASHRAE Transactions 96(1): 1389-1396.

Heisler, G. M.; Dewalle, D. R. 1988. 2. Effects of windbreak structure on wind flow, Agriculture, Ecosystems \& Environment 22-23: 41-69. https://doi.org/10.1016/0167-8809(88)90007-2

Hoelscher, M.; Nehls, T.; Jänicke, B.; Wessolek, G. 2016. Quantifying cooling effects of facade greening: Shading, transpiration and insulation, Energy and Buildings 114: 283-290. http://doi.org/10.1016/j.enbuild.2015.06.047

Honjo, T.; Takakura, T. 1990-1991. Simulation of thermal effects of urban green areas on their surrounding areas, Energy and Buildings 15(3-4): 443-446. https://doi.org/10.1016/0378-7788(90)90019-F

Howard, E. 1898. Garden cities of tomorrow. London: General Books LLC.

Howe, D. A.; Hathaway, J. M.; Ellis, K. N.; Mason, L. R. 2017. Spatial and temporal variability of air temperature across urban neighborhoods with varying amounts of tree canopy, Urban Forestry \& Urban Greening 27: 109-116.

https://doi.org/10.1016/j.ufug.2017.07.001

Huang, J.; Davis, S.; Akbari, H. 1990. A guidebook for the control of summer heat islands. Berkeley, California: Lawrence Berkeley Laboratory.

Hui, S. C. 2010. Development of technical guidelines for green roof systems in Hong Kong, in Proceedings of the Joint Symposium 2010 on Low Carbon High Performance Buildings.

Huo, X.; Ann, T. W.; Wu, Z. 2018. An empirical study of the variables affecting site planning and design in green buildings, Journal of Cleaner Production 175: 314-323. https://doi.org/10.1016/j.jclepro.2017.12.091

Jackson, L. E. 2003. The relationship of urban design to human health and condition, Landscape and Urban Planning 64(4): 191-200. https://doi.org/10.1016/S0169-2046(02)00230-X

Jänicke, B.; Meier, F.; Hoelscher, M.; Scherer, D. 2015. Evaluating the effects of façade greening on human bioclimate in a complex urban environment, Advances in Meteorology. Article ID 747259. https://doi.org/10.1155/2015/747259

Jayasooriya, V.; Ng, A.; Muthukumaran, S.; Perera, B. 2017. Green infrastructure practices for improvement of urban air quality, Urban Forestry \& Urban Greening 21: 34-47. https://doi.org/10.1016/j.ufug.2016.11.007

Jennings, V.; Larson, L.; Yun, J. 2016. Advancing sustainability through urban green space: Cultural ecosystem services, equity, and social determinants of health, Environmental Research and Public Health 13: 196. https://doi.org/10.3390/ijerph13020196

Jim, C. 2002. Planning strategies to overcome constraints on greenspace provision in urban Hong Kong, Town Planning Review 73(2): 127-152. https://doi.org/10.3828/tpr.73.2.1 
Jim, C. Y. 2013. Sustainable urban greening strategies for compact cities in developing and developed economies, Urban Ecosystems 16: 741-761.

https://doi.org/10.1007/s11252-012-0268-X

Jonsson, P. 2004. Vegetation as an urban climate control in the subtropical city of Gaborone, Botswana, International Journal of Climatology 24: 1307-1322. https://doi.org/10.1002/joc.1064

Kala, J.; De Kauwe, M. G.; Pitman, A. J.; Medlyn, B. E.; Wang, Y.-P.; Lorenz, R.; Perkins-Kirkpatrick, S. E. 2016. Impact of the representation of stomatal conductance on model projections of heatwave intensity, Scientific Reports Nature 6: 23418. https://doi.org/10.1038/srep23418

Kalani, K. W. D.; Dahanayake, C.; Chow, C. L. 2016. Studying the potential of energy saving through vertical greenery systems: Using EnergyPlus simulation program, Energy and Buildings 138: 47-59. http://doi.org/10.1016/j.enbuild.2016.12.002

Kaloustian, N.; Aouad, D.; Battista, G.; Zinzi, M. 2018. Leftover spaces for the mitigation of urban overheating in municipal Beirut, Climate 6(3): 68. https://doi.org/10.3390/cli6030068

Kaplan, R.; Kaplan, S. 1989. The experience of nature: A psychological perspective. Cambridge, New York: Cambridge University Press.

Kato, T.; Yamada, T.; Hino, M. 2006. Spatial structure of air temperature and humidity in urban park forest and its surrounding, Journal of the Institute of Science and Engineering. Chuo University 12: 63-71.

Kent, C. W.; Grimmond, S.; Gatey, D. 2017a. Aerodynamic roughness parameters in cities: Inclusion of vegetation, Journal of Wind Engineering \& Industrial Aerodynamics 169: 168176. https://doi.org/10.1016/j.jweia.2017.07.016

Kent, C. W.; Lee, K.; Ward, H. C.; Hong, J.-W.; Hong, J.; Gatey, D.; Grimmond, S. 2017b. Aerodynamic roughness variation with vegetation: analysis in a suburban neighbourhood and a city park, Urban Ecosystems 21: 227-243.

https://doi.org/10.1007/s11252-017-0710-1

Kikegawa, Y.; Genchi, Y.; Kondo, H.; Hanaki, K. 2006. Impacts of city-block-scale countermeasures against urban heat-island phenomena upon a building's energy-consumption for airconditioning, Applied Energy 83(6): 649-668.

https://doi.org/10.1016/j.apenergy.2005.06.001.

Kim, J. H.; Gu, D.; Sohn, W.; Kil, S. H.; Kim, H.; Lee, D. K. 2016. Neighborhood landscape spatial patterns and land surface temperature. An empirical study on single family residential areas in Austin, Texas, International Journal for Environmental Research in Public Health 13: 880.

https://doi.org/10.3390/ijerph13090880

Kolb, P. F.; Robberecht, R. 1996. High temperature and drought stress effects on survival of Pinus ponderosa seedlings, Tree Physiology 16: 665-672.

https://doi.org/10.1093/treephys/16.8.665

Kong, F.; Sun, C.; Liu, F.; Yin, H.; Yingxia Pu, F. J.; Cavan, G.; Skelhorn, C.; Middel, A.; Dronova, I. 2016. Energy saving potential of fragmented green spaces due to their temperature regulating ecosystem services in the summer, Applied Energy 183: $1428-1440$. https://doi.org/10.1016/j.apenergy.2016.09.070

Kong, L.; Lau, K. K.-L.; Yuan, C.; Chen, Y.; Xu, Y.; Ren, C.; Ng, E. 2017. Regulation of outdoor thermal comfort by trees in Hong Kong, Sustainable Cities and Society 31: 12-25. http://doi.org/10.1016/j.scs.2017.01.018

Konopacki, S.; Akbari, H. 2000. Energy savings calculations for heat-island reduction strategies in Baton Rouge, Sacramento, and Salt Lake City. Lawrence Berkeley Laboratory Report LBNL-42890, Berkeley, CA.
Konopacki, S.; Akbari, H. 2002. Energy savings for heat-island reduction strategies in Chicago and Houston (including updates for Baton Rouge, Sacramento, and Salt Lake City). Lawrence Berkeley Laboratory Report LBNL-94720, Berkeley, CA.

Koppenaal, R. S.; Colombo, S. J.; Blumwald, E. 1991. Acquired thermotolerance of jack pine, white spruce and black spruce seedlings, Tree Physiology 8(1): 83-91.

https://doi.org/10.1093/treephys/8.1.83

Kosaka, E.; Iida, A.; Vanos, J.; Middel, A.; Yokohari, M.; Brown, R. 2018. Microclimate variation and estimated heat stress of runners in the 2020 Tokyo Olympic Marathon, Atmosphere 9: 192. https://doi.org/10.3390/atmos9050192

Kotthaus, S.; Grimmond, C. S. B. 2014. Energy exchange in a dense urban environment - Part I: Temporal variability of long-term observations in central London, Urban Climate 10: 261-280. https://doi.org/10.1016/j.uclim.2013.10.002

Krayenhoff, E. S.; Santiago, J.-L.; Martilli, A.; Christen, A.; Oke, T. R. 2015. Parametrization of drag and turbulence for urban neighbourhoods with trees, Boundary-Layer Meteorology 156: 157-189. https://doi.org/10.1007/s10546-015-0028-6

Kuo, F. E.; Sullivan, W. C. 2001. Aggression and violence in the inner city, Environment and Behavior 33: 543-571. https://doi.org/10.1177/00139160121973124

Kupper, P.; Sõber, J.; Sellin, A.; Lõhmus, K.; Tullus, A.; Räim, O.; Lubenets, K.; Tulva, I.; Uri, V.; Zobel, M.; Kull, O.; Sõber, A. 2011. An experimental facility for free air humidity manipulation (FAHM) can alter water flux through deciduous tree canopy, Environmental and Experimental Botany 72: 432-438. https://doi.org/10.1016/j.envexpbot.2010.09.003

Kuras, E. R.; Richardson, M. B.; Calkins, M. M.; Ebi, K. L.; Hess, J. J.; Kintziger, K. W.; Jagger, M. A.; Middel, A.; Scott, A. A.; Spector, J. T.; Uejio, C. K.; Vanos, J. K.; Zaitchik, B. F.; Gohlke, J. M.; Hondula, D. M. 2017. Opportunities and challenges for personal heat exposure research, Environmental Health Perspectives 125(8): 085001. https://doi.org/10.1289/EHP556

Kustas, W.; Norman, J.; Anderson, M.; French, A. 2003. Estimating subpixel surface temperatures and energy fluxes from the vegetation index - Radiometric temperature relationship, Remote Sensing of Environment 85: 429-440. https://doi.org/10.1016/S0034-4257(03)00036-1

Kyriakodis, G.-E.; Santamouris, M. 2017. Using reflective pavements to mitigate urban heat island in warm climates - Results from a large scale urban mitigation project, Urban Climate 24: 326-339. https://doi.org/10.1016/j.uclim.2017.02.002

La Roche, P.; Berardi, U. 2014. Comfort and energy savings with active green roofs, Energy and Buildings 82: 492-504. http://doi.org/10.1016/j.enbuild.2014.07.055

Landsberg, H. 1970. Climatic consequences of urbanization, Journal of the Washington Academy of Sciences 60(3): 82-87.

Lang, S.; Blaschke, T.; Kothencz, G.; Holbling, D. 2018. Urban green mapping and valuation, in Q. Weng, D. Quattrochi, P. Gamba (Eds.). Urban remote sensing. Taylor and Francis Series in Satellite Remote Sensing. Taylor and Francis, 338.

Leuning, R. 1995. A critical-appraisal of a combined stomatalphotosynthesis model for C-3 plants, Plant Cell and Environment 18: 339-355.

https://doi.org/10.1111/j.1365-3040.1995.tb00370.x

Leuzinger, S.; Vogt, R.; Körner, C. 2010. Tree surface temperature in an urban environment, Agricultural and Forest Meteorology 150(1): 56-62. http://doi.org/10.1016/j.agrformet.2009.08.006

Li, W.; Radke, J.; Liu, D.; Gong, P. 2012. Measuring detailed urban vegetation with multisource high-resolution remote sensing imagery for environmental design and planning, 
Environmental Planning B: Planning and Design 39: 568-585. https://doi.org/10.1068/b37135

Li, X.; de Foy, B. 2012. Spatial pattern of greenspace affects land surface temperature: evidence from the heavily urbanized Beijing metropolitan area, China, Landscape Ecology 27: 887-898. https://doi.org/10.1007/s10980-012-9731-6

Lin, Y.-S.; Medlyn, B. E.; Duursma, R. A.; Prentice, I. C.; Wang, H.; Baig, S.; Eamus, D.; de Dios, V. R.; Mitchell, P.; Ellsworth, D. S.; de Beeck, M. O.; Wallin, G.; Uddling, J.; Tarvainen, L.; Linderson, M.-L.; Cernusak, L. A.; Nippert, J. B.; Ocheltree, T. W.; Tissue, D. T.; Martin-StPaul, N. K.; Rogers, A.; Warren, J. M.; De Angelis, P.; Hikosaka, K.; Han, Q.; Onoda, Y.; Gimeno, T. E.; Barton, C. V. M.; Bennie, J.; Bonal, D.; Bosc, A.; Löw, M.; Macinins-Ng, C.; Rey, A.; Rowland, L.; Setterfield, S. A.; Tausz-Posch, S.; Zaragoza-Castells, J.; Broadmeadow, M. S. J.; Drake, J. E.; Freeman, M.; Ghannoum, O.; Hutley, L. B.; Kelly, J. W.; Kikuzawa, K.; Kolari, P.; Koyama, K.; Limousin, J. M.; Meir, P.; da Costa, A. C. L.; Mikkelsen, T. N.; Salinas, N.; Sun, W.; Wingate, L. 2015. Optimal stomatal behaviour around the world, Nature Climate Change 5: 459-464. https://doi.org/10.1038/nclimate2550

Lontorfos, V.; Efthymiou, C.; Santamouris, M. 2018. On the time varying mitigation performance of reflective geoengineering technologies in cities, Renewable Energy 115: 926-930. https://doi.org/10.1016/j.renene.2017.09.033

Lorenz, R.; Davin, E. L.; Lawrence, D. M.; Stöckli, R.; Seneviratne, S. I. 2013. How important is vegetation phenology for European climate and heat waves?, Journal of Climate 26: 10077-10100. https://doi.org/10.1175/JCLI-D-13-00040.1

Lu, J.; Li, C.-D.; Yang, Y.-C.; Zhang, X.-H.; Jin, M. 2012. Quantitative evaluation of urban park cool island factors in mountain city, Journal of Central South University of Technology 19(6): 1657-1662. https://doi.org/10.1007/s11771-012-1189-9

Maes, J.; Barbosa, A.; Baranzelli, C.; Zulian, G.; Silva, F. B.; Vandecasteele, I.; Hiederer, R.; Liquete, C.; Paracchini, M. L.; Mubareka, S.; Jacobs-Crisioni, C.; Castillo, C. P.; Lavalle, C. 2014. More green infrastructure is required to maintain ecosystem services under current trends in land use change in Europe, Landscape Ecology 30: 517-534. https://doi.org/10.1007/s10980-014-0083-2

Manickathan, L.; Defraeye, T.; Allegrini, J.; Derome, D.; Carmeliet, J. 2018. Parametric study of the influence of environmental factors and tree properties on the transpirative cooling effect of trees, Agricultural and Forest Meteorology 248: 259-274. https://doi.org/10.1016/j.agrformet.2017.10.014

Manso, M.; Castro-Gomes, J.; Paulo, B.; Bentes, I.; Teixeira, C. 2018. Life cycle analysis of a new modular greening system, Science of the Total Environment 627: 1146-1153. https://doi.org/10.1016/j.scitotenv.2018.01.198

Mao, Y.; Nijssen, B.; Lettenmaier, D. P. 2015. Is climate change implicated in the 2013-2014 California drought? A hydrologic perspective, Geophysical Research Letters 42(8): 2805-2813. https://doi.org/10.1002/2015GL063456

Marando, F.; Slavatori, E.; Fusaro, L.; Manes, F. 2016. Removal of $\mathrm{PM}_{10}$ by forests as nature-based solution for air quality improvement in the Metropolitan City of Rome, Forests 7: 150. https://doi.org/10.3390/f7070150

March, D.; Hatch, S. L.; Morgan, C.; Kirkbride, J. B.; Bresnahan, M.; Fearon, P.; Susser, E. 2008. Psychosis and place, Epidemiologic Reviews 30: 84-100. https://doi.org/10.1093/epirev/mxn006

Mathieu, R.; Freeman, C.; Aryal, J. 2007. Mapping private gardens in urban areas using object oriented techniques and very high resolution satellite imagery, Landscape Urban Planning 81: 179-192.

https://doi.org/10.1016/j.landurbplan.2006.11.009

Mavrakou, T.; Polydoros, A.; Cartalis, C.; Santamouris, M. 2018. Recognition of thermal hot and cold spots in urban areas in support of mitigation plans to counteract overheating: Application for Athens, Climate 6(1): 16.

https://doi.org/10.3390/cli6010016

Mbow, C.; Smith, P.; Skole, D.; Duguma, L.; Bustamante, M. 2014. Achieving mitigation and adaptation to climate change through sustainable agroforestry practices in Africa, Current Opinion in Environmental Sustainability 6: 8-14.

https://doi.org/10.1016/j.cosust.2013.09.002

McPherson, E. G.; Simpson, J. R.; Peper, P. J.; Scott, K. I.; Xiao, Q. 2000. Tree guidelines for Coastal Southern California communities. Western Center for Urban Forest Research and Education USDA Forest Service, Pacific Southwest Research Station.

McPherson, E. G.; Xiao, Q.; van Doorn, N. S.; Johnson, N.; Albers, S.; Peper, P. J. 2018. Shade factors for 149 taxa of inleaf urban trees in the USA, Urban Forestry \& Urban Greening 31: 204-211. https://doi.org/10.1016/j.ufug.2018.03.001

Medlyn, B. E.; Duursma, R. A.; Eamus, D.; Ellsworth, D. S.; Prentice, I. C.; Barton, C. V. M.; Crous, K. Y.; De Angelis, P.; Freeman, M.; Wingate, L. 2011. Reconciling the optimal and empirical approaches to modelling stomatal conductance, Global Change Biology 17(6): 2134-2144. https://doi.org/10.1111/j.1365-2486.2010.02375.x

Meier, F.; Scherer, D. 2012. Spatial and temporal variability of urban tree canopy temperature during summer 2010 in Berlin, Germany, Theoretical and Applied Climatology 110(3): 373-384. https://doi.org/10.1007/s00704-012-0631-0

Merino, I.; Contreras, A.; Jing, Z.-P.; Gallardo, F.; Canovas, F. M.; Gomez, L. 2014. Plantation forestry under global warming: Hybrid poplars with improved thermotolerance provide new insights on the in vivo function of small heat shock protein chaperones, Plant Physiology 164(2): 978-991. https://doi.org/10.1104/pp.113.225730

Merlin, O.; Bitar, A.; Walker, P.; Kerr, Y. 2010. An improved algorithm for disaggregating microwave-derived soil moisture based on red, near-infrared and thermal-infrared data, Remote Sensing of Environment 114: 2305-2316.

https://doi.org/10.1016/j.rse.2010.05.007

Mirzaei, P. A.; Haghighat, F. 2010. Approaches to study Urban Heat Island - Abilities and limitations, Building and Environment 45: 2192-2201. https://doi.org/10.1016/j.buildenv.2010.04.001

Mochida, A.; Lun, I. Y. F. 2008. Prediction of wind environment and thermal comfort at pedestrian level in urban area, Journal of Wind Engineering \& Industrial Aerodynamics 96: 1498-1527. https://doi.org/10.1016/J.JWEIA.2008.02.033

Monclus, R.; Villar, M.; Barbaroux, C.; Bastien, C.; Fichot, R.; Delmotte, F. M.; Brignolas, F. 2009. Productivity, water-use efficiency and tolerance to moderate water deficit correlate in 33 poplar genotypes from a Populus deltoides $\times$ Populus trichocarpa F1 progeny, Tree Physiology 29: 1329-1339. https://doi.org/10.1093/treephys/tpp075

Monsi, M.; Saeki, T. 2005. On the factor light in plant communities and its importance for matter production. 1953, Annals of Botany 95: 549-67. https://doi.org/10.1093/aob/mci052

Monterusso, M. A.; Rowe, D. B.; Rugh, C. L. 2005. Establishment and persistence of Sedum spp. and native taxa for green roof applications, HortScience 40(2): 391-396. 
Morakinyo, T. E.; Dahanayake, K. W. D. K. C.; Ng, E. 2017a. Temperature and cooling demand reduction by green-roof types in different climates and urban densities: A co-simulation parametric study, Energy and Buildings 145: 226-237. http://doi.org/10.1016/j.enbuild.2017.03.066

Morakinyo, T. E.; Kong, L.; Lau, K. K.-L.; Yuan, C.; Ng, E. 2017 b. A study on the impact of shadow-cast and tree species on in-canyon and neighborhood's thermal comfort, Building and Environment 115: 1-17. http://doi.org/10.1016/j.buildenv.2017.01.005

Morakinyo, T. E.; Lai, A.; Lau, K. K.-L.; Ng, E. 2017c. Thermal benefits of vertical greening in a high-density city: Case study of Hong Kong, Urban Forestry \& Urban Greening. In Press, Corrected Proof. http://doi.org/10.1016/j.ufug.2017.11.010

Morakinyo, T. E.; Lam, Y. F. 2015. Simulation study of dispersion and removal of particulate matter from traffic by road-side vegetation barrier, Environmental Science and Pollution Research 23(7): 6709-6722. http://doi.org/10.1007/s11356-015-5839-y

Morakinyo, T. E.; Lam, Y. F. 2016. Simulation study on the impact of tree-configuration, planting pattern and wind condition on street-canyon's micro-climate and thermal comfort, Building and Environment 103: 262-275.

http://doi.org/10.1016/j.buildenv.2016.04.025

Morakinyo, T. E.; Lau, K. K. L.; Ren, C.; Ng, E. 2018. Performance of Hong Kong's common trees species for outdoor temperature regulation, thermal comfort and energy saving, Building and Environment 137: 157-170.

http://doi.org/10.1016/j.buildenv.2018.04.012

Moriyama, M.; Kono, H.; Yoshida, A.; Miyazaki, H.; Takebayashi, H. 2001. Data analysis on "cool spot" effect of green canopy in urban areas, Journal of Architecture and Planning (Transactions of AIJ) 66: 49-56. https://doi.org/10.3130/aija.66.49_1

Moriyama, M.; Takebayashi, H.; Fukumoto, K. 1997. Effects of green areas on urban air temperature by numerical solution, Kobe University Repository 15: 101-115.

Myint, S. W. 2006. Urban vegetation mapping using sub-pixel analysis and expert systems rules: a critical approach, International Journal of Remote Sensing 27: 2645-2665. https://doi.org/10.1080/01431160500534630

Myint, S. W.; Gober, P.; Brazel, A.; Grossman-Clarke, S.; Weng, P. 2011. Per-pixel vs object based classification of urban land cover extraction using high spatial resolution imagery, Remote Sensing of Environment 115: 1145-1161. https://doi.org/10.1016/j.rse.2010.12.017

Naeem, S.; Cao, C.; Qazi, W.; Zamani, M.; Wei, C.; Archarya, B.; Rehman, A. 2018. Studying the association between green space characteristics and land surface temperature for sustainable urban environments: An analysis of Beijing and Islamabad, International Journal of Geo-Information 7: 38-72. https://doi.org/10.3390/ijgi7020038

Nagase, A.; Dunnett, N. 2010. Drought tolerance in different vegetation types for extensive green roofs: effects of watering and diversity, Landscape and Urban Planning 97: 318-327. https://doi.org/10.1016/j.landurbplan.2010.07.005

Nagashima, K. 1996. From decocity towards ecocity, Ekistics 63: 70-79.

Nakayoshi, M.; Kanda, M.; Shi, R.; de Dear, R. 2014. Outdoor thermal physiology along human pathways: a study using a wearable measurement system, International Journal of Biometeorology 59(5): 503-515.

https://doi.org/10.1007/s00484-014-0864-y
National Parks Board. 2017. A handbook on developing sustainable highrise gardens bringing greenery skywards.

https://www.nparks.gov.sg/-/media/srg/files/handbook-1.pdf

Ng, E. 2009. Policies and technical guidelines for urban planning of high-density cities-air ventilation assessment (AVA) of Hong Kong, Building and Environment 44(7): 1478-1488. https://doi.org/10.1016/j.buildenv.2008.06.013

Ng, E.; Chen, L.; Wang, Y.; Yuan, C. 2012. A study on the cooling effects of greening in a high-density city: An experience from Hong Kong, Building and Environment 47: 256-271. http://doi.org/10.1016/j.buildenv.2011.07.014

Nichol, J.; Lee, C. 2005. Urban vegetation monitoring in Hong Kong using high resolution multispectral images, International Journal of Remote Sensing 26: 903-918. https://doi.org/10.1080/01431160412331291198

Nichol, J.; Wong, M. 2007. Remote sensing of urban vegetation life form by spectral mixture analysis of high-resolution IKONOS satellite images, International Journal of Remote Sensing 28: 985-1000. https://doi.org/10.1080/01431160600784176

Norton, B. A.; Coutts, A. M.; Livesley, S. J.; Harris, R. J.; Hunter, A. M.; Williams, N. S. 2015. Planning for cooler cities: A framework to prioritise green infrastructure to mitigate high temperatures in urban landscapes, Landscape and Urban Planning 134: 127-138. https://doi.org/10.1016/j.landurbplan.2014.10.018

Nowak, D. J.; Civerolo, K. L.; Rao, S. T.; Sistla, G.; Luley, C. J.; Crane, D. E. 2000. A modeling study of the impact of urban trees on ozone, Atmospheric Environment 34: 1601-1613. https://doi.org/10.1016/S1352-2310(99)00394-5

Nowak, D. J.; Crane, D. E.; Stevens, J. C. 2006. Air pollution removal by urban trees and shrubs in the United States, Urban Forestry \& Urban Greening 4: 115-123. https://doi.org/10.1016/j.ufug.2006.01.007

Oke, T. R. 1982. The energetic basis of the urban heat island, Quarterly Journal of the Royal Meteorological Society 108: 1-24. https://doi.org/10.1002/qj.49710845502

Oke, T. R. 2002. Boundary layer climates. Routledge. https://doi.org/10.4324/9780203407219

Oleson, K. W.; Lawrence, D. M.; Gordon, B.; Flanner, M. G.; Kluzek, E.; Peter, L. J.; Levis, S.; Swenson, S. C.; Thornton, P. E. 2010. Technical description of version 4.0 of the Community Land Model (CLM). NCAR Technical Note. Boulder, CO, USA.

Oliveira, S.; Andrade, H.; Vaz, T. 2011. The cooling effect of green spaces as a contribution to the mitigation of urban heat: A case study in Lisbon, Building and Environment 46(11): 2186-2194. https://doi.org/10.1016/j.buildenv.2011.04.034

Paliwal, R.; Röder, M. S.; Kumar, U.; Srivastava, J. P.; Joshi, A. K. 2012. QTL mapping of terminal heat tolerance in hexaploid wheat (T. aestivum L.), Theoretical and Applied Genetics 125(3): 561-575. https://doi.org/10.1007/s00122-012-1853-3

Palomo del Barrio, E. 1998. Analysis of the green roofs cooling potential in buildings, Energy and Buildings 27(2): 179-193. https://doi.org/10.1016/S0378-7788(97)00029-7

Paolini, R.; Synnefa, A.; Haddad, S.; Ulpiani, G.; Garshasbi, S.; Prasad, D.; Santamouris, M. 2018. Cooling energy and electricity savings with urban climate mitigation. Submitted for publication.

Peng, S.; Piao, S.; Ciais, P.; Friedlingstein, P.; Ottle, C.; Breon, F. M.; Nan, H.; Zhou, L.; Myneni, R. B. 2012. Surface urban heat island across 419 global big cities, Environmental Science Technology 46: 696-703. https://doi.org/10.1021/es2030438 
Peri, G.; Rizzo, G.; Scaccianoce, G.; La Gennusa, M. 2016. Vegetation and soil - related parameters for computing solar radiation exchanges within green roofs: Are the available values adequate for an easy modeling of their thermal behavior?, Energy and Buildings 129: 535-548.

https://doi.org/10.1016/j.enbuild.2016.08.018

Perini, K.; Magliocco, A. 2014. Effects of vegetation, urban density, building height, and atmospheric conditions on local temperatures and thermal comfort, Urban Forestry \& Urban Greening 13(3): 495-506. https://doi.org/10.1016/j.ufug.2014.03.003

Pigliautile, I.; Pisello, A. L. 2018. A new wearable monitoring system for investigating pedestrians' environmental conditions: Development of the experimental tool and startup findings, Science of the Total Environment 630: 690-706. https://doi.org/10.1016/j.scitotenv.2018.02.208

Pinho, C.; Fonseca, L.; Korting, T.; Kux, H. 2012. Land-cover classification of an intra-urban environment using high-resolution images and object-based image analysis, International Journal of Remote Sensing 33: 5793-5995. https://doi.org/10.1080/01431161.2012.675451

Pisello, A. L.; Piselli, C.; Cotana, F. 2016. Thermal-physics and energy performance of an innovative green roof system: The cool-green roof, Solar Energy 116: 337-356.

https://doi.org/10.1016/j.solener.2015.03.049

Pita, P.; Cañas, I.; Soria, F.; Ruiz, F.; Toval, G. 2005. Use of physiological traits in tree breeding for improved yield in droughtprone environments. The case of Eucalyptus globulus, Investigación Agraria Sistemas y Recursos Forestales 14: 383393. https://doi.org/10.5424/srf/2005143-00931

Pitman, S. D.; Daniels, C. B.; Ely, M. E. 2015. Green infrastructure as life support: urban nature and climate change, Transactions of the Royal Society of South Australia 139(1): 97-112. https://doi.org/10.1080/03721426.2015.1035219

Potchter, O.; Cohen, P.; Lin, T.-P.; Matzarakis, A. 2018. Outdoor human thermal perception in various climates: A comprehensive review of approaches, methods and quantification, Science of the Total Environment 631-632: 390-406. https://doi.org/10.1016/j.scitotenv.2018.02.276

Pugh, T. A. M.; MacKenzie, A. R.; Whyatt, J. D.; Hewitt, C. N. 2012. Effectiveness of green infrastructure for improvement of air quality in urban street canyons, Environmental Science \& Technology 46: 7692-7699. https://doi.org/10.1021/es300826w

Qian, Y.; Zhen, W.; Yu, W.; Pickett, S. 2015b. Quantifying spatiotemporal pattern of pattern of urban greenspace: new insights from high resolution data, Landscape Ecology 30: 1165-1173. https://doi.org/10.1007/s10980-015-0195-3

Qian, Y.; Zhou, W.; Li, W.; Han, L. 2015a. Understanding the dynamics of greenspace in the urbanized area of Beijing based on high resolution satellite images, Urban Forestry \& Urban Greening 14: 39-47. https://doi.org/10.1016/j.ufug.2014.11.006

Raman, A. P.; Anoma, M. A.; Zhu, L.; Rephaeli, E.; Fan, S. 2014. Passive radiative cooling below ambient air temperature under direct sunlight, Nature 515: 540-4. https://doi.org/10.1038/nature13883

Razzaghmanesha, M.; Beechama, S.; Brienbc, C. J. 2014. Developing resilient green roofs in a dry climate, Science of the Total Environment 490(15): 579-589. https://doi.org/10.1016/j.scitotenv.2014.05.040

Reeve, A. C.; Desha, C.; Hargreaves, D.; Hargroves, K. 2015. Biophilic urbanism: contributions to holistic urban greening for urban renewal, Smart and Sustainable Built Environment 4: 215-233. https://doi.org/10.1108/SASBE-11-2014-0057

Reich, P. B.; Sendall, K. M.; Stefanski, A.; Wei, X.; Rich, R. L.; Montgomery, R. A. 2016. Boreal and temperate trees show strong acclimation of respiration to warming, Nature 531: 633-636. https://doi.org/10.1038/nature17142

Ren, Z.; He, X.; Zheng, H.; Zhang, D.; Yu, X.; Shen, G.; Guo, R. 2013. Estimation of the relationship between urban park characteristics and park cool island intensity by remote sensing data and field measurement, Forests 4: 868-886. https://doi.org/10.3390/f4040868

Rogers, A.; Medlyn, B. E.; Dukes, J. S.; Bonan, G.; von Caemmerer, S.; Dietze, M.; Kattge, J.; Leakey, A. D.; Mercado, L. M.; Niinemets, Ü.; Prentice, I. C.; Serbin, S. P.; Sitch, S.; Way, D. A.; Zaehle, S. 2017. A roadmap for improving the representation of photosynthesis in Earth system models, New Phytologist 213: 22-42. https://doi.org/10.1111/nph.14283

Rose, L. S.; Levinson, R. 2013. Analysis of the effect of vegetation on albedo in residential areas: Case studies in suburban Sacramento and Los Angeles, CA, GIScience \& Remote Sensing 50(1): 64-77. https://doi.org/10.1080/15481603.2013.778557

Rosenfeld, A. H.; Romm, J. J.; Akbari, H.; Pomerantz, M. 1998. Cool communities: strategies for heat islands mitigation and smog reduction, Energy and Buildings 28: 51-62. https://doi.org/10.1016/S0378-7788(97)00063-7

Rossi, F.; Pisello, A. L.; Nicolini, A.; Filipponi, M.; Palombo, M. 2014. Analysis of retro-reflective surfaces for urban heat island mitigation: A new analytical model, Applied Energy 114: 621-631. https://doi.org/10.1016/j.apenergy.2013.10.038

Rosso, F.; Pisello, A. L.; Cotana, F.; Ferrero, M. 2016. On the thermal and visual pedestrians' perception about cool natural stones for urban paving: A field survey in summer conditions, Building and Environment 107: 198-214.

https://doi.org/10.1016/j.buildenv.2016.07.028

Rowe, D. B. 2011. Green roofs as a means of pollution abatement, Environmental Pollution 159: 2100-2110. https://doi.org/10.1016/j.envpol.2010.10.029

Saaroni, H.; Amorim J. H.; Hiemstra, J. A.; Pearlmutter, D. 2018. Urban Green Infrastructure as a tool for urban heat mitigation: Survey of research methodologies and findings across different climatic regions, Urban Climate 24: 94-110. https://doi.org/10.1016/j.uclim.2018.02.001

Sailor, D. J. 2008. A green roof model for building energy simulation programs, Energy and Buildings 40: 1466-1478. https://doi.org/10.1016/j.enbuild.2008.02.001

Sailor, D. J.; Dietsch, N. 2007. The urban heat island Mitigation Impact Screening Tool (MIST), Environmental Modelling \& Software 22(10): 1529-1541.

https://doi.org/10.1016/j.envsoft.2006.11.005

Saito, I.; Ishihara, O.; Katayama, T. 1990-991. Study of the effect of green areas on the thermal environment in an urban area, Energy and Buildings 15(3-4): 493-498.

Sandström, U. G. 2002. Green infrastructure planning in urban Sweden, Planning Practice and Research 17: 373-385. https://doi.org/10.1080/02697450216356

Santamouris, M. 2014a. Cooling the cities - A review of reflective and green roof mitigation technologies to fight heat island and improve comfort in urban environments, Solar Energy 103: 682-703. http://doi.org/10.1016/j.solener.2012.07.003

Santamouris, M. 2014b. On the energy impact of urban heat island and global warming on buildings, Energy and Buildings 82: 100-113. https://doi.org/10.1016/j.enbuild.2014.07.022 
Santamouris, M. 2015. Regulating the damaged thermostat of the cities - Status, impacts and mitigation strategies, Energy and Buildings 91: 43-56.

https://doi.org/10.1016/j.enbuild.2015.01.027

Santamouris, M.; Ding, L.; Fiorito, F.; Oldfield, P.; Osmond, P.; Paolini, R.; Prasad, D.; Synnefa, A. 2017. Passive and active cooling for the outdoor built environment - Analysis and assessment of the cooling potential of mitigation technologies using performance data from 220 large scale projects, Solar Energy 154: 14-33.

https://doi.org/10.1016/j.solener.2016.12.006

Santamouris, M.; Haddad, A. S.; Synnefa, A.; Paolini, R.; Hatvani-Kovacs, G.; Garshasbi, S. 2018. Heat mitigation program. Darwin Northern territory. Final Report. University of New South Wales, Sydney, Australia.

Santos Nouri, A.; Costa, J. P.; Santamouris, M.; Matzarakis, A. 2018. Approaches to outdoor thermal comfort thresholds through public space design: A review, Atmosphere 9(3): 108. https://doi.org/10.3390/atmos9030108

Satellite Imaging Corporation. 2018. Satellite sensors [online]. Available from Internet:

https://www.satimagingcorp.com/satellite-sensors

Savi, T.; Dal Borgo, A.; Love, V. L.; Andri, S.; Tretiach, M.; Nardini, A. 2016. Drought versus heat: What's the major constraint on Mediterranean green roof plants?, Science of the Total Environment 566-567: 753-760.

https://doi.org/10.1016/j.scitotenv.2016.05.100

Savva, Y.; Denneler, B.; Koubaa, A.; Tremblay, F.; Bergeron, Y.; Tjoelker, M. G. 2007. Seed transfer and climate change effects on radial growth of jack pine populations in a common garden in Petawawa, Ontario, Canada, Forest Ecology and Management 242(2-3): 636-647.

https://doi.org/10.1016/j.foreco.2007.01.073

Schweitzer, O.; Erell, E. 2014. Evaluation of the energy performance and irrigation requirements of extensive green roofs in a water-scarce Mediterranean climate, Energy and Buildings 68: 25-32. https://doi.org/10.1016/j.enbuild.2013.09.012

Scott, K. I.; Benjamin, M. T. 2003. Development of a biogenic volatile organic compound emission inventory for the SCOS97-NARSTO domain, Atmospheric Environment 37: 39-49. https://doi.org/10.1016/S1352-2310(03)00381-9

Scott, K. I.; Simpson, J. R.; McPherson, E. G. 1999. Effects of tree cover on parking lot microclimate and vehicle emissions, Journal of Arboriculture 25: 129-142.

Selmi, W.; Weber, C.; Riviere, E.; Blond, N.; Mehdi, L.; Nowak, D. 2016. Air pollution removal by trees in public green spaces in Strasbourg City, France, Urban Forestry \& Urban Greening 17: 192-201. https://doi.org/10.1016/j.ufug.2016.04.010

Shahidan, M. F.; Jones, P. J.; Gwilliam, J.; Salleh, E. 2012. An evaluation of outdoor and building environment cooling achieved through combination modification of trees with ground materials, Building and Environment 58: 245-257. https://doi.org/10.1016/j.buildenv.2012.07.012

Sharma, A.; Conry, P.; Fernando, H. J. S.; Hamlet, A. F.; Hellmann, J. J.; Chen, F. 2016. Green and cool roofs to mitigate urban heat island effects in the Chicago metropolitan area: Evaluation with a regional climate model, Environmental Research Letters 11: 064004.

https://doi.org/10.1088/1748-9326/11/6/064004

Shashua-Bar, L.; Hoffman, M. 2000. Vegetation as a climatic component in the design of an urban street: An empirical model for predicting the cooling effect of urban green areas with trees, Energy and Buildings 31(3): 221-235. https://doi.org/10.1016/S0378-7788(99)00018-3
Shashua-Bar, L.; Hoffman, M. E. 2004. Quantitative evaluation of passive cooling of the UCL microclimate in hot regions in summer, case study: urban streets and courtyards with trees, Building and Environment 39(9): 1087-1099.

https://doi.org/10.1016/j.buildenv.2003.11.007

Shashua-Bar, L.; Pearlmutter, D.; Erell, E. 2009. The cooling efficiency of urban landscape strategies in a hot dry climate, Landscape and Urban Planning 92(3-4): 179-186. https://doi.org/10.1016/j.landurbplan.2009.04.005

Silva, H.; Fillpot, B. S. 2018. Modeling nexus of urban heat island mitigation strategies with electricity/power usage and consumer costs: a case study for Phoenix, Arizona, USA, Theoretical and Applied Climatology 131(1-2): 661-669. https://doi.org/10.1007/s00704-016-1985-5

Skoulika, F.; Santamouris, M.; Kolokotsa, D.; Boemia, N. 2013. On the thermal characteristics and the mitigation potential of a medium size urban park in Athens, Greece, Landscape and Urban Planning 123: 73-86.

https://doi.org/10.1016/j.landurbplan.2013.11.002

Solecki, W. D.; Rosenzweig, C.; Parshall, L.; Pope, G.; Clark, M.; Cox, J.; Wiencke, M. 2005. Mitigation of the heat island effect in urban New Jersey, Global Environmental Change Part B: Environmental Hazards 6(1): 39-49.

https://doi.org/10.1016/j.hazards.2004.12.002

Speak, A.; Rothwell, J.; Lindley, S.; Smith, C. 2012. Urban particulate pollution reduction by four species of green roof vegetation in a UK city, Atmospheric Environment 61: 283-293. https://doi.org/10.1016/j.atmosenv.2012.07.043

Spronken-Smith, R. A. 1994. Energetics and cooling in urban parks. Vancouver: The University of British Columbia.

Spronken-Smith, R.; Oke, T. 1998. The thermal regime of urban parks in two cities with different summer climates, International Journal of Remote Sensing 19(11): 2085-2104. https://doi.org/10.1080/014311698214884

Stathopoulou, M.; Cartalis, C. 2009. Downscaling AVHRR land surface temperatures for improved surface urban heat island intensity estimation, Remote Sensing of Environment 113: 2592-2605. https://doi.org/10.1016/j.rse.2009.07.017

Stéfanon, M.; Drobinski, P.; D’Andrea, F.; de Noblet-Ducoudré, N. 2012. Effects of interactive vegetation phenology on the 2003 summer heat waves, Journal of Geophysical Research 117: D24103. https://doi.org/10.1029/2012JD018187

Stéfanon, M.; Drobinski, P.; D’Andrea, F.; Lebeaupin-Brossier, C.; Bastin, S. 2014. Soil moisture-temperature feedbacks at meso-scale during summer heat waves over Western Europe, Climate Dynamics 42: 1309-1324.

https://doi.org/10.1007/s00382-013-1794-9

Stewart, I. D.; Oke, T. R.; Krayenhoff, E. S. 2014. Evaluation of the 'local climate zone' scheme using temperature observations and model simulations, International Journal of Climatology 34: 1062-1080. https://doi.org/10.1002/joc.3746

Sun, C.-Y.; Brazel, A. J.; Chow, W. T. L.; Hedquist, B. C.; Prashad, L. 2009. Desert heat island study by mobile transect and remote sensing techniques, Theoretical and Applied Climatology 98: 323-335. https://doi.org/10.1007/s00704-009-0120-2

Taha, H. 1996. Modeling the impacts of increased urban vegetation on the Ozone Air Quality in the South Coast Air Basin, Atmospheric Environment 30: 3423-3430. https://doi.org/10.1016/1352-2310(96)00035-0

Taha, H. 2005. Urban surface modification as a potential ozone air-quality improvement strategy in California - Phase 1: Initial mesoscale modeling. Final report prepared by Altostratus 
Inc. for the California Energy Commission, Sacramento, California, PIER Environmental Research.

Taha, H. 2007. Urban surface modification as a potential ozone air-quality improvement strategy in California - Phase 2: Fineresolution meteorological and photochemical modeling of urban heat islands. Final report prepared by Altostratus Inc. for the California Energy Commission, Sacramento, California, PIER Environmental Research.

Taha, H. 2008a. Urban surface modification as a potential ozone air-quality improvement strategy in California: A mesoscale modeling study, Boundary-Layer Meteorology 127: 219-239. https://doi.org/10.1007/s10546-007-9259-5

Taha, H. 2008b. Meso-urban meteorological and photochemical modeling of heat island mitigation, Atmospheric Environment 42: 8795-8809.

https://doi.org/10.1016/j.atmosenv.2008.06.036

Taha, H. 2013. Meteorological, emissions, and air-quality modeling of heat-island mitigation: Recent findings for California, U.S.A., International Journal of Low Carbon Technologies 10(1): 3-14. https://doi.org/10.1093/ijlct/ctt010

Taha, H. 2015a. Cool cities: counteracting potential climate change and its health impacts, Current Climate Change Reports 1(3): 163-175.

https://doi.org/10.1007/s40641-015-0019-1

Taha, H. 2015b. Meteorological, air-quality, and emission-equivalence impacts of urban heat island control in California, Sustainable Cities and Society 19: 207-221. https://doi.org/10.1016/j.scs.2015.03.009

Taha, H. 2017. Characterization of urban heat and exacerbation: Development of a heat island index for California, Climate 5: 59. https://doi.org/10.3390/cli5030059

Taha, H.; Chang, S. C.; Akbari, H. 2000. Meteorological and air quality impacts of heat island mitigation measures in three U.S. cities. Lawrence Berkeley Laboratory Report LBNL-44222, Berkeley, CA.

Taha, H.; Konopacki, S.; Gabersek, S. 1996. Modeling the meteorological and energy effects of urban heat islands and their mitigation: A 10-Region study. Lawrence Berkeley Laboratory Report LBL-38667, Berkeley, CA.

Taha, H.; Levinson, R.; Mohegh, A.; Gilbert, H.; Ban-Weiss, G.; Chen, S. 2018. Air-temperature response to neighborhoodscale variations in Albedo and canopy cover in the real world: Fine-resolution meteorological modeling and mobile temperature observations in the Los Angeles climate archipelago, Climate 6: 53. https://doi.org/10.3390/cli6020053

Taha, H.; Sailor, D. 2010. Evaluating the effects of radiative forcing feedback in modeling urban ozone air quality in Portland, Oregon: Two-way coupled MM5-CMAQ numerical model simulations, Boundary-Layer Meteorology 137: 291-305. https://doi.org/10.1007/s10546-010-9533-9

Taha, H.; Wilkinson, J.; Bornstein, R.; Xiao, Q.; McPherson, G.; Simpson, J.; Anderson, C.; Lau, S.; Lam, J.; Blain, C. 2015. An urban-forest control measure for ozone in the Sacramento, CA Federal Non-Attainment Area (SFNA), Sustainable Cities and Society 21: 51-65.

https://doi.org/10.1016/j.scs.2015.11.004

Takano, T.; Nakamura, K.; Watanabe, M. 2002. Urban residential environments and senior citizens' longevity in megacity areas: The importance of walkable green spaces, Journal of Epidemiology Community Health 56: 913-918. https://doi.org/10.1136/jech.56.12.913

Takebayashi, H. 2017. Influence of urban green area on air temperature of surrounding built-up area, Climate 5: 60 . https://doi.org/10.3390/cli5030060
Tan, C. L.; Wong, N. H.; Jusuf, S. K. 2014. Effects of vertical greenery on mean radiant temperature in the tropical urban environment, Landscape and Urban Planning 127: 52-64. http://doi.org/10.1016/j.landurbplan.2014.04.005

Tan, Z.; Lau, K. K. L.; Ng, E. 2017. Planning strategies for roadside tree planting and outdoor comfort enhancement in subtropical high-density urban areas, Building and Environment 120: 93-109. http://doi.org/10.1016/j.buildenv.2017.05.017

Tanaka, A.; Takano, T.; Nakam Ura, K.; Takeuchi, S. 1996. Health levels influenced by urban residential conditions in a Megacity - Tokyo, Urban Studies 33(6): 879-894.

https://doi.org/10.1080/00420989650011645

Teskey, R.; Wertin, T.; Bauweraerts, I.; Ameye, M.; McGuire, M. A.; Steppe, K. 2015. Responses of tree species to heat waves and extreme heat events, Plant Cell and Environment 38(9): 1699-1712. https://doi.org/10.1111/pce.12417

Todd, J. A.; Crawley, D.; Geissler, S.; Lindsey, G. 2001. Comparative assessment of environmental performance tools and the role of the Green Building Challenge, Building Research \& Information 29(5): 324-335.

https://doi.org/10.1080/09613210110064268

TreePeople. 2017. City of Los Angeles approved street tree list [online], [cited 01 July 2017]. Available from Internet: http://www.marvista.org/productphotos/LA-City-ApproveStreet-Trees.pdf

Tzoulas, K.; Korpela, K.; Venn, S.; Yli-Pelkonen, V.; Kaźmierczak, A.; Niemela, J.; James, P. 2007. Promoting ecosystem and human health in urban areas using Green Infrastructure: A literature review, Landscape Urban Planning 81: 167-178. https://doi.org/10.1016/j.landurbplan.2007.02.001

Ulrich, R. S. 1984. View through a window may influence recovery from surgery, Science 224: 420-421. https://doi.org/10.1126/science.6143402

Ulrich, R. S.; Simonst, R. F.; Lositot, B. D.; Fioritot, E.; Milest, M. A.; Zelsont, M. 1991. Stress recovery during exposure to natural and urban environments, Journal of Environmental Psychology 11(3): 201-230. https://doi.org/10.1016/S0272-4944(05)80184-7

Upmanis, H.; Eliasson, I.; Lindqvist, S. 1998. The influence of green areas on nocturnal temperatures in a high latitude city (Goteborg, Sweden), International Journal of Climatology 18(6): 681-700. https://doi.org/10.1002/(SICI)10970088(199805)18:6<681::AID-JOC289>3.0.CO;2-L

Urban Atlas. 2012 [online], [cited 01 July 2017]. Available from Internet: https://land.copernicus.eu/local/urban-atlas/urbanatlas-2012

Urban, J.; Ingwers, M. W.; McGuire, M. A.; Teskey, R. O. 2017. Increase in leaf temperature opens stomata and decouples net photosynthesis from stomatal conductance in Pinus taeda and Populus deltoides x nigra, Journal of Experimental Botany 68: 1757-1767. https://doi.org/10.1093/jxb/erx052

Vacek, P.; Struhala, K.; Matejka, L. 2017. Life-cycle study on semi intensive green roofs, Journal of Cleaner Production 154: 203213. https://doi.org/10.1016/j.jclepro.2017.03.188

Vahmani, P.; Ban-Weiss, G. 2016. Climatic consequences of adopting drought-tolerant vegetation over Los Angeles as a response to California drought, Geophysical Research Letters 43(15): 8240-8249. https://doi.org/10.1002/2016GL069658

Vahmani, P.; Hogue, T. S. 2015. Urban irrigation effects on WRF-UCM summertime forecast skill over the Los Angeles metropolitan area, Journal of Geophysical Research 120(19): 9869-9881. https://doi.org/10.1002/2015JD023239

Van de Voorde, T.; Vlaeminck, J.; Canters, F. 2008. Comparing different approaches for mapping urban vegetation cover 
from Landsat ETM+ data: A case study on Brussels, Sensors 8: 3880-3902. https://doi.org/10.3390/s8063880

Vanos, J. K.; Warland, J. S.; Gillespie, T. J.; Slater, G. A.; Brown, R. D.; Kenny, N. A. 2012. Human energy budget modeling in urban parks in Toronto and applications to emergency heat stress preparedness, Journal of Applied Meteorology and Climatology 51(9): 1639-1653.

https://doi.org/10.1175/JAMC-D-11-0245.1

Vassos, E.; Agerbo, E.; Mors, O.; Pedersen, C. B. 2016. Urbanrural differences in incidence rates of psychiatric disorders in Denmark, The British Journal of Psychiatry 208: 435-440. https://doi.org/10.1192/bjp.bp.114.161091

Vaz Monteiro, M.; Blanusa, T.; Verhoef, A.; Richardson, M.; Hadley, P.; Cameron, R. W. F. 2017. Functional green roofs: Importance of plant choice in maximizing summertime environmental cooling and substrate insulation potential, Energy and Buildings 141: 56-68.

https://doi.org/10.1016/j.enbuild.2017.02.011

Venhari, A. A.; Tenpierik, M.; Hakak, A. M. 2017. Heat mitigation by greening the cities, a review study, Environment, Earth and Ecology 1(1): 5-32. https://doi.org/10.24051/eee/67281

Vinocur, B.; Altman, A. 2005. Recent advances in engineering plant tolerance to abiotic stress: Achievements and limitations, Current Opinion in Biotechnology 16(2): 123-132. https://doi.org/10.1016/j.copbio.2005.02.001

von Caemmerer, S.; Evans, J. R. 2015. Temperature responses of mesophyll conductance differ greatly between species, Plant, Cell \& Environment 38: 629-637. https://doi.org/10.1111/pce.12449

Vos, P. E.; Maiheu, B.; Vankerkom, J.; Janssen, S. 2013. Improving local air quality in cities: to tree or not to tree?, Environmental Pollution 183: 113-122. https://doi.org/10.1016/j.envpol.2012.10.021

Wahid, A.; Gelani, S.; Ashraf, M.; Foolad, M. R. 2007. Heat tolerance in plants: an overview, Environmental and Experimental Botany 61(3): 199-223. https://doi.org/10.1016/j.envexpbot.2007.05.011

Ward, K.; Lauf, S.; Kleinschmit, B.; Endlicher, W. 2016. Heat waves and urban heat islands in Europe: A review of relevant drivers, Science of the Total Environment 569-570: 527-539. https://doi.org/10.1016/j.scitotenv.2016.06.119

Watkins, R. 1999. The impact of the urban environment on the energy demand for cooling buildings. Project report, Brunel University, London.

Watkins, R.; Palmer, J.; Kolokotroni, M.; Littlefair, P. 2002. The London heat island - Surface and air temperature measurements in a park and street gorges, ASHRAE Transactions 108(1): 419-427.

Wedding, G. C.; Crawford-Brown, D. 2007. Measuring site-level success in brownfield redevelopments: A focus on sustainability and green building, Journal of Environmental Management 85(2): 483-495.

https://doi.org/10.1016/j.jenvman.2006.10.018

Wolch, J. R.; Byrne, J.; Newell, J. P. 2014. Urban green space, public health, and environmental justice: The challenge of making cities “just green enough", Landscape Urban Planning 125: 234-244.

https://doi.org/10.1016/j.landurbplan.2014.01.017

Wong, N. H.; Chen, Y.; Ong, C. L.; Sia, A. 2003b. Investigation of thermal benefits of rooftop garden in the tropical environment, Building and Environment 38(2): 261-270.

http://doi.org/10.1016/S0360-1323(02)00066-5
Wong, N. H.; Cheong, D. W.; Yan, H.; Soh, J.; Ong, C. L.; Sia, A. 2003a. The effects of rooftop garden on energy consumption of a commercial building in Singapore, Energy and Buildings 35(4): 353-364.

https://doi.org/10.1016/S0378-7788(02)00108-1

Wong, N. H.; Chong, A. Z. M. 2010. Performance evaluation of misting fans in hot and humid climate, Building and Environment 45: 2666-2678.

https://doi.org/10.1016/J.BUILDENV.2010.05.026

Wong, N. H.; Puay Yok, T.; Yu, C. 2007. Study of thermal performance of extensive rooftop greenery systems in the tropical climate, Building and Environment 42(1): 25-54.

http://doi.org/10.1016/j.buildenv.2005.07.030

Wong, N. H.; Yong, A.; Tan, K.; Chen, Y.; Sekar, K.; Tan, Y. P.; Chan, D.; Chiang, K.; Wong, N. C. 2010. Thermal evaluation of vertical greenery systems for building walls, Building and Environment 45(3): 663-672.

http://doi.org/10.1016/j.buildenv.2009.08.005

$\mathrm{Wu}, \mathrm{C} .2004$. Normalized spectral mixture analysis for monitoring urban composition using ETM+ imagery, Remote Sensing for Environment 93: 480-492. https://doi.org/10.1016/j.rse.2004.08.003

Xiao, X. D.; Dong, L.; Yan, H.; Yang, N.; Xiong, Y. 2018. The influence of the spatial characteristics of urban green space on the urban heat island effect in Suzhou Industrial Park, Sustainable Cities and Society 40: 428-439.

https://doi.org/10.1016/j.scs.2018.04.002

Yan, H.; Fan, S.; Guo, C.; Wu, F.; Zhang, N.; Dong, I. 2014. Assessing the effects of landscape design parameters on intraurban air temperature variability: the case of Beijing, China, Building and Environment 76: 44-53.

https://doi.org/10.1016/j.buildenv.2014.03.007

Yang, G.; Ge, Y.; Xue, H.; Yang, W.; Shi, Y.; Peng, C.; Du, Y.; Fan, X.; Ren, Y.; Chang, J. 2015b. Using ecosystem service bundles to detect trade-offs and synergies across urban-rural complexes, Landscape and Urban Planning 136: 110-121. https://doi.org/10.1016/j.landurbplan.2014.12.006

Yang, J.; Chang, Y.; Yan, P. 2015a. Ranking the suitability of common urban tree species for controlling $\mathrm{PM}_{2.5}$ pollution, Atmospheric Pollution Research 6: 267-277. https://doi.org/10.5094/APR.2015.031

Yang, J.; Wang, Z. H. 2017. Planning for a sustainable desert city: The potential water buffering capacity of urban green infrastructure, Landscape and Urban Planning 167: 339-347. https://doi.org/10.1016/j.landurbplan.2017.07.014

Yang, J.; Yu, Q.; Gong, P. 2008. Quantifying air-pollution removal by green roofs in Chicago, Atmospheric Environment 42: 7266-7273. https://doi.org/10.1016/j.atmosenv.2008.07.003

Yao, Y.; Luo, Y.; Huang, J.; Zhao, Z. 2013. Comparison of monthly temperature extremes simulated by CMIP3 and CMIP5 models, Journal of Climate 26: 7692-7707. https://doi.org/10.1175/JCLI-D-12-00560.1

Ye, C.; Argayoso, M. A.; Redoña, E. D.; Sierra, S. N.; Laza, M. A.; Dilla, C. J.; Mo, Y.; Thomson, M. J.; Chin, J.; Delaviña, C. B.; Diaz, G. Q.; Hernandez, J. E. 2012. Mapping QTL for heat tolerance at flowering stage in rice using SNP markers, Plant Breeding 131(1): 33-41. https://doi.org/10.1111/j.1439-0523.2011.01924.x

Ye, X.; Busov, V.; Zhao, N.; Meilan, R.; McDonnell, L. M.; Coleman, H. D.; Mansfield, S. D.; Chen, F.; Li, Y. Cheng, Z. M. 2011. Transgenic populus trees for forest products, bioenergy, and functional genomics, Critical Reviews in Plant Sciences 30(5): 415-434. https://doi.org/10.1080/07352689.2011.605737 
Yli-Pelkonen, V.; Setala, H.; Viippola, V. 2017. Urban forests near roads do not reduce gaseous air pollutant concentrations but have an impact on particles levels, Landscape and Urban Planning 158: 39-47.

https://doi.org/10.1016/j.landurbplan.2016.09.014

Yu, C.; Hien, W. N. 2006. Thermal benefits of city parks, Energy and Buildings 38: 105-120. https://doi.org/10.1016/j.enbuild.2005.04.003

Yu, Z.; Xu, S.; Zhang, Y.; Jørgensen, G.; Vejre, H. 2018. Strong contributions of local background climate to the cooling effect of urban green vegetation, Scientific Reports - Nature 8: 6798. https://doi.org/10.1038/s41598-018-25296-w

Yuan, F.; Bauer, M. E. 2007. Comparison of impervious surface and normalized difference vegetation index as indicators of surface urban heat island effects in Landsat imagery, Remote Sensing for the Environment 106: 375-386. https://doi.org/10.1016/j.rse.2006.09.003

Yue, W.; Xu, J.; Tan, W.; Xu, L. 2007. The relationship between land surface temperature and NDVI with remote sensing techniques: application to Shanghai Landsat 7 ETM+ data, International Journal of Remote Sensing 28: 3205-3226. https://doi.org/10.1080/01431160500306906

Zhang, L.; Tan, P. Y.; Diehl, J. A. 2017. A conceptual framework for studying urban green spaces effects on health, Journal of Urban Ecology 3(1).

Zheng, T.; Lau, K. K.-L.; Ng, E. 2016. Urban tree design approaches for mitigating daytime urban heat island effects in a high-density urban environment, Energy and Buildings 114: 265-274. https://doi.org/10.1016/j.enbuild.2015.06.031

Zoulia, I.; Santamouris, M.; Dimoudi, A. 2009. Monitoring the effect of urban green areas on the heat island in Athens, Environmental Monitoring and Assessment 156(1-4): 275-292. https://doi.org/10.1007/s10661-008-0483-3

Zuo, J.; Zhao, Z. Y. 2014. Green building research - current status and future agenda: A review, Renewable and Sustainable Energy Reviews 30: 271-281. https://doi.org/10.1016/j.rser.2013.10.021

Zweifel, R.; Zimmermann, L.; Zeugin, F.; Newbery, D. M. 2006. Intra-annual radial growth and water relations of trees: implications towards a growth mechanism, Journal of Experimental Botany 57: 1445-1459. https://doi.org/10.1093/jxb/erj125 